


\section{DISCLAIMER}

This report was prepared as an account of work sponsored by an agency of the United States Government. Neither the United States Government nor any agency Thereof, nor any of their employees, makes any warranty, express or implied, or assumes any legal liability or responsibility for the accuracy, completeness, or usefulness of any information, apparatus, product, or process disclosed, or represents that its use would not infringe privately owned rights. Reference herein to any specific commercial product, process, or service by trade name, trademark, manufacturer, or otherwise does not necessarily constitute or imply its endorsement, recommendation, or favoring by the United States Government or any agency thereof. The views and opinions of authors expressed herein do not necessarily state or reflect those of the United States Government or any agency thereof. 


\section{DISCLAIMER}

Portions of this document may be illegible in electronic image products. Images are produced from the best available original document. 


\section{NOTICE}

This report was prepared as an account of work sponsored by the United States Government. Neither the United States nor the United States Energy Research and Development Administration, nor any of their employees, nor any of their contractors, subcontractors, or their employees, makes any warranty, express or implied, or assumes any legal liability or responsibility for the accuracy, completeness or usefulness of any information, apparatus, product or process disclosed, or represents that its use would not infringe privately owned riqhts.

This report has been reproduced directly from the best available copy.

Available from the National Technical Information Service, U.S. Department of Commerce, Springfield, Virginia 22161.

\begin{tabular}{cccccccccccccc}
\multicolumn{10}{c}{ NATIONAL TECHNICAL INFORMATION SERVICE PAPER COPY PRICES } \\
EFFECTIVE JAN. 1, 1976
\end{tabular}

For additional pages, add $\$ 4.50$ for each beginning 100 pages. Add $\$ 2.50$ per copy for foreign price.

Microfiche $\$ 3.00$ (domestic) $\$ 4.50$ (foreign). 
BERC/RI.76/14

Distribution Category UC-92b

\title{
DEVELOPING EMPIRICAL CORRELATIONS FROM BASIC \\ GPC DATA AND DERIVING OF FUNDAMENTAL GPC \\ PARAMETERS FOR A GIVEN SYSTEM
}

\author{
By \\ D. E. Hirsch \\ H. J. Coleman \\ J. E. Dooley \\ C. J. Thompson

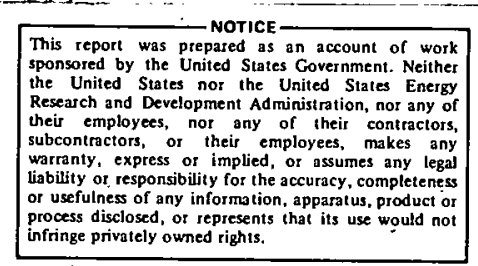 \\ Bartlesville Energy Research Center \\ Bartlesville, Oklahoma
}

Date Published-August 1977

\section{ENERGY RESEARCH AND DEVELOPMENT ADMINISTRATION}

TECHNICAL INFORMATION CENTER

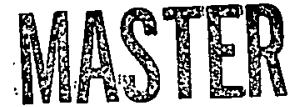

DISTRIBUTJUN OF THIS UUCUMENI IS UNLIMITEQ

OULUMENI IS UNLIMITEO 


\section{THIS PAGE \\ WAS INTENTIONALLY \\ LEFT BLANK}




\section{CONTENTS}

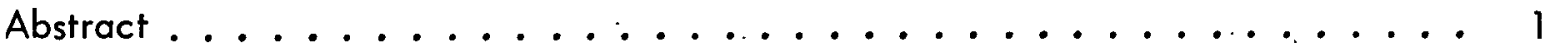

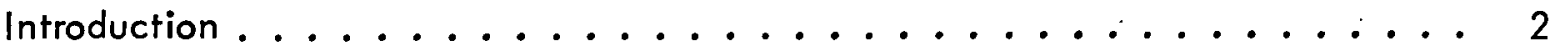

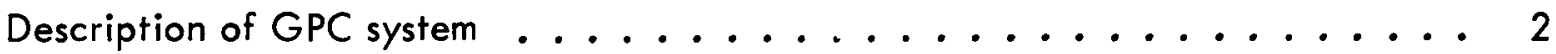

Column efficiency and molecular volume-retention volume relationships .... 3

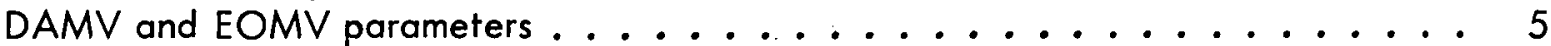

Parameters which influence DAMV and EOMV values ........6 6

Methods for determining DAMV and EOMV values ............. 15

Methods for determining DAMV values of compounds . . . . . . 15

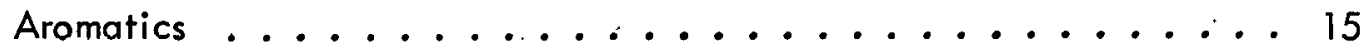

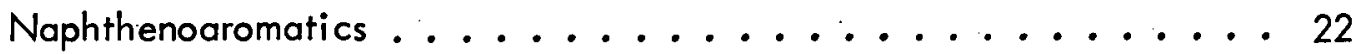

Methods for determining EOMV values of compounds . . . . . . . . . 22

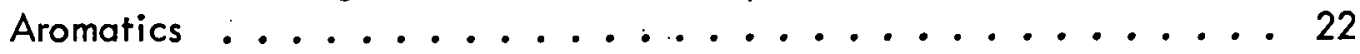

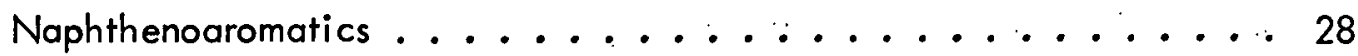

Errors in DAMV and EOMV value determinations ........... 30

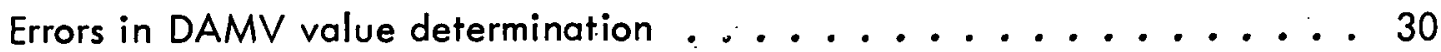

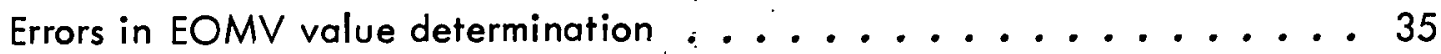

DAMV Parameter--variation and use in molecular volume determinations . . . . 39

DAMV parameter variation ................ 39

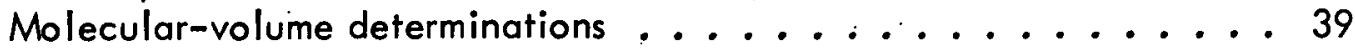

EOMV parameter and retention-volume determinations ...... 41

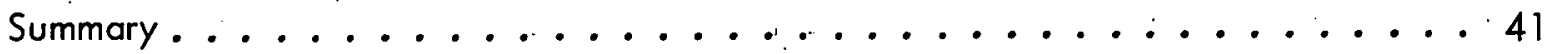

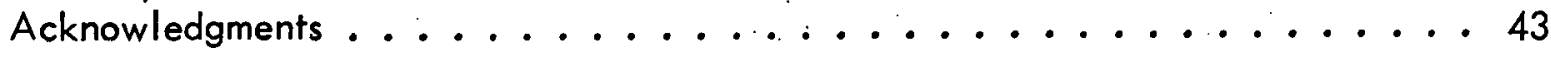

References........................... 43

APPENDIX A. - Additional methods for determing the DAMV and the EOMV of wholly aromatic compounds ....... 45

An SRC method for determining DAMV values ...... : 45

A total ring count method for determining EOMV values. . 45

APPENDIX B. - $\quad$ Determination of DAMV and EOMV incremental values . . 57

Determination of DAMV values for carbons and bonds. .... 57

Derivation of the DAMV aromatization factor...... 59

Derivation of the DAMV condensation factor . . .... 60

Determination of EOMV values for carbons and bonds. $\because 60$

Derivation of the EOMV aromatization factor ......662

Derivation of the EOMV condensation factor . . .

APPENDIX C. - Determination of DAMV and EOMV substitution factor

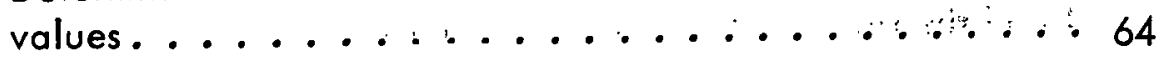




\section{ILLUSTRATION}

Page

1. Vectorial representation of the relationship between the DAMV and

EOMV parameters using benzene and naphthalene .............

\section{TABLES}

1. Column efficiency at given retention volumes $\ldots \ldots \ldots \ldots \ldots \ldots \ldots \ldots$

2. Molecular volume-retention volume relationships ...............

3. Chain methylene plus a bond retention-volume increments for

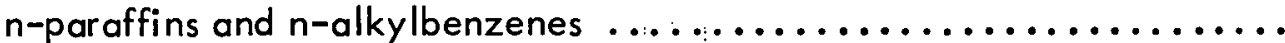

4. Values for retention volume, molecular volume, DAMV parameter, and EOMV parameter for aromatics and naphthenoaromatics ............

5. Summary of DAMV and EOMV increment values for carbons and bonds...

6. Determination of linearity factor counts for use in DAMV and EOMV

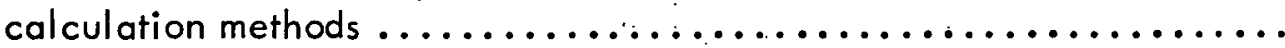

7. Significant DAMV and EOMV substitution factor values ............

8. "Effective" bond counts for aromatic systems derived from DAMV and EOMV calculation methods (given later) for use in naphthenoaromatics DAMV and EOMV calculation methods ...............

9. Aromatization factor values $(A F)$ to be used in DAMV and EOMV

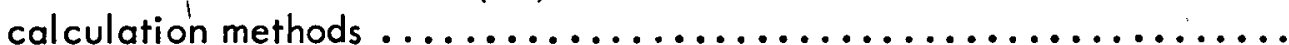

10. Rules for determining values for the coefficients and constants in equation 1 for calculation DAMV values for wholly aromatic compounds by the carbon and bond count method ...............

11. Calculation of DAMV values for wholly aromatic compounds (using equation 1 and rules of table 10) by the carbon and bond count

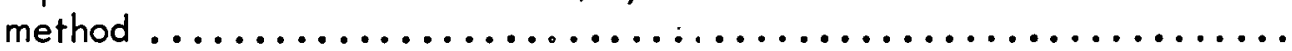

12. Rules for determining the values for the coefficients and constants in equation 2 for calculation DAMV values for naphthenoaromatics ......

13. Calculation of DAMV values for naphthenoaromatics using equation

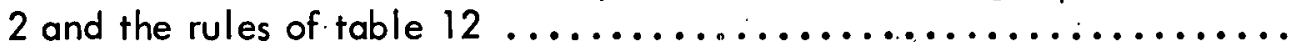

14. Rules for determining the values for the coefficients and constants in equation 3 for calculating EOMV values for wholly aromatic

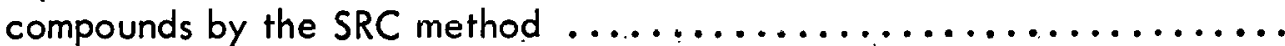

15. Calculation of EOMV values for wholly aromatic compounds. (using equation 3 and the rules of table 14) by the SRC method ...........

16. Rules for determining the value for the coefficients and constants in equation 4 for calculating EOMV values for naphthenoaromatics ......

17. Calculation of EOMV values for naphthenoaromatics using equation

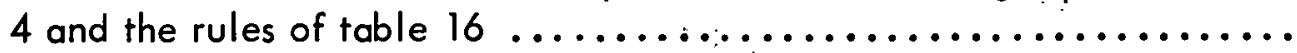


TABLES-Continued

Page

18. DAMV, EOMV, molecular volume, and density value errors ........ 38

19. Values and rules for estimating molecular volumes for homologous series and for different substitution isomers $\ldots \ldots \ldots \ldots \ldots \ldots \ldots \ldots \ldots . . \ldots 40$

20. Effect of alkylation on EOMV values ................... 42

A-1 Rules for determining values for the coefficients and constants in equation $A-1$ for calculating DAMV values of wholly aromatic

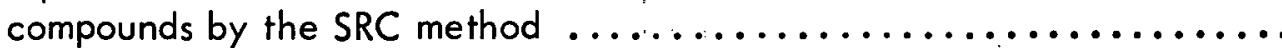

A-2 Calculation of DAMV values for wholly aromatic compounds (using equation 2 and the rules of table $A-1$ ) by the SRC method .......... 48

A-3 Rules for determining values for the rings used in calculating EOMV values for wholly aromatic compounds by the total ring count method .. . 51

A-4 Calculation of EOMV values for wholly aromatic compounds using the total ring count method and the rules of table $A-3 \ldots \ldots \ldots \ldots \ldots$

C-1 Determination of effects of polysubstitution and "effective" polysubstitution of DAMV and EOMV vạlues for use in calculation

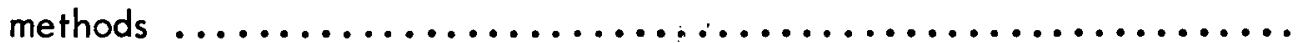




\title{
DEVELOPING EMPIRICAL CORRELATIONS FROM BASIC GPC DATA AND DERIVING OF FUNDAMENTAL GPC PARAMETERS FOR A GIVEN SYSTEM
}

by

D. E. Hirseh, ' H. J. Coleman, ${ }^{3}$ J. E. Dooley, ${ }^{2}$ and C. J. Thompson ${ }^{3}$

\begin{abstract}
The Bartlesville Energy Research Center, in cooperation with American Petroleum Institute Research Project 60, used gel permeation chromatography (GPC) in the separation and characterization of the heavy ends of petroleum. The correlations are now being used to characterize oils from other fossil fuel sources such as coal, shale, and tar sands.

By the use of retention-volume data for a few compounds, several fundamental parameters were developed and correlated. The parameters involved are expressed in terms of retention volume increments which are additive and allow precise calculation of molecular volumes, densities, and retention volumes of many compounds (without GPC experimentation) based upon retention-volume data on a few compounds. The result is an array of numerical values and groups of selective rules for their combinations. Heteroatomic molecules (N, S, and $O$ analogs of hydrocarbons) could be included.

The fundamental GPC parameter correlations can be extended and shown to be of extreme practical importance in characterizing saturate, monoaromatic, diaromatic, and polyaromatic-polar concentrates from $350^{\circ}$ to $550^{\circ} \mathrm{C}$ petroleum distillates. Lower boiling $\left(200^{\circ}\right.$ to $350^{\circ} \mathrm{C}$ ) samples also have been analyzed by this method with excellent success.
\end{abstract}

i Research chemist (resigned).

2 Project leader.

3 Research supervisor. 


\section{INTRODUCTION}

The use of GPC for separating compounds of different molecular volumes has been described by several authors. The method has been used to determine molecular volumes and to separate and characterize such complex mixtures as high-boiling petroleum fractions $(1-11) .4$ This report describes the use of empirically derived guidelines, based upon retention volumes of a few compounds for the following:

1. To develop and define GPC parameters based upon fundamental retention-volume increments (numerical values) for definable atoms, bonds, and structural groups.

2. To develop, without experimentation, correlations (selective rules) for the derived parameters that permit accurate determination of retention volumes, molecular volumes, and densities of pure compounds based upon structural considerations.

The GPC parameters correlate the retention volume-molecular volume relationship of given compounds to that established for the n-paraffins in this GPC system. Literature values for the n-paraffins molecular volumes are used with their retention volumes from this system to build the correlations. In addition, the parameters to be correlated are defined based upon a column constant for this system. This column constant $(1,561 \mathrm{ml})$ is the retention volume value at which the system solvent (benzene) should elute compared to a hypothetical $n$-paraffin of the same molecular volume if only molecular volume were operative in determining retention volume in the system. From this reference point a parameter which measures nonparaffinicity (unsaturation) is developed and defined as effects other than molecular volume differences (EOMV). A second parameter defined as differences attributable to molecular volume differences (DAMV) correlates the column constant reference and the molecular volume of a given compound to the aforementioned n-paraffin.

\section{DESCRIPTION OF GPC SYSTEM}

The GPC column was $2.54 \mathrm{~cm}$. ID by $455 \mathrm{~cm}$ long ( 1 in by $15 \mathrm{ft}$ ) with the bottom half packed with 400 Angstrom pore-size polystyrene gel and the top half with 100 Angstrom pore-size polystyrene gel. Benzene was the system solvent, the flow rate was $1 \mathrm{ml} / \mathrm{min}$, the charge size was a maximum of $2 \mathrm{~g}$, and the fractions collected in the experiments were $10 \mathrm{ml}$ in size. The use of two different pore-size gels in one column permitted resolution of materials with a molecular-weight range from 100 to 1,000. The order of the gels in the column allowed the larger molecules, excluded by the smaller pore-size gel (upper section), to pass rapidly downward onto the larger pore-size gel where their separation

4 Underlined numbers in parentheses refer to items in the list of references at the end of this report. 
was accomplished. The smaller molecules, on the other hand, began to separate immediately in the upper section of the column.

\section{COLUMN EFFICIENCY AND MOLECULAR VOLUME-RETENTION VOLUME RELATIONSHIPS}

All compounds studied eluted between about 1,150 $\mathrm{ml}$ for $\mathrm{n}$-tetracosane $\left(\mathrm{C}_{24}\right)$ and about $1,730 \mathrm{ml}$ for pyrene. $\mathrm{n}$-Decylthiophene, which eluted at $1,343 \mathrm{ml}$, was used to show the effect of charge size on column efficiency at this retention volume. A value of 5,300 theoretical plates was obtained with a $0.75-\mathrm{g}$ charge and a value of 2,700 theoretical plates, with a 4.5-g charge. For this reason, charge size for all model compounds was held below $0.5 \mathrm{~g}$. The efficiency of the system at several points within the 1,150 to $1,730 \mathrm{ml}$ retention-volume range is shown in table 1 , and generally column efficiency increases with increasing retention volume.

Examination of the data in tables 2. A and 2.B shows that the retention-volume interval between consecutive carbon numbers of a homologous series increases with retention volume across the approximate 1,150 to $1,630 \mathrm{ml}$ retention-volume range. The average additional volume required to elute the adjacent carbon numbers of $n$-alkylbenzenes (an additional methylene plus a bond) in the $C_{6}$ to $C_{10}$ range $(1,629$ to $1,473 \mathrm{ml}$ retentionvolume range for $n$-alkylbenzenes) is $39.0 \mathrm{ml}$ as shown in table $3 . A$. The values for two other carbon-number ranges and retention volumes are also shown in table 3.A. Most of the compounds used in the section on development and correlation of GPC parameters had retention volumes in the range where the average alkylbenzene chain methylene plus a bond retention-volume increment $(B C M+B)$ was about $39.0 \mathrm{ml}$ (essentially constant). The corresponding paraffin chain methylene plus a bond retention-volume increment $(P C M+B)$ can be determined from table 2 . A and is seen to be $32.0 \mathrm{ml}$ in table 3 . B . The $P C M+B$ values for other carbon number ranges and retention volumes are also shown in table 3. B.

TABLE 1. - Column efficiency at given retention volumes

\begin{tabular}{|c|c|c|c|}
\hline n-Alkylbenzene & $\begin{array}{l}\text { Retention } \\
\text { volume, } \mathrm{ml}\end{array}$ & $\begin{array}{l}\text { Theoretical } \\
\text { plates }\end{array}$ & $\begin{array}{c}\text { Theoretical } \\
\text { plate (TP) equation }\end{array}$ \\
\hline n-Nonadecylbenzene & 1,192 & 3,070 & 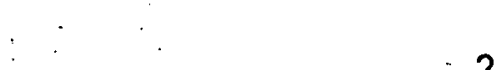 \\
\hline n-Pentadecylbenzene & 1,244 & 3,270 & $T P=\frac{4(\text { retention volume })}{\text { peak width at base }}$ \\
\hline n-Dersylhenzene & 1,333 & 3,840 & \\
\hline n-Hexylbenzene & 1,419 & 5,300 & \\
\hline Tolvene & 1,594 & 8,300 & \\
\hline Benzene & $1 ; 629$ & 6,980 & \\
\hline
\end{tabular}


TABLE 2. - Molecular volume-retention volume relationships

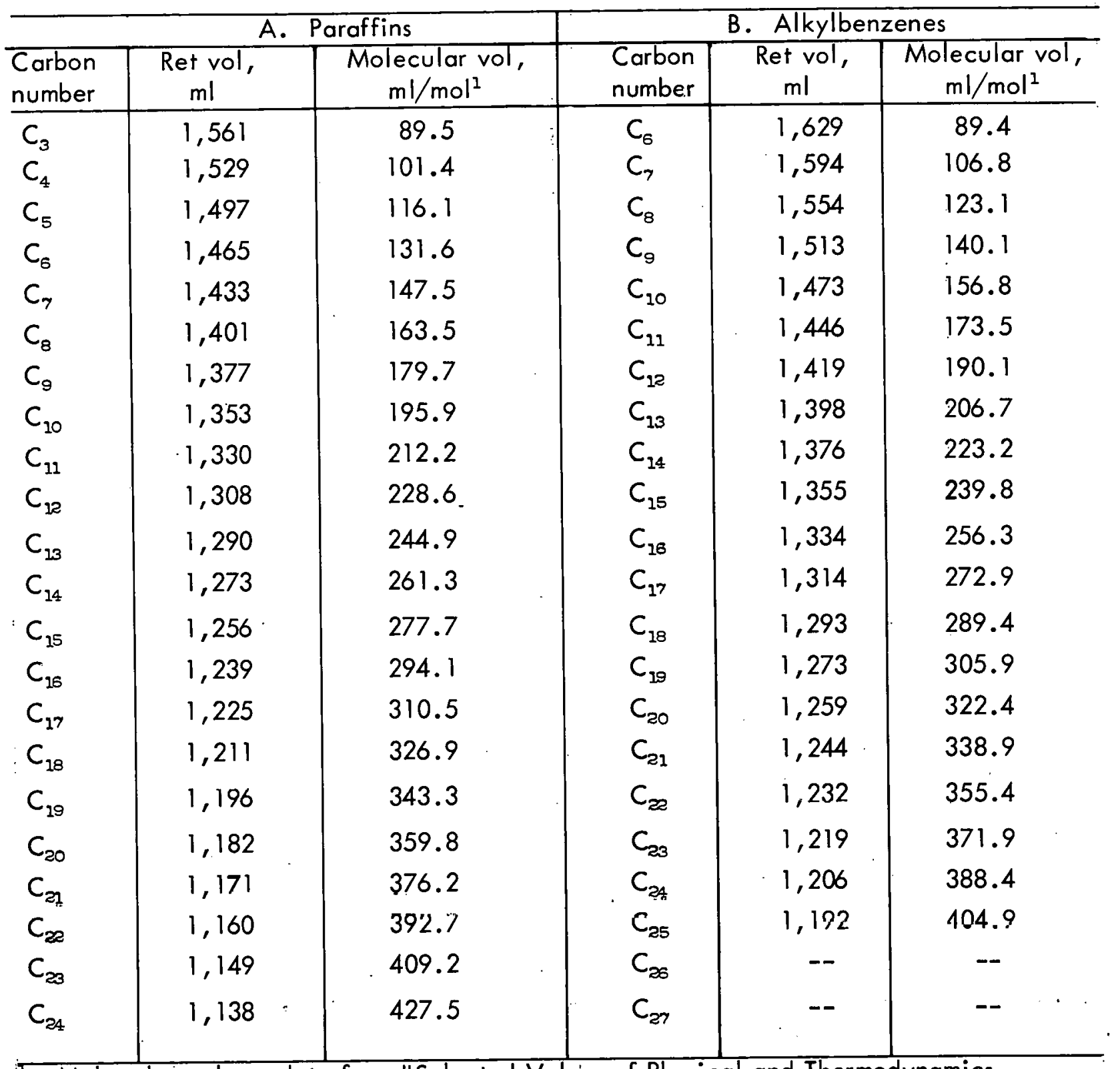

Molecular volume data from "Selected Values of Physical and Thermodynamics Properties of Hydrocarbons and Related Compounds," by Frederick D. Rossini, Kenneth S. Pitzer, Raymond L. Arnett, Rita M. Braun, and George C. Pimentel: Published for API by Carnegie Press, 1953. 
TABLE 3. - Chain methylene plus a bond retention-volume increment for $n$-paraffins and n-alkylbenzenes

A. $n$-Paraffin chain methylene plus a bond retention-volume increment $(P C M+B)$

\begin{tabular}{l|l|c|c}
\hline $\begin{array}{c}\text { Retention } \\
\text { volume range, } \mathrm{ml}\end{array}$ & $\begin{array}{c}\text { Carbon number } \\
\mathrm{n} \text {-paraffin }\end{array}$ & $\begin{array}{c}\text { Retention } \\
\text { volume } \\
\text { difference, } \mathrm{ml}\end{array}$ & $\begin{array}{c}\text { Retention volume } \\
\text { difference per } \\
\text { carbon number, } \mathrm{ml}\end{array}$ \\
\hline 1,138 to 1,182 & $\mathrm{C}_{24}$ to $\mathrm{C}_{20}$ & 44 & 11 \\
1,239 to 1,308 & $\mathrm{C}_{16}$ to $\mathrm{C}_{12}$ & 69 & 17 \\
1,308 to 1,401 & $\mathrm{C}_{12}$ to $\mathrm{C}_{8}$ & 93 & 23 \\
1,401 to 1,465 & $\mathrm{C}_{8}$ to $\mathrm{C}_{6}$ & 64 & 32 \\
\hline
\end{tabular}

B. n-Alkylbenzene chain methylene plus a bond retention-volume increment $(B C M+B)$

\begin{tabular}{c|c|c|c}
\hline $\begin{array}{c}\text { Retention } \\
\text { volume range, } \mathrm{ml}\end{array}$ & $\begin{array}{c}\text { Carbon number } \\
\text { of alkylbenzene }\end{array}$ & $\begin{array}{c}\text { Retention } \\
\text { volume } \\
\text { difference, } \mathrm{ml}\end{array}$ & $\begin{array}{c}\text { Retention volume } \\
\text { difference per } \\
\text { carbon number, } \mathrm{ml}\end{array}$ \\
\hline 1,192 to 1,244 & $\mathrm{C}_{25}$ to $\mathrm{C}_{21}$ & 52 & 12.5 \\
1,334 to 1,419 & $\mathrm{C}_{16}$ to $\mathrm{C}_{12}$ & 85 & 21.5 \\
1,473 to 1,629 & $\mathrm{C}_{10}$ to $\mathrm{C}_{6}$ & 156 & 39.0 \\
\hline
\end{tabular}

\section{DAMV AND EOMV PARAMETERS}

In order to determine the molecular volumes of aromatic and naphthenoaromatic compounds, either from their structure or from their GPC retention volumes, two G PC parameters defined earlier, DAMV and EOMV, have been determined that are based upon retentionvolume increments for carbons and bonds. The relationship between DAMV and EOMV is defined to be $1,561 \mathrm{ml}-\mathrm{DAMV}+\mathrm{EOMV}=$ retention volume. $1,561 \mathrm{ml}$ is the retention volume of a hypothetical n-paraffin whose molecular volume is equivalent to that of ." benzene (the reference, DAMV $=0$ ) obtained from an extrapolation of the n-paraffin molecular volume and retention volume data of table 2.A. The DAMV of any other compound, $R$, is the difference between $1,561 \mathrm{ml}$ and the retention volume of a hypothetical $n$-paraffin whose molecular volume is equivalent to that of $R$, obtained from interpolation of the $n$-paraffin molecular volume and retention volume data of table 2.A. The EOMV 
of a compound, $R$, is the difference between its retention volume and the retention volume of a hypothetical $n$-paraffin whose molecular volume is equivalent to that of $R$ obtained from interpolation of the $n$-paraffin molecular volume and retention volume data of table 2.A. Two results from these definitions are that $n$-paraffins have a DAMV but no EOMV and benzene (the reference) has no DAMV but does have an EOMV.

Figure 1 uses benzene and naphthalene to show further, vectorially, the relationship between these two parameters. Benzene, with a retention volume of $1,629 \mathrm{ml}$, has, by definition, no DAMV but has $1,629 \mathrm{ml}-1,561 \mathrm{ml}=68 \mathrm{ml}$ EOMV. A hypothetical $\mathrm{n}-$ paraffin whose molecular volume is equivalent to naphthalene would elute at $1,484 \mathrm{ml}$ by interpolation in table 2. A, and hence, naphthalene has $1,561 \mathrm{ml}-1,484 \mathrm{ml}=77 \mathrm{ml}$ DAMV and $1,638 \mathrm{ml}$ (the retention volume of nnaphthalene) $-1,484=154 \mathrm{ml} \mathrm{EOMV}$.

Hence, DAMV values of compounds, calculated from their structure, will yield the point where a hypothetical n-paraffin of equivalent molecular volume elutes and thus determine the molecular volumes and densities of the compounds without an experimental GPC run. Likewise, calculation of the EOMV, which is shown in figure 1 to oppose DAMV, will yield the retention volume of a compound once its molecular volume has been established (without an experimental GPC run). Conversely, if the retention volume is known, the molecular volume can be obtained from the calculated EOMV value and used to check the molecular volume value calculated from the DAMV value. DAMV and EOMV values for several aromatics and naphthenoaromatics are given in table 4. Values for "derived" DAMV and EOMV retention-volume increments for molecular groups are given in table 5. The "derived" increments are obtained from dififerences in DAMV, EOMV, and structure of systems of compounds of known DAMV and EOMV values and known structure. Derivation and confirmation of these values are shown in appendix $B$.

\section{Parameters Which Influence DAMV and EOMV Values}

Before the development of methods to determine the DAMV and EOMV of aromatics and naphthenoaromatics is discussed, nine additional parameters must be considered and evaluated. Later, it will be shown that no more than six of these parameters are used in a single calculation method and that generally four of them are sufficient.

First, when a benzo group, thieno group, or ace group is added to an aromatic ring, the two rings are known to undergo a mutual condensation.-- that is, the molecule formed is smaller than the sum of the volumes of the elements added to form it. It was found that a fundamental condensation factor (C.F.) or multiples of it satisfied all of the aromatic. molecules examined (see table 5). The value of the C.F. is determined to be a constant $(-16 \mathrm{ml}$ ) for DAMV (since the molecule is smaller than the sum of the elements used to form it -- for example, benzene + benzo = naphthalene. The C. F. value is determined. to be a constant $(+16 \mathrm{ml})$ for EOMV since the condensation effect of bringing two aromatic nucleii together increases the deviation of the molecule from paraffinicity -- that is, increases its aromaticity. Derivation and corifirmation of the C. F. values are given in 

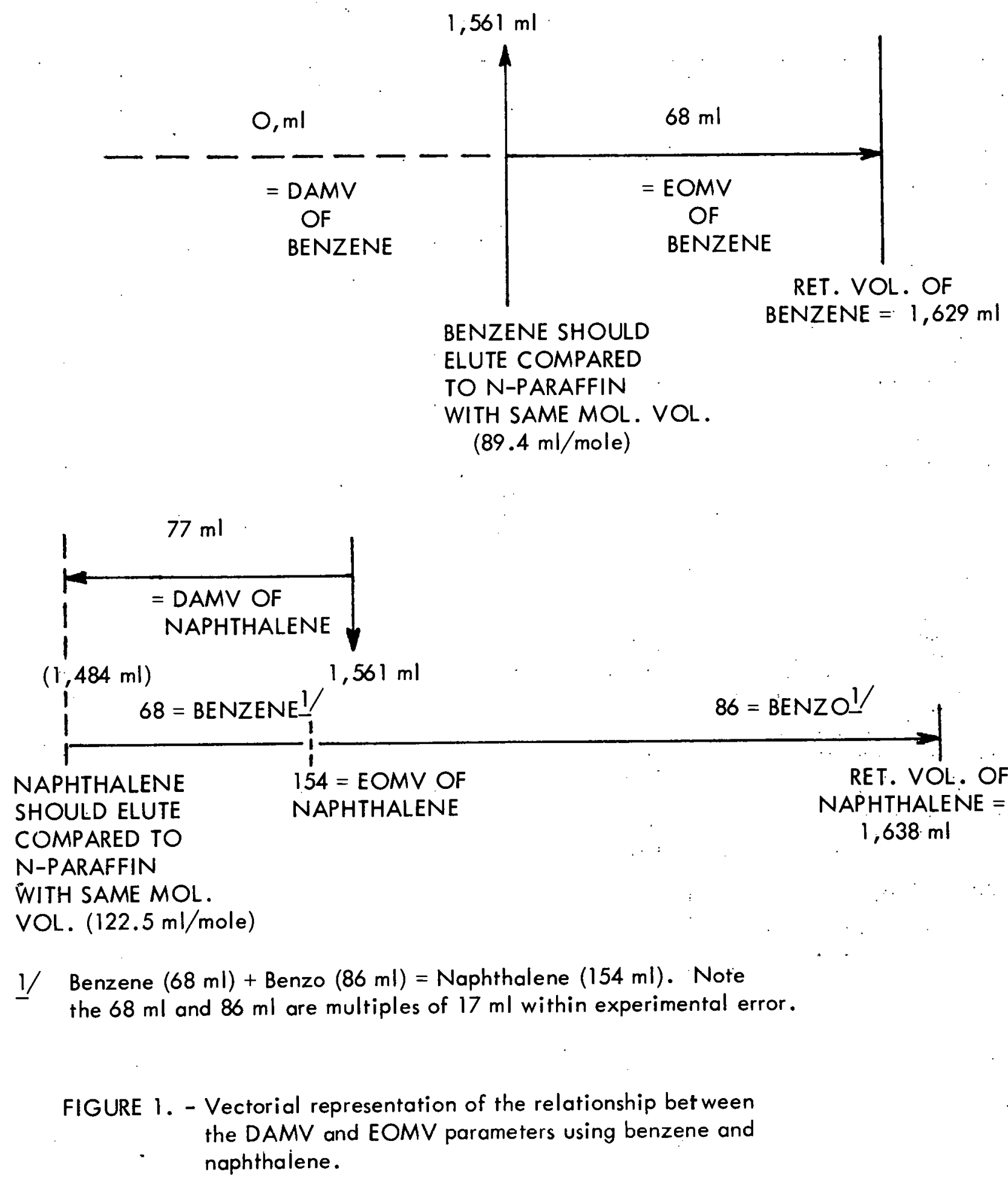
TABLE 4. - Values for retention volume, molecular volume, DAMV parameter, and EOMV parameter for aromotics and naphthenoaromatics

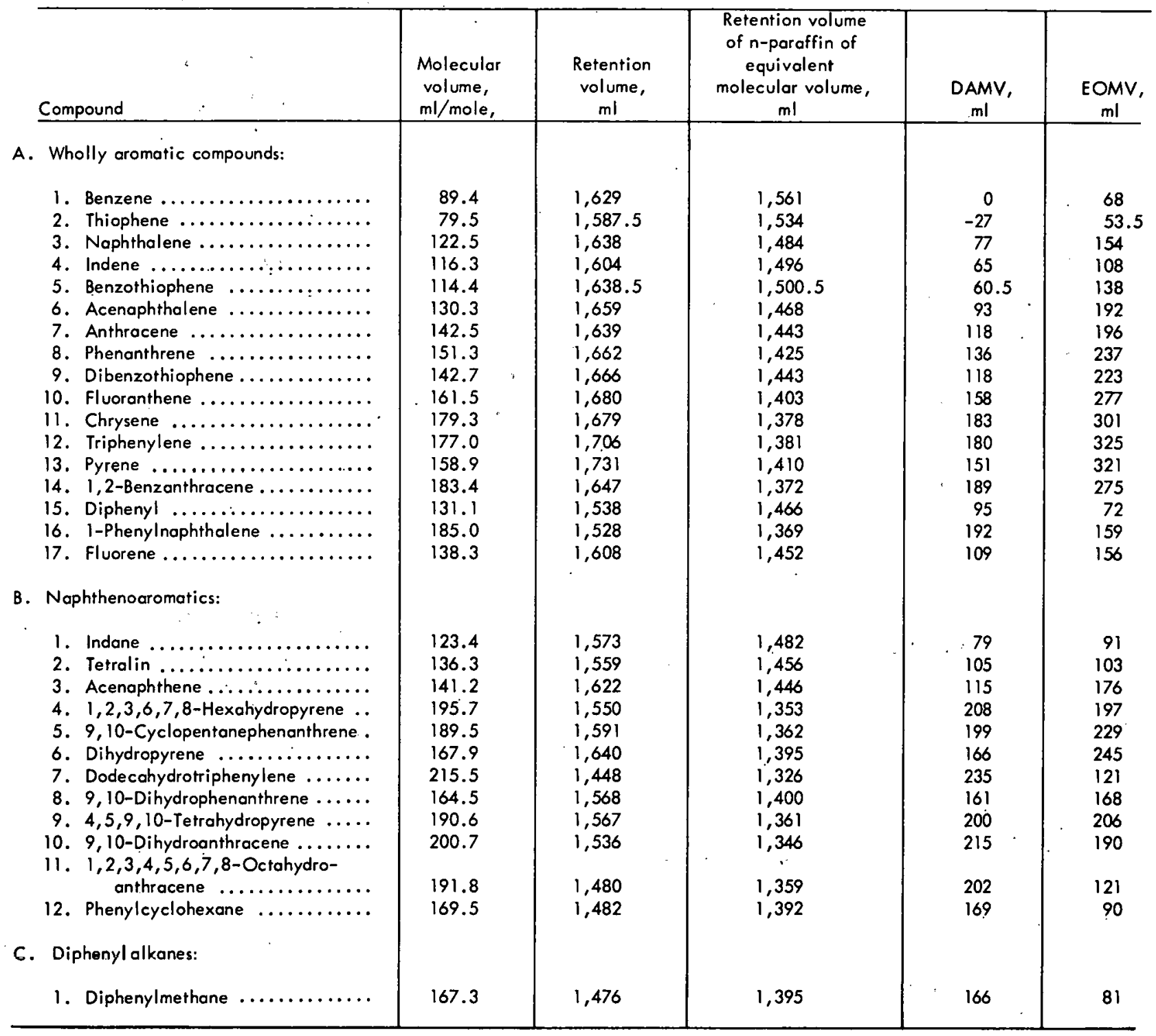


TABLE 5. - Summary of DAMV and EOMV increment values

for carbons and bonds

Carbon, bond, or factor

"Derived" DAMV increment values, $\mathrm{ml}$

A. DAMV increments:

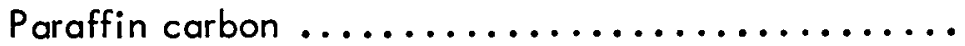

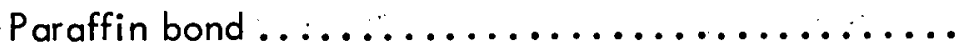

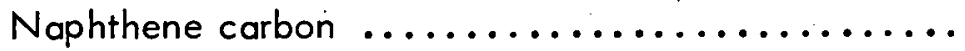

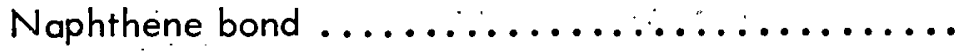

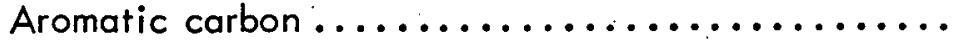

Aromatic bond $\ldots \ldots \ldots \ldots \ldots \ldots \ldots \ldots \ldots \ldots \ldots \ldots \ldots$

Diphenyl bond..$\ldots \ldots \ldots \ldots \ldots \ldots \ldots \ldots \ldots$

Condensation factor $(1$ ring $) . \ldots \ldots \ldots \ldots \ldots \ldots$

Condensation factor (2 rings, condensed) ...........

"Derived" EOMV increment values,

$\mathrm{ml}$

B. EOMV increments:

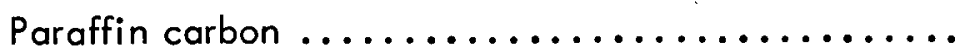

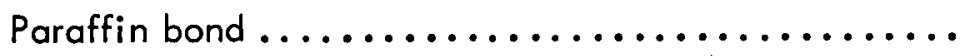

$-8$

$-16$

Naphthene $C_{5}$ vs $C_{6}$ ring and substitution increment

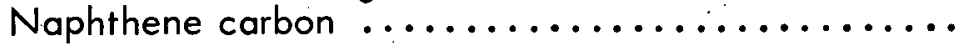

Naphthene bond ...........................

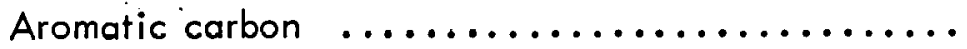

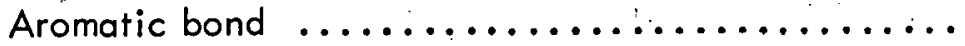

Condensation factor $(1$ ring) $\ldots \ldots \ldots \ldots \ldots \ldots \ldots$

Condensation factor (2 rings, condensed) $\ldots \ldots \ldots \ldots$.

0
0
12
4
4
8
8
+8
+16


appendix $B$. The $+16 \mathrm{ml}$ increment for the EOMV is not to be confused with the $17 \mathrm{ml}$ multiples for EOMV values of footnote 1 of figure 1 .

The second of the nine parameters is a linearity factor (L.F.) that applies to four-ring wholly aromatic molecules. The degree of nonlinearity in all methods is shown, in table 6, to be determined as a function of the number of phenanthrene or fluorene molecules that can be counted in the molecule. The rings may be counted more than once. The method of determining the L.F. count, in the table, is the same for DAMV and $E O M V$, although it will be shown that the values for the L.F. counts differ for DAMV and EOMV. Confirmation of these counts will be given by example later.

The third parameter is a substitution factor (S.F.) for naphthenoaromatics that arises from the effect of polysubstitution of an aromatic ring on retention volume and the fact that each junction of a naphthene ring with an aromatic ring acts as an "effective" chain substitution of the ring. The S.F. is determined by comparing naphthenoaromatics to polymethyl substituted aromatics. Through trisubstitution, the S.F. is negligible -- that is, the polysubstituted methyls act as though they were in a chain. For tetrasubstitution and higher substitution of benzene, the S.F. is significant. For the DAMV of naphthene rings, all but one carbon of the naphthene ring are regarded as one "effective" substitution on the ring, and the remaining naphthene carbon as another "effective" substitution. Since there are two carbons in the ring making up one "effective" substitution in the case of a five-membered ring versus three carbons in the case of a six-membered ring and one carbon making up the second "effective" substitution, the weight of the five-membered ring (two "effective" substitutions) is $(2 / 3+) / 2=.5 / 6$ of a six-membered ring for the $D A M V$ value, as shown in table 7 . For the EOMV values, the same weighting minus $12 \mathrm{ml}$ is applied, or a five-membered ring has a weight of $5 / 6$ of a six-membered ring minus $12 \mathrm{ml}$. Significant values are given in table 7 . The derivation of these values is in appendix $C$.

The fourth parameter is the "effective" bond count factor (EBCF) which is needed to deter-: mine the number of bonds dearomatized in going from an aromatic precursor to a naphthenoaromatic derivative. This is necessary because the methods for determining both DAMV and EOMV of naphthenoaromatics involve calculations which, in effect, assume partial hydrogenation or dearomatization of molecules with completely aromatic character. The important thing to know is the difference in "effective" bond counts between the starting completely aromatic molecule and the aromatic portion of the naphthenoaromatic derivative. Table 8 shows the "effective" bond counts for both DAMV and EOMV calculations involving nophthenoaromatics. Derivation and confirmation of these "effective" bond counts will be shown by examples using calculation methods to be derived later in the text.

The fifth parameter that arises in determination of DAMV and EOMV values of all naphthenoaromatics and all aromatics which are indene derivatives is the aromatization factor (A.F.). This factor arises when an aromatic carbon or bond is converted, by the DAMV 
TABLE 6. - Determination of linearity factor counts for use

Compound

(1)

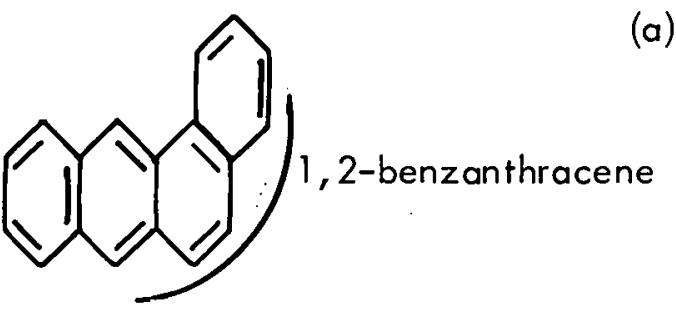

(2)

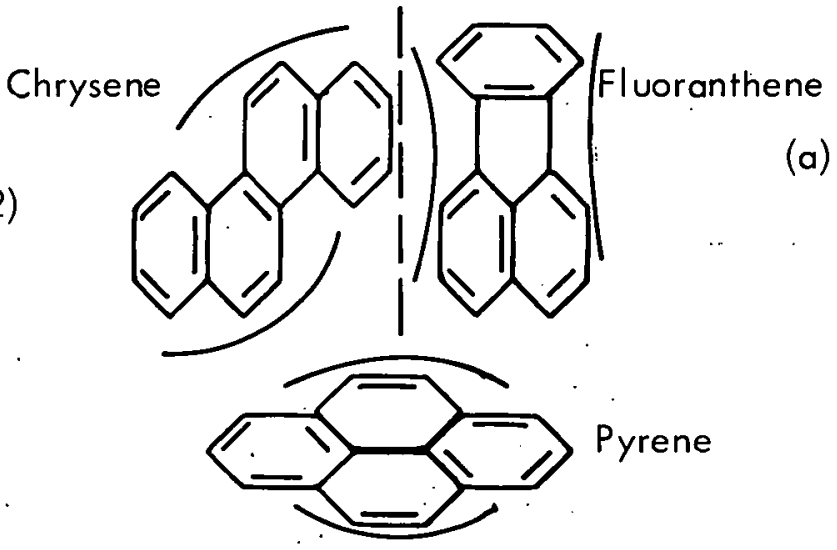

(3)

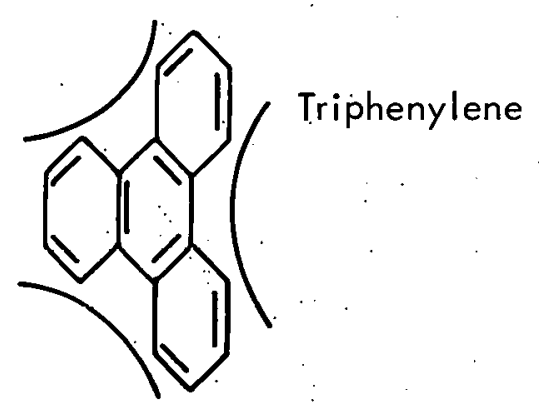

(a) The three curved lines show that the phenanthrene and benzoindene structure can be counted three times in the molecule and, hence, the L.F. count = three.

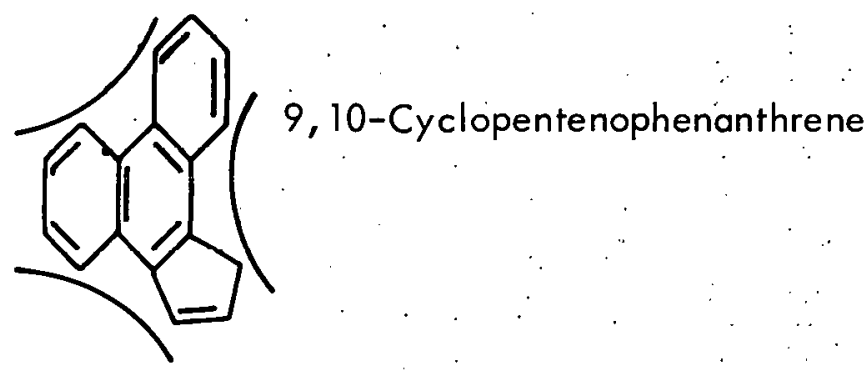


TABLE 7. - Significant DAMV and EOMV substitution factor values

\begin{tabular}{|c|c|c|c|}
\hline \multirow[b]{2}{*}{ Type of substitution } & \multirow{2}{*}{$\begin{array}{l}\text { DAMV value, } \\
\mathrm{ml}^{1}\end{array}$} & \multicolumn{2}{|c|}{ EOMV value, $\mathrm{ml}$} \\
\hline & & Six-membered ring ${ }^{1}$ & Five-membered ring ${ }^{1}, 2$ \\
\hline $1,2,3,5$-Tetrasubstitution $\ldots \ldots \ldots \ldots$ & 6 & 12 & 10 \\
\hline $1,2,3,4$-Tetrasubstitution $\ldots \ldots \ldots \ldots$ & 12 & 12 & 10 \\
\hline Combined penta- and hexasubstitution... & 360 & 24 & $8+12=20$ \\
\hline
\end{tabular}

I The method of determining substitution factors is given in appendix $C$.

2 Five-membered ring has an EOMV value of two-thirds that of a six-membered ring for one "effective" substitution and the same value for the other "effective" substitution: $(2 / 3+i) / 2=5 / 6$ of $24 \mathrm{ml}(=20 \mathrm{ml})$ for combined pentaand hexasubstitution as discussed in the text.

3 The ring is shown in appendix $C$ to lose five-eighths of its value if it represents combined penta- and hexasubstitution; hence, five $12 \mathrm{ml}$ increments $=60 \mathrm{ml}$. 
TABLE 8. - "Effective" bond counts for aromotic systems derived from DAMV and EOMV colculation methods (given later) for use in naphthenoaromotic DAMV and EOMV calculation

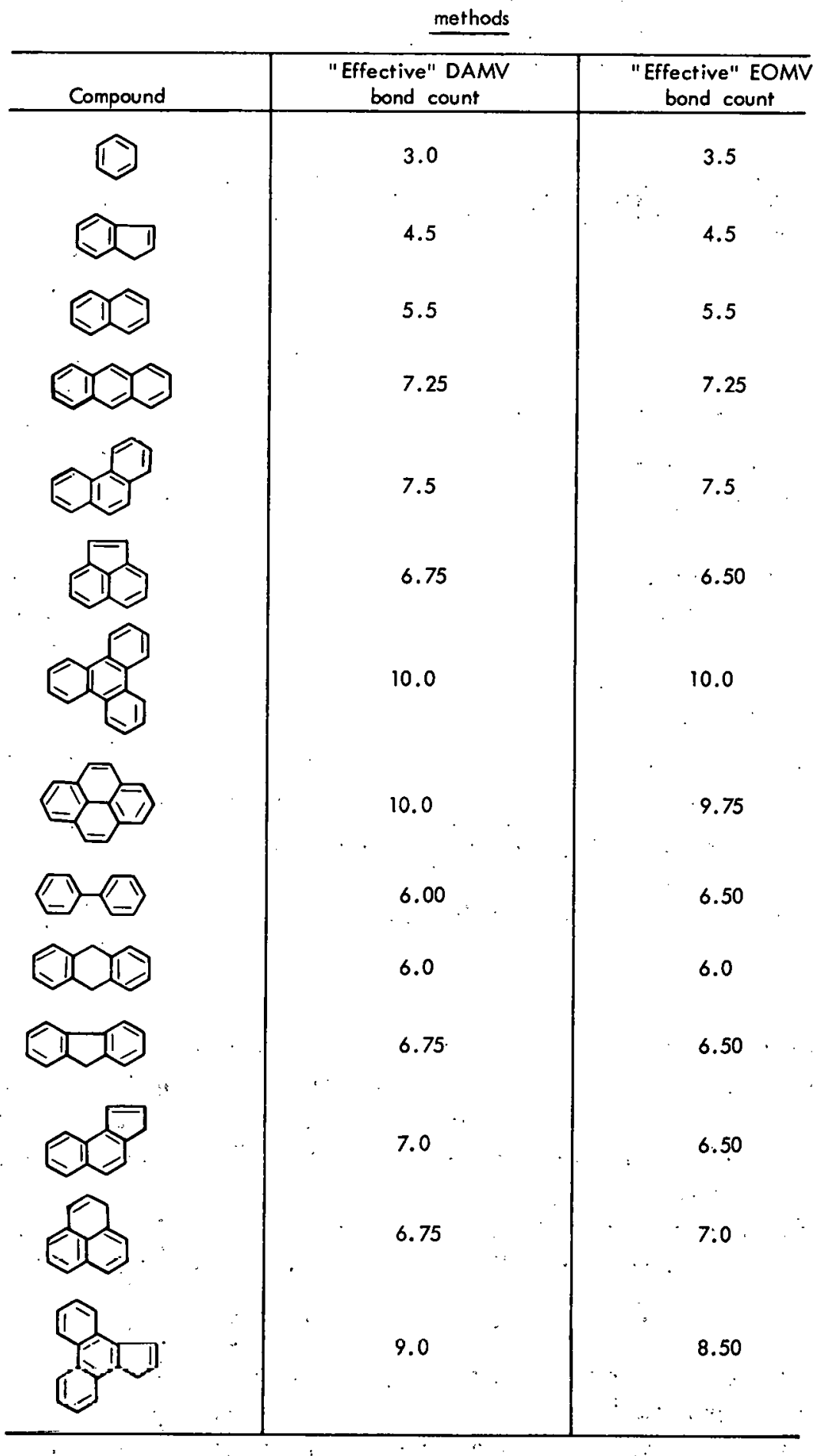


and EOMV calculation methods to be given later, into a naphthene carbon or bond (or vice versa). It also arises when an aromatic bond is converted to a diphenyl bond. A 2-ml-per-carbon and 4-ml-per-bond DAMV increment value between naphthenic and aromatic compounds is derived in appendix $B$, as are EOMV values. The significant values are given in table 9 .

TABLE 9. - Aromatization factor values $(A F)$ to be used in DAMV and EOMV calculation methods ${ }^{1}$

The sixth parameter is the total aromatic carbon factor (TACF). This factor arises when one determines the DAMV or EOMV of aromatics start-

Structural group change

DAMV AF, $\mathrm{ml}$

\begin{tabular}{|c|c|c|}
\hline Aromatic naphthenic carbon ... & +2 & +4 \\
\hline Aromatic naphthenic bond .... & +4 & $\begin{array}{l}\text { +8 per double } \\
\text { bond }\end{array}$ \\
\hline Naphthenic aromatic carbon... & -2 & -4 \\
\hline Naphthenicraromatic bond .... & -4 & $\begin{array}{l}-8 \text { per double } \\
\text { bond }\end{array}$ \\
\hline Aromatic paraffinic carbon .... & $2+12$ & - \\
\hline Aromatic - paraffinic bond ..... & $2+12$ & - \\
\hline Aromatic diphenyl bond ...... & - & -4 \\
\hline Diphenyl-naphthenic bond .... & - & -4 \\
\hline
\end{tabular}

I For explanation of the derivation of these values see appendix B.

.2 In addition to aromatic to naphthenic AF. ing from the DAMV of the saturate which has the same skeletal structure [SRC Methods appendix $A$ (DAMV) and later in the text (EOMV)]. These methods lead to expressions which are a function of the total aromatic carbons minus one for the DAMV (with a sulfur atom equivalent to two aromatic carbons) and a function of the total aromatic carbons minus two for the EOMV (with a sulfur atom equivalent to one aromatic carbon).

The seventh parameter to be considered is called the ace or bridged ring factor (BRF) and applies only to DAMV calculation for naphthenoaromatics and EOMV calculations for aromatics. One "derived" DAMV increment count $(1.2 \mathrm{ml})$ is subtracted for each common side above one when two or more adjacent sides of a naphthene ring are common to aromatic rings. One "derived" EOMV increment count $(17 \mathrm{ml}$ ) is added (in the total ring count method for determining EOMV of aromatics to be given in appendix A) for each side above one when two or more sides of an aromatic ring are common to other six-membered rings.

The eighth parameter, which we will call a paraffin factor (PF), applies only to DAMV and EOMV values for naphthenoaromatics. This factor is employed when aromatic carbons are hydrogenated to carbons that are paraffinic rather than naphthenic in character, that is, the aromatic rings have no aromatic bonds joining them, for example, 9, 10-dihydroanthracene (four paraffinic bonds and two paraffinic-carbons). One naphthenic to 
paraffinic derived DAMV increment value $(12 \mathrm{ml})$ is added for each paraffinic carbon and bond. For the EOMV, the "derived" EOMV increment values for going from naphthenic to paraffinic carbons and bonds is $+2 \mathrm{ml}$ per carbon and bond.

The ninth parameter, called the fourth ring factor (FRF), applies to DAMV values for naphthenoaromatics only. One "derived" DAMV increment value $(12 \mathrm{ml})$ is subtracted in the calculation of any configuration of a four-ring naphthenoaromatic.

The validity of the bond count assumptions and the values of the nine parameters presented in this section will be verified by the fact that internal consistency is obtained by their universal application in the DAMV and EOMV calculation methods for aromatics and naphthenoaromatics. Again, it will be shown that no calculation method requires more than six of these factors, and generally only four are used. The reader is reminded that calculations of DAMV and EOMV values from structure permits determination of retention volumes without experimentation--see figure 1 .

\section{METHODS FOR DETERMINING DAMV AND EOMV VALUES}

\section{Methods for Determining DAMV Values of Compounds}

Aromatics

Based upon the fundamental DAMV increment values for the structural elements established in the previous section, two methods of determining the DAMV of aromatics were developed. The first method (the carbon and bond count method) calculates the DAMV for aromatics in the manner explained in appendix $B$. Each molecule is considered to be a benzolog, thienolog, or acelog of a precursor molecule whose DAMV value is already established by a similar calculation; that is, in appendix $B$, we determined the experimental DAMV value for naphthalene to be $77 \mathrm{ml}$. The method calculates a value of $76 \mathrm{ml}$ (within experimental error). Anthracene, phenanthrene, acenaphthylene or a naphthothiophene are computed considering naphthalene to be their precursor. The carbon and bond count $(N)$, the number of CF's $(n)$, and the LF count value and thus, the value for the ring added to naphthalene to form them, is computed using the rules given in table 10 and the calculated $76 \mathrm{ml}$ DAMV value for naphthalene added to them. These compounds, following the calculation of their DAMV values, are used as precursors for computation of the four-ring molecules, etc.

The general equation used for determining aromatic DAMV values by this method is as follows:

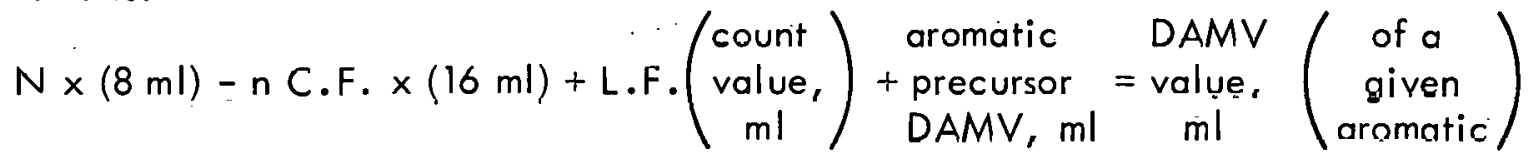

where $N=$ total carbon and bond count and $n=$ an integer coefficient. Calculations for 
TABLE 10.- - Rules for determining values for the coefficients and constants

A. The carbon and bond count $(N)$ is the toral number of carbons plus bonds added for formation of an additional ring. Naphthenic carbons and bonds of ace rings are counted as 1.5 aromatic carbons and bonds. References to aromatic double and single bonds refer to bonds as represented in correctly drawn structures. See appendix B.

1. One-half is added to the count if a ring is added to an existing double bond.

2. One -quarter is added to the count if a ring is added to one or two existing single bonds.

3. A thiophenic sulfur is analogous to two aromatic carbons and thieno is analogous to benzo.

4. Phenyl in diphenyl is analogous to the benzo group plus one and one-half counts for the diphenyl bond. See appendix B.

5. For other phenyl derivatives, the entire phenyl group including one and one-half aromatic bond counts for the diphenyl bond is counted.

6. Nonlinear. molecules above three rings are treated as derivatives of phenanthrene.

B. Condensation factors (C.F.) to be multiplied by $16 \mathrm{ml}$ and subtracted are counted $(n)$ as follows:

1. For naphthalene, indene, and nonlinear addition of tive- and sixmembered hydrocarbon rings above benzene. (See 4 and 5 below.)

a. One C.F. if the first ring, two C.F. if the second ring, and three C.F. if the third ring.

2. For linear addition of five- and six-membered rings above naphthalene, indene, or phenanthrene. (See 4 and 5 below.)

a. Three C.F. for the first ring.

b. Two C. F. for a second six-membered ring. 
TABLE 10. - Rules for determining values for the coefficients and constants in equation 1 for calculating DAMV values for wholly aromatic compounds by the carbon and bond count method--Continued

3. For nonlinear additions which lead to molecules in which two or more sides of a five-membered hydrocarbon ring or partially saturated six-membered ring are common to other rings:

a. Three C.F. for the first ring above indene (or dihydronaphthalene when the ring is six-membered).

b. Two C.F. for the second ring above indene when the rings are sixmembered.

c. One C.F. less than the values in $3 a$ and $3 b$, above, when the rings are five-membered or partially saturated six-membered and counted above naphthalene.

4. Five-membered hydrocarbon rings yie.ld nonlinear molecules if internal and either linear or nonlinear molecules if external depending upon their position.

5. Thieno rings are considered analogous to benzo rings and yield nonlinear molecules if internal and either linear or nonlinear molecules if external depending upon their position.

6. A phenyl group has one-half C.F. when substituted on a single ring and one C.F. when substituted on other ring systems:

C. For four-ring molecules, a linearity factor (L.F.), obtained as in table 6, add the following values:

1. If the L.F. count (table 6) is one, $10 \mathrm{ml}$ is added.

2. If the L.F. count is two, $4 \mathrm{ml}$ is added:

3. If the L.F. count is three, $0 \mathrm{ml}$ is added.

several aromatic molecules are given in table 11 , and it will be noted that some molecules may be calculated from more than one precursor. The values for the parameters (and the rules of table 10 applied) are also given in the table. Three observations can be made from the rules given in table 10: 
TABLE 11. - Colculation of DAMV volues for wholly aromatic compounds (Using equation (1) and rules of table 10 by the carbon and bond count method

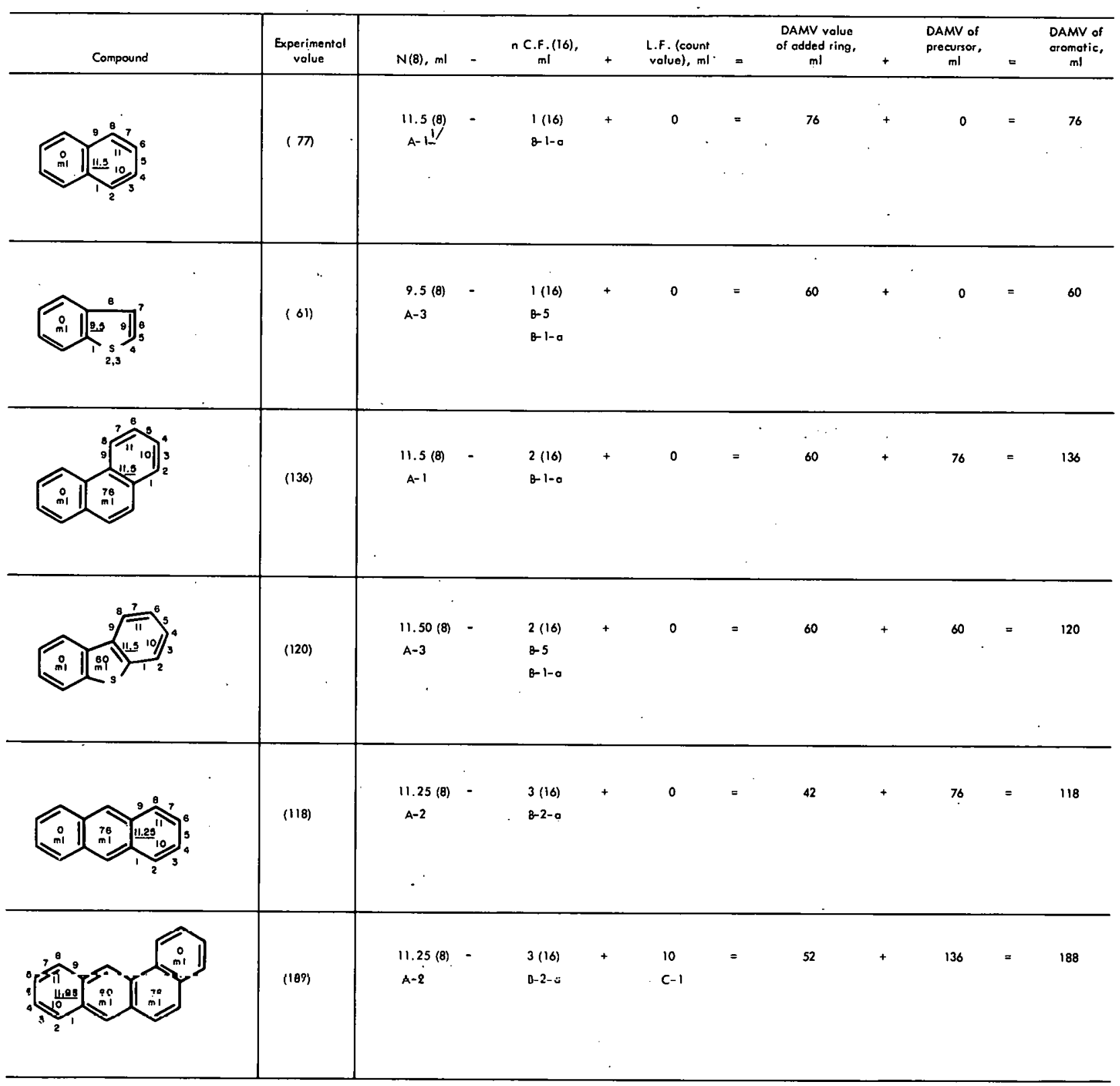

1/ Rule applied, from roble 10. 


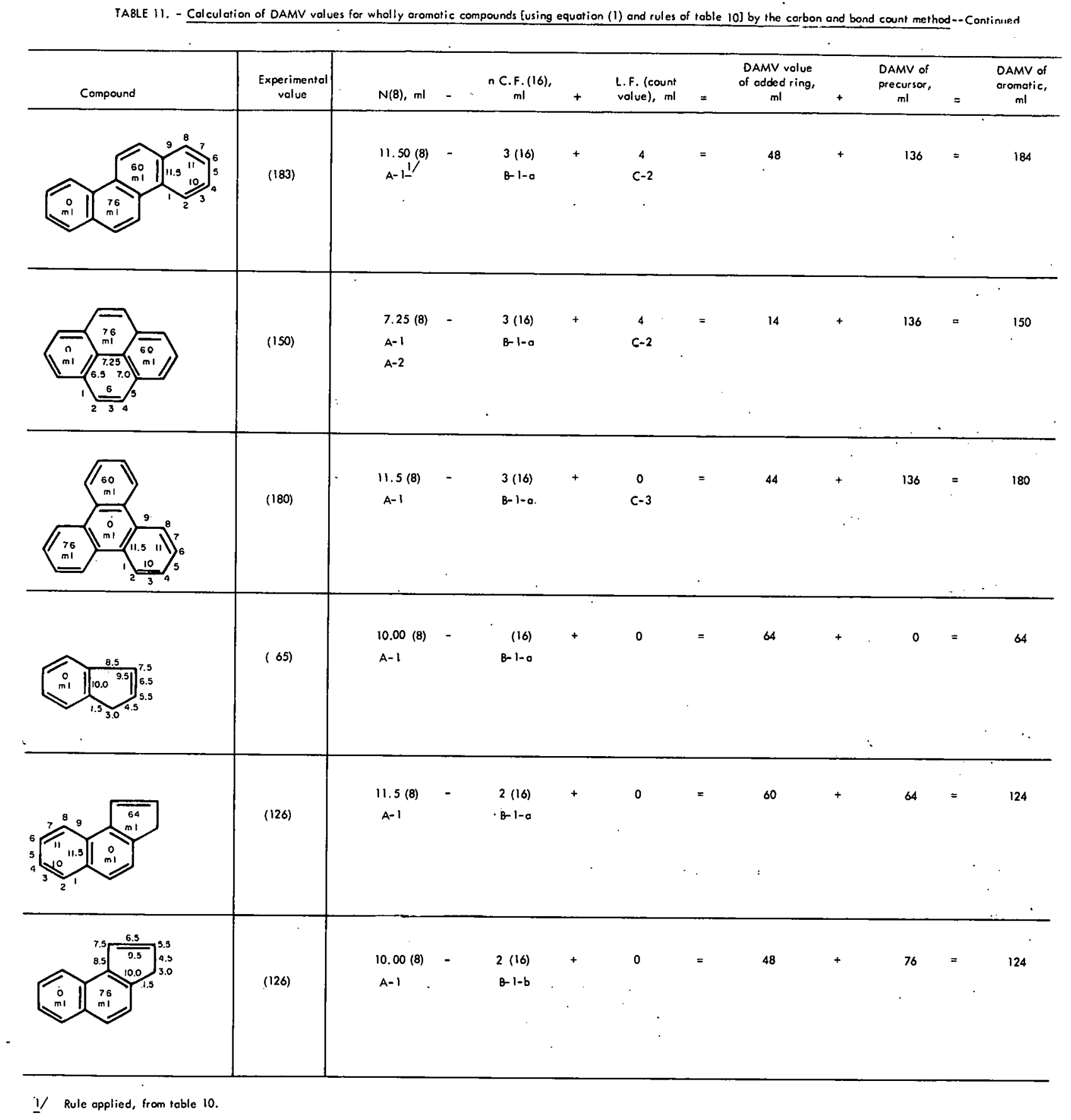


TABLE 11. - Calculation of DAMV values for wholly a comatic compounds [using equation (1) and rules of table 10] by the carbon and bond count method--Continued

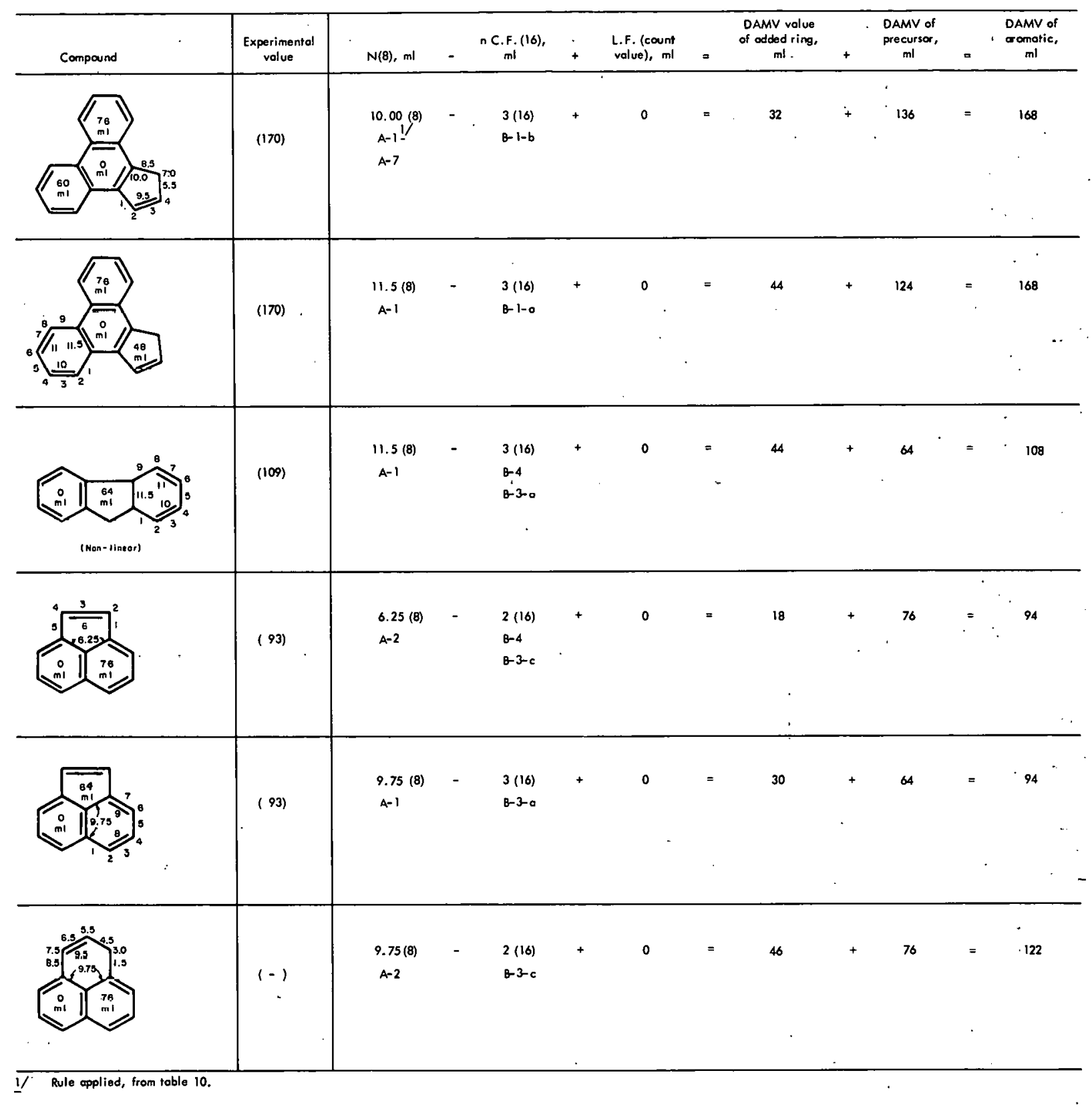


TABLE 11. - Calculation of DAMV values for wholly aromatic compounds [using equation (1) and rules of table.10] by the carbon and bond caint method--Continued

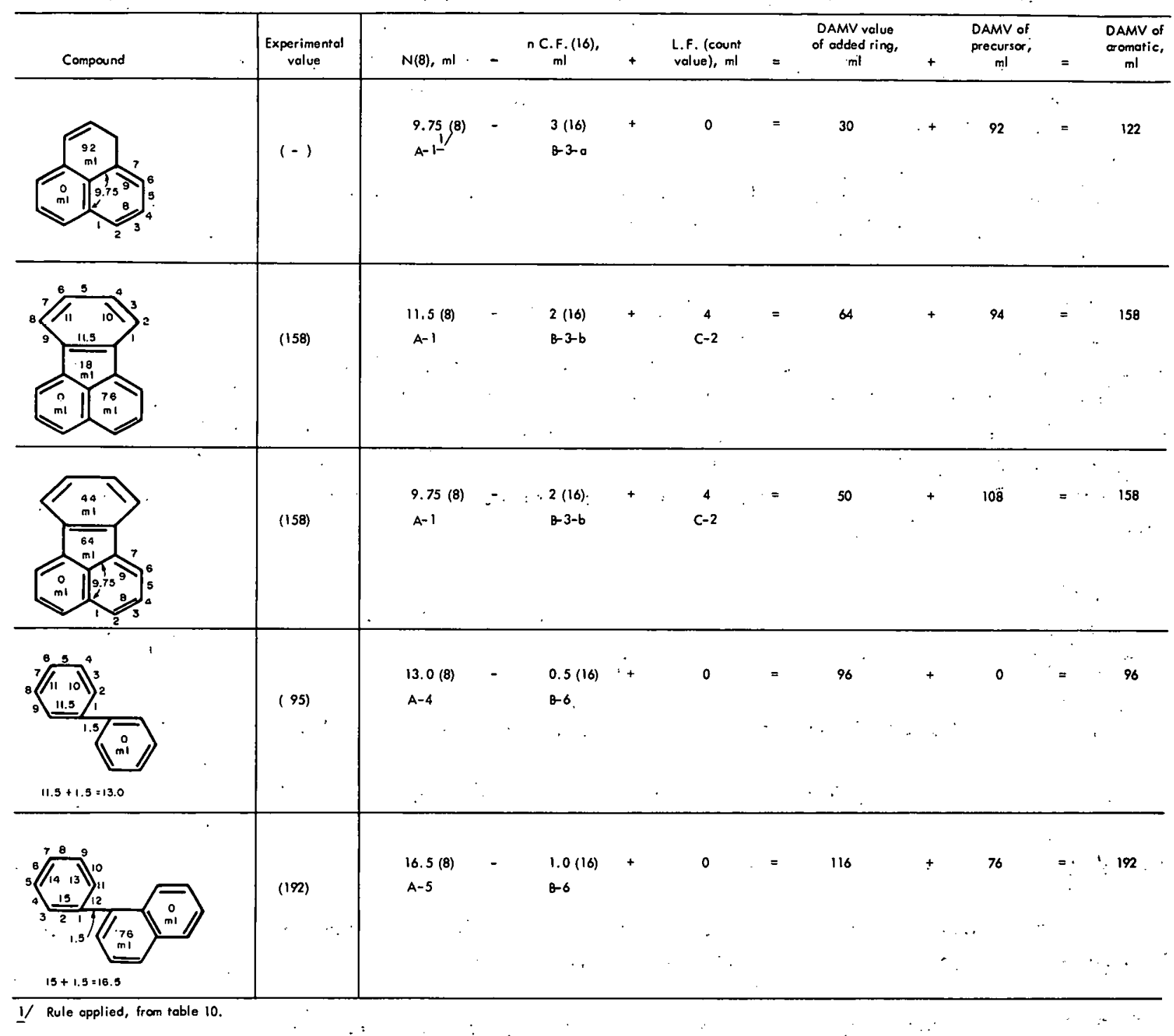


1. A thiophenic sulfur atom counts as two aromatic carbon atoms, table 10A3;

2. There is a definable pattern to the number of condensation factors applied for each ring number which is affected by linearity of the molecule, table 10B3;

3. The difference between four-ring aromatics may be regarded as a function of their linearity, table $10 \mathrm{C}$.

\section{Naphthenoaromatics}

The DAMV for naphthenoaromatics can be determined starting from their aromatic precursors (as determined by the carbon and bond count method, tables 10 and 11). Certain rings are considered to have been hydrogenated to form the naphthenoaromatic. The condensation factors (C:F.), aromatization factors (A.F.), substitution factors (S.F.), fourth ring factors (F.R.F.), and paraffin factors (P.F.) are determined by the rules of table 12. The following. equation is employed:

$$
\begin{aligned}
& \begin{array}{l}
\text { Aromatic } \\
\text { precursor } \\
\text { DAMV, } \mathrm{ml}
\end{array}+\left(\begin{array}{c}
\mathrm{n} \\
\text { or } \\
\mathrm{n}-\mathrm{l} / 2
\end{array}\right) \text { C.F. } \times(16 \mathrm{ml})+\left(\begin{array}{c}
\text { number of } \\
\text { carbons } \\
\text { hydrogenated }
\end{array}\right) \times(2 \mathrm{ml})-\left(\begin{array}{c}
\text { number of } \\
\text { double bonds } \\
\text { removed }
\end{array}\right) \\
& \times(4 \mathrm{ml})-\text { s S.F. } \times(12 \mathrm{ml})-b(B . R . F .) \times(12 \mathrm{ml})-f(F . R . F .) \times(12 \mathrm{ml}) \\
& +p(\text { P.F. }) \times(12 \mathrm{ml})=\text { DAMV value, } \mathrm{ml} \text { (of a given naphthenoaromatic), }
\end{aligned}
$$

where $n, s, b, f$, and $p$ are integer coefficients.

All factors are not used in every calculation. Calculations for several naphthenoaromatic DAMV values using the rules of table 12 are given in table 13.

\section{Methods for Determining EOMV Values of Compounds}

\section{Aromatics}

Based upon the fundamental EOMV values for the structural elements established earlier, two methods of determining the EOMV of aromatics were developed. The first method is a saturate ring count $(S R C)$ method similar to that for the DAMV which starts from a value for the naphthene having the same skeletal structure as the aromatic compound being determined and utilizes the assumption made earlier (that two-ring carbons will not contribute to the EOMV value) to establish the total aromatic carbon count. The following equation is used: 
TABLE 12. - Rules for determining the values for the coefficients and constants equation 2 for calculating DAMV values for naphthenoaromatics

A. The aromatic precursor value chosen is that obtained from the carbon and bond count method given in table 10 and 11 .

B. Condensation factors (C.F.) gained on dearomatization by hydrogenation are determined from the C.F. counts that are given in table 11 except for indene cyclopentano derivatives. These values are in parentheses in the rings designated as hydrogenated (those with dashed bonds) in table 13 . They are to be multiplied by $16 \mathrm{ml}$ and added after being counted as follows:

1. For molecules hydrogenated all the way to a monoaromatic, the total C.F.'s in the hydrogenated rings minus one-half are multiplied by $16 \mathrm{ml}$ and added. [Note that a one ring $8 \mathrm{ml}$ (or one-half a $16 \mathrm{ml}$ (C.F.) is left for the lone remaining benzene.]

2. For molecules hydrogenated to a diaromatic or polyaromatic, the total C.F.'s in the hydrogenated rings is treated as follows:

a. When a choice exists (in three-ring molecules) the count is the average value for the ring or rings hydrogenated. Five-membered rings except in indene in cyclopentano derivatives cannot be considered as zero count rings.

b. When a choice exists (in four-ring molecules) the maximum C.F. count for a given ring or rings, taken in counterclockwise order, is used starting with one threebond, six-membered ring as the zero ring (DAMV of benzene $=$ zero) .

c. No choice exists when diphenyl or a dibenzonaphthene is formed.

C. The aromatization factors (A.F.), from table ?, are added as follows:

1. For each carbon hydrogenated, $2 \mathrm{ml}$ is added.

2. For each bond hydrogenated [the difference in "effective" bond counts (table 8 ) between the aromatic precursor and the aromatic portion of naphthenoaromatic], $4 \mathrm{ml}$ is added. 
TABLE 12. - Rules for determining the values for the coefficients values for naphthenoaromatics--Continued

D. Substitution factors (S.F.) are those determined in table 7 and are subtracted as follows:

1. One-half 12-ml derived DAMV increment for "effective" tetrasubstitution in a linear molecule is subtracted.' (See appendix $C_{\text {.) }}$

2. One 12-ml derived DAMV increment for "effective" tetrasubstitution in a nonlinear molecule is subtracted. (See appendix C.)

3. Five, 12-m/ derived DAMV increments for penta- and hexasubstitution combined are subtracted. The ring loses five of eight increments to a value of $3 / 8$. (See appendix $\mathrm{C}$.)

E. The ace- or bridged-ring factor (B.R.F.) is determined and subtracted as follows:

1. One 12-ml derived DAMV increment is subtracted for each common side, above one, when two sides of a naphthene ring are common to other aromatic rings.

2. One 12-ml derived DAMV increment is subtracted for each common side when three sides of a naphthene ring are common to other aromatic rings.

F. The fourth-ring factor (F.R.F.) is determined and subtracted as follows:

1. One 12-ml derived DAMV increment is șubtracted in the calculation of any configuration of four-ring naphthenoaromatic.

G. The naphthene to paraffinic factor (P.F.) is determined and added as follows:

1. One $12-\mathrm{ml}$ derived naphthenic to paraffinic DAMV increment is added for each carbon and bond hydrogenated past naphthenic to paraffinic character [aromatic rings of the aromatic portion are then no longer connected by an aromatic bond (including diphenyl bonds)--for example, 9, 10-dihydroanthracene]. 
TABLE 13. - Colculation of DAMV values for nophtheno aromatics using equation (2) and the rules of toble 12

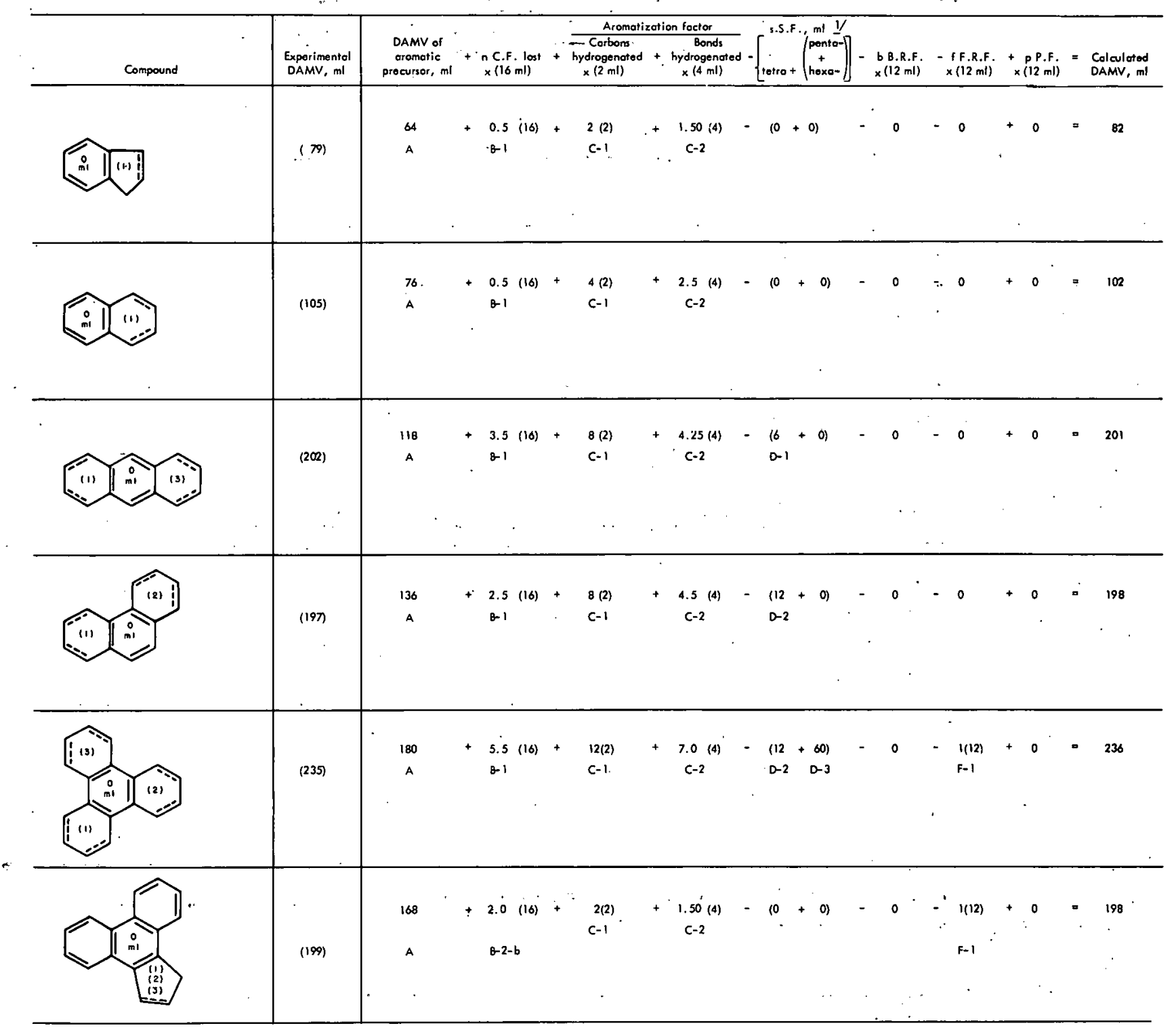


TABLE 13. - Colculotion of DAMV values for nophtheno aromotics using equation (2) and the rules of table 12--Continued

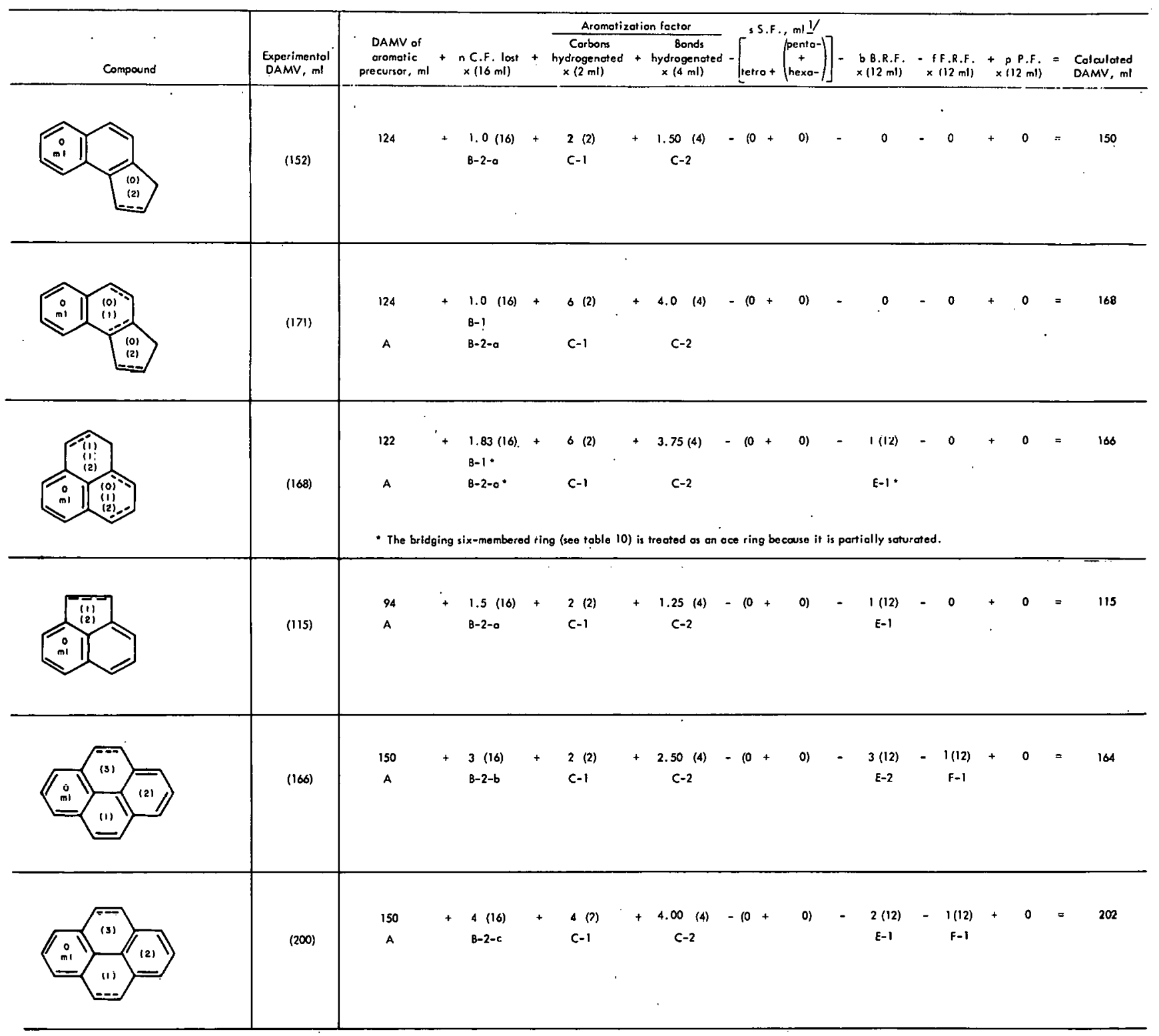


TAELE 13. - Colculotion of DAMV values for nophtheno aromatics using equotion (2) and the rules of table 12--Continued

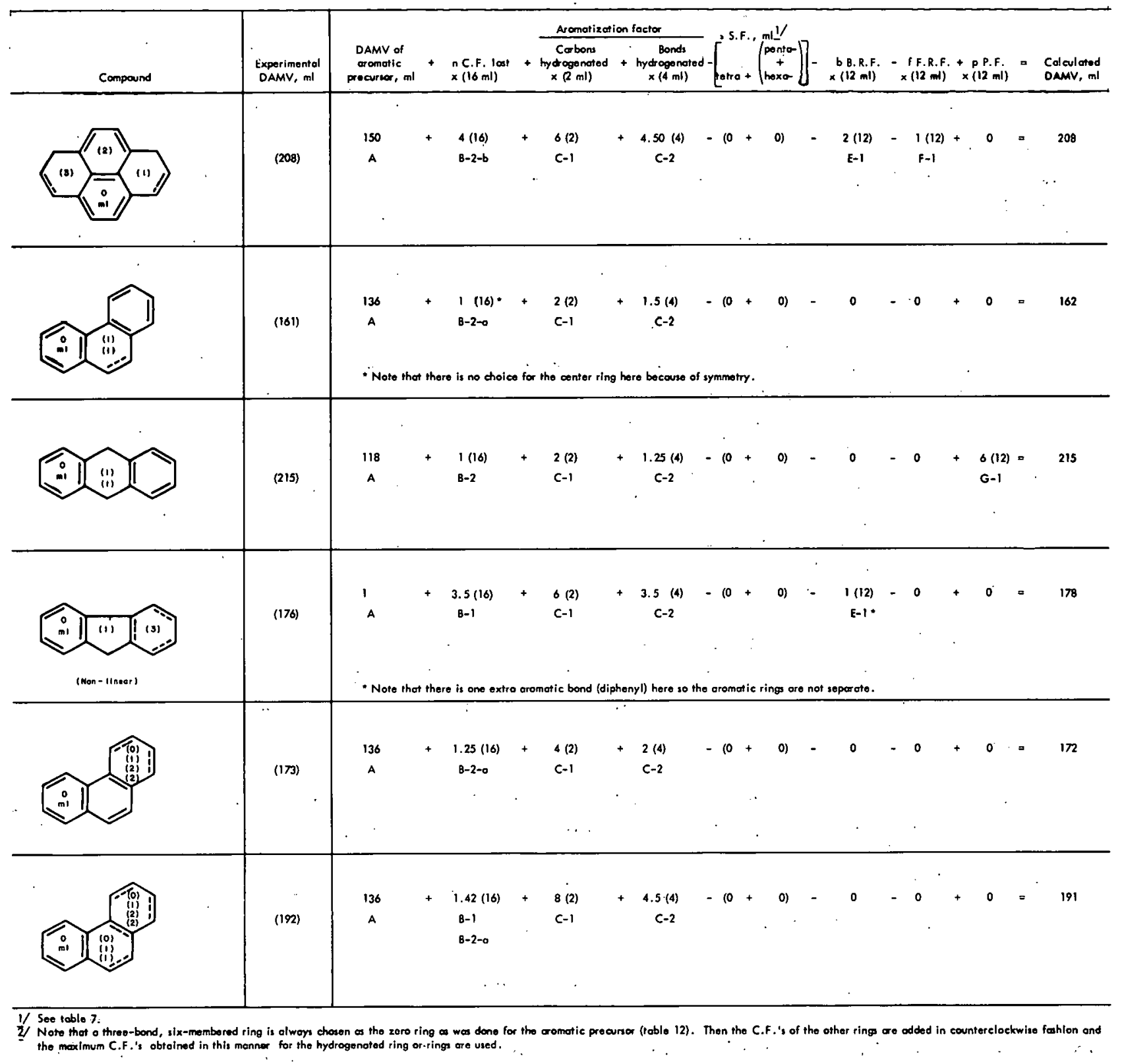




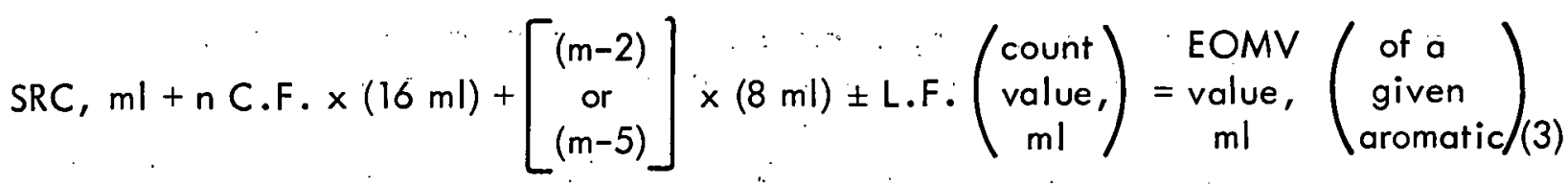

where $n=$ integer coefficient.

Rules for determining the elements of the method: SRC, C.F., TACF minus two (m-2) or TACF minus five $(m-5)$ and L.F. are given in table 14 . The calculations, employing these rules, for several aromatic compounds are given in table 15 and the values of the elements of the method (and the rules of table 14 applied) are shown. Five factors are brought out by the method:

1. A thiophenic sulfur atom counts as one aromatic carbon atom, as opposed to two aromatic carbons for DAMV shown earlier. This difference is attributed to non-paraffinicity (EOMV) and atom size (DAMV).

2. Six-membered aromatic rings always have values which, when uncorrected for linearity, are multiples of $17 \mathrm{ml}$ and differ by $17 \mathrm{ml}$ for benzo groups $(68 \mathrm{ml}$ or $85 \mathrm{ml})$. The values for thieno rings $(53.5 \mathrm{ml}$ or $70.5 \mathrm{ml})$ also differ by $17 \mathrm{ml}$ though not multiples of $17 \mathrm{ml}$.

3. There is a definable pattern to the number of condensation factors each ... molecule has which can be related to the number of one-bond, twobond, and three-bond rings in the molecule and whether a ring is added to a double or single bond.

4. The difference between four-ring aromatics may be regarded as a function of their linearity and number of aromatic carbon atoms.

5. EOMV values for rings are linearly additive to give the EOMV of the compounds they form.

\section{Naphthenoaromatics}

The EOMV for naphthenoaromatics can be determined from their wholly aromatic precursor by subtracting an EOMV increment for each bond and carbon dearomatized and by subtracting the appropriate amount for decondensation (expansion of the molecule on dearomatized and by subtracting the appropriate amount for decondensation (expansion of the molecule or dearomatization). The SRC method EOMV values are used for the aromatic precursors that are treated as though they were being hydrogenated. The following equation applies: 
TABLE 14. - Rules for determining the values for the coefficients and constants in equation 3 for calculating EOMV values for wholly aromatic compounds by the (SRC) method

A. The saturate ring count (SRC) is determined for ririgs as follows:

1. Six-membered hydrocarbon rings count $36 \mathrm{ml}$ each.

2. Five-membered hydrocarbon rings count $24 \mathrm{ml}$ each.

3. Thiacyclopentane rings count $29.5 \mathrm{ml}$ each.

4. Rings joined by a diphenyl bond (including fluorene) have one ring with a value of $40 \mathrm{ml}$ ( $36 \mathrm{ml}+4 \mathrm{ml}$ for the diphenyl bond), and one ring with a value of $0 \mathrm{ml}$.

B. Condensation factors (C.F.) to be multiplied by $16 \mathrm{ml}$ and added are counted $(n)$ as follows:

1. The total C.F. count is equal to the maximum number of three-bond rings that can be drawn in the molecule when the six-membered rings are drawn so that any two have only one common side (the number of sides common to five-membered rings is of no consequerice, and no C.F. count is produced by a single three-bond, six-membered ring joined to a five-membered ring).

2. If two six-membered rings are joined by a diphenyl bond, neither the $0-\mathrm{ml}$ (SRC) count ring, nor the 40-ml (SRC) count ring (A-4, above) count a C.F. unless one ring is in a condensed structure where the condensed portion has one C.F. count.

3. Thieno groups are analogous to benzo groups in the same environment and produce nonlinear molecules when internal, and produces linear or nonlinear molecules if external depending upon their position.

4. One extra C.F. is added for each side greater than one that a sixmembered ring has in common with other six-membered rings--that is, peri-condensation.

C. The total, aromatic carbons factor $(T A C F=m)$ to be multiplied by $8 \mathrm{mi}$ and added is çounted as follows:

1. Total aromatic carbons minus two times $8 \mathrm{ml}$ are added for all but anthracene and anthracene derivatives.

a. A sulfur atom counts as one aromatic carbon.

b. The r.rrhnns of the $0-\mathrm{ml}$ (SRG) sount ring ( $(\Lambda-4$, above) sire counted only wherc both rings and the included diphenyl bond are in a condensed structure. 
TABLE 14. - Rules for determining the values for the coefficients and constants in equation 3 for calculating EOMV values for wholly aromatic compounds by the (SRC) method--Continued

2. Total aromatic carbons minus five times $8 \mathrm{ml}$ are added for anthracene and anthracene derivatives and la and $\mathrm{lb}$ apply.

D. For four-ring molecules the linearity factor (L.F.) count, obtained as in table 7 , adds or subtracts the following values:

1. If the L.F. count is ore, $4 \mathrm{ml}$ is subtracted.

2. If the L.F. count is two, $0 \mathrm{ml}$ is added.

3. If the L.F. count is three, $4 \mathrm{ml}$ is added.

$$
\begin{gathered}
\left(\begin{array}{c}
\text { Aromatic } \\
\text { precursor } \\
\text { EOMV, } \mathrm{ml}
\end{array}\right)-n(C . F .) \times(16 \mathrm{ml})-\left(\begin{array}{c}
\text { number of } \\
\text { carbons } \\
\text { hydrogenated }
\end{array}\right) \times(4 \mathrm{ml})-\left(\begin{array}{c}
\text { number of } \\
\text { double bonds } \\
\text { removed }
\end{array}\right) \\
\times(8 \mathrm{ml})-\mathrm{s}(\text { S.F. }) \times(12 \mathrm{ml})-\mathrm{p}(\mathrm{P} . \mathrm{F} .) \times(12 \mathrm{ml})=\mathrm{EOMV} \text { value, } \mathrm{ml}\left(\begin{array}{c}
\text { of } \mathrm{a} \\
\text { given } \\
\text { naphtheno- } \\
\text { aromatic }
\end{array}\right.
\end{gathered}
$$

All factors are not used in every calculation and the rules for determining the several factors are given in table 16. Calculations for several naphthenoaromatic EOMV values using the rules of table 16 are given in table 17.

\section{ERRORS IN DAMV AND EOMV VALUE DETERMINATIONS}

\section{Errors in DAMV Value Determinations}

DAMV values depend upon retention volumes of $n$-paraffins, benzene, and several compounds averaged to determine the carbon, bond, SRC values, and condensation factors. Therefore, one might reasonably expect an error as large as $\pm 2 \mathrm{ml}$ due to experimental errors in determining these values, assuming that all density values are correct to three decimals. In addition, since values for one aromatic are used to determine higher ring aromatics (in the carbon and bond count method) and SRC counts of higher ring naphthenes (in the SRC method), additive errors as large as $\pm 4 \mathrm{ml}$ overall in determinations for completely aromatic compounds can be expected. All 37 DAMV value determinations for completely aromatic compounds calculated by the two methods, that could be experimentally checked, are found in table $18 . \mathrm{A}$, to be within $\pm 2 \mathrm{ml}$. Table $18 \mathrm{C}$ shows the maximum errors in determination of molecular volume ( \pm 1.7 percent) and of density 


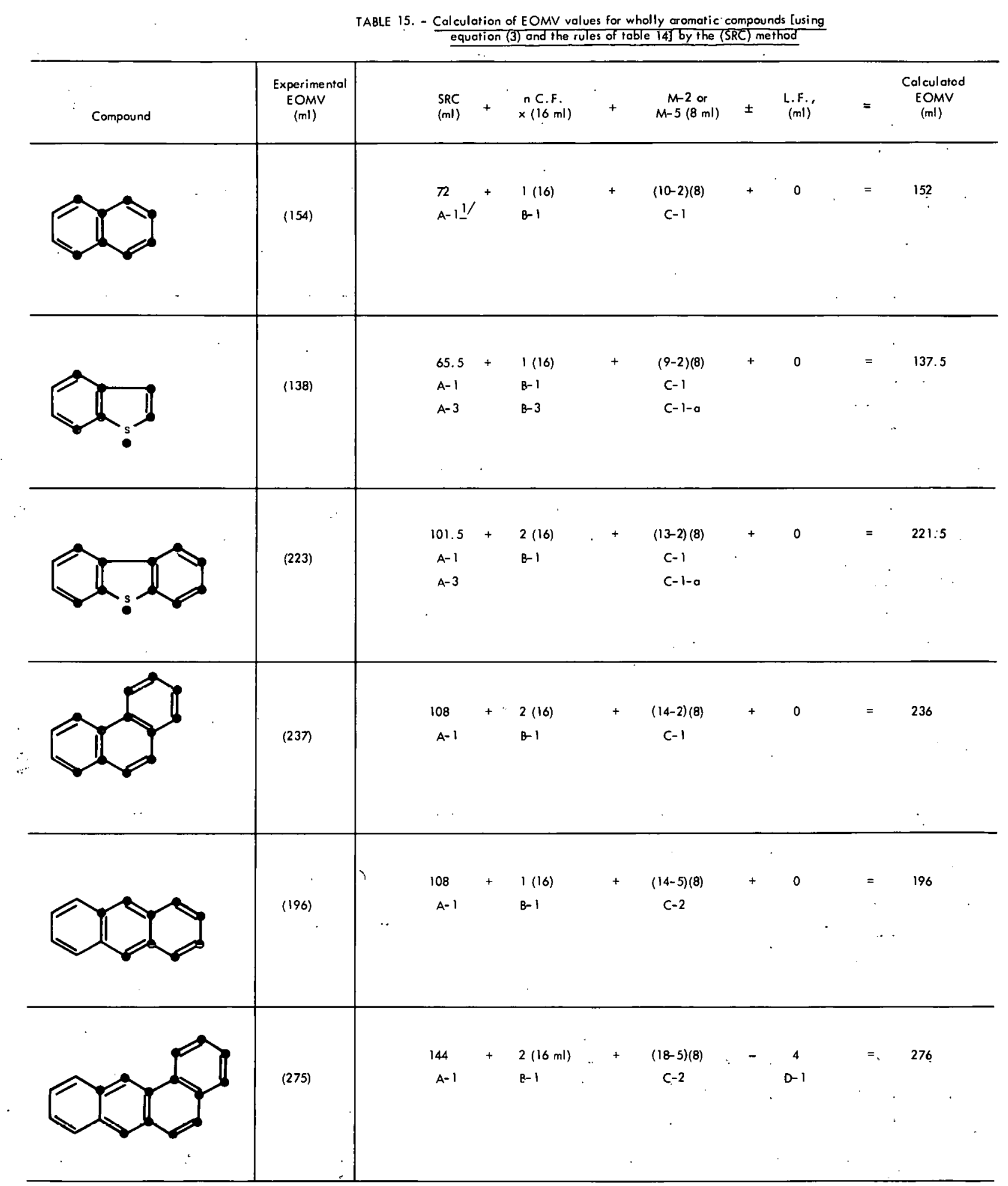

1/ Rule applied, from table 14. 


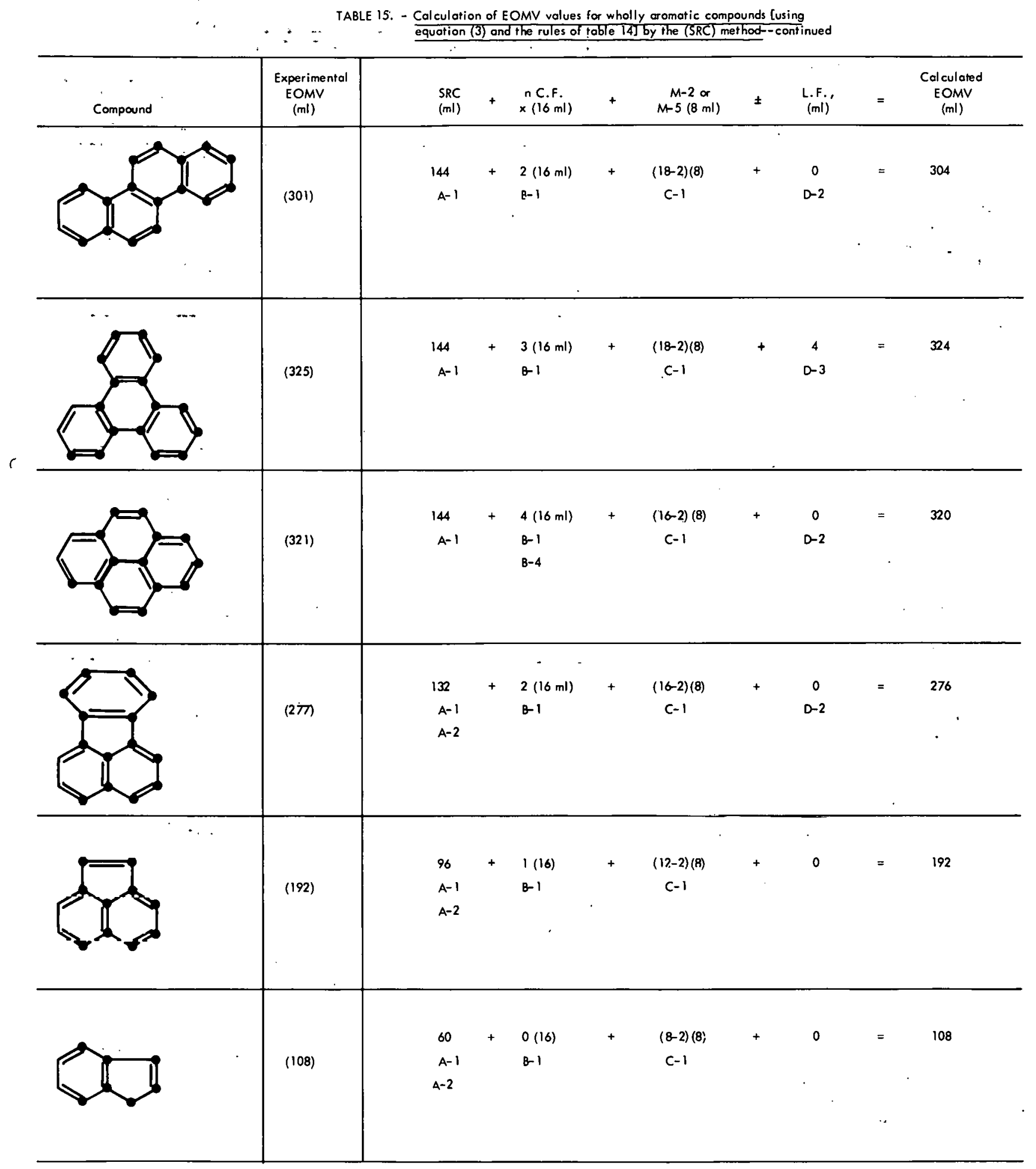


TABLE 15. - Calculation of EOMV values for wholly aromatic compounds [using equotion (3) and the rules of table 14$]$ by the (SRC) method--Continued

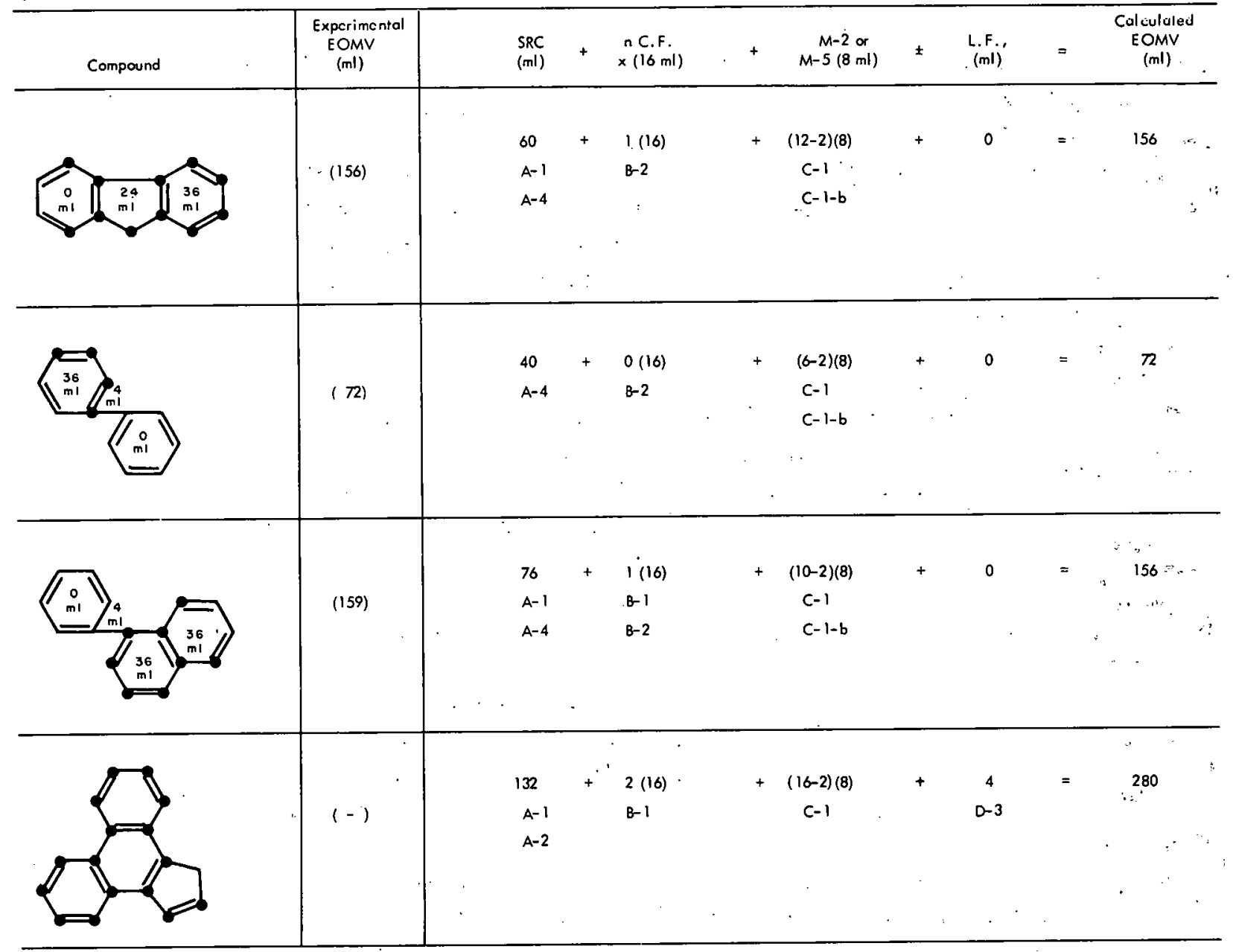



TABLE 16. - Rules for determining the values for the coefficients and constants in

A. The aromatic precursor value chosen is that obtained by the SRC method in table 15.

B. Condensation factors (C.F.) lost on hydrogenation are obtained as the difference in C.F. between the aromatic precursor and the aromatic portion of the naphthenoaromatics derivative as determined by the SRC method. This count, to be multiplied by $16 \mathrm{ml}$ and subtracted, is determined as follows:

1. For diaromatics the total C.F. difference gives the count.

2. For linear triaromatics and polyaromatics and nonlinear triaromatics and polyaromatics with a five-membered ring, the total C.F. difference is counted.

3. For nontinear triaromatics and higher polyaromatics, one more $(n+1)$ than the total C.F. difference is counted.

C. The aromatization factor (A.F.), from table 9, is subtracted as follows:

1. For each carbon hydrogenated, $4 \mathrm{ml}$ is subtracted.

2. For each double bond hydrogenated (using table 8 to obtain the "effective" bond count difference between the naphthenoaromatic and its precursor), $8 \mathrm{ml}$ is subtracted.

D. Substitution factors are those determined in table 7 (aromatic rings are counted as "effective" substitutions) and are subtracted as follows:

1. One 12-ml "derived" EOMV value increment for each of the fuvilli, fifth, and six "effeetive" substitutions if accomplishod with six-membered rings.

2. $[12 \mathrm{ml}+2 / 3(12 \mathrm{ml})] / 2$ for two "effective" substitutions accomplished by a five-membered ring. This is $5 / 6 \times 12$ $=10 \mathrm{ml}$ for each fifth and sixth substitution, or more correctly, $8 \mathrm{ml}$ for one "effective" substitution and $12 \mathrm{ml}$ for the second "effective" substitution, see table 7 and appendix $\mathrm{C}$. 
TABLE 16. - $\frac{\text { Rules for determining the values for the coefficients }}{\frac{\text { and constants in equation } 4 \text { for calculating EOMV }}{\text { values for naphthenoaromatics--Continued }}}$

E. Other factors applied are as follows:

1. $2 \mathrm{ml}$ per carbon and bond hydrogenated is added (for one and one-half times regular EOMV count rings that are found when methylenes totally separate aromatic rings) that is, aromatic rings have no aromatic bond joining them (discussed earlier in text).

2. $4 \mathrm{ml}$ are subtracted when an external double bond is converted to a diphenyl bond, as discussed earlier in text, and $8 \mathrm{ml}$ are subtracted when an internal aromatic bond is converted to a diphenyl bond.

Such a bond is always a common side of two naphthene rings instead of one (as is the case for the external diphenyl bond). ${ }^{1}$

3. $4 \mathrm{ml}$ are subtracted when a diphenyl bond is converted to a naphthenic bond. ${ }^{1}$

I Note: aromatic bond $=8 \mathrm{ml}$, diphenyl bond $=4 \mathrm{ml}$, and naphthenic bond $=0 \mathrm{ml}$.

values ( \pm 1.8 percent) from DAMV values at several points across the 89.5 to 557.2 molecular volume range. Finally, one can see in table $18 \mathrm{~A}$ that more than 80 percent of the determinations are within $\pm 1 \mathrm{ml}$ of the experimental error for retention-volume data.

Since DAMV values for naphthenoaromatics started with calculated DAMV values for . aromatic precursors which were found to be within $\pm 2 \mathrm{ml}$ of the predicted value, and similar errors are incurred for naphthenoaromatics experimental values, we could reasonably estimate an error as great as $\pm 4 \mathrm{ml}$ as acceptable and expect that we might find the error to be as good as $\pm 3 \mathrm{ml}$. This was the case and, in fact, 15 of the 18 determinations, which could be experimentally checked, as shown in table $18 \mathrm{~A}$, were within $\pm 2 \mathrm{ml}$.

\section{Errors in EOMV Value Determinations}

Since EOMV values are also dependent upon retention-volume values for compounds, , carbons, bonds, and condensation factors, essentially the same errors would be estimated for wholly aromatics and naphthenoaromatics that were found for DAMV values (that is, $\pm 4 \mathrm{ml}$ ). Once again, all determinations which could be experimentally checked (44 total), as shown in table $18 \mathrm{~B}$, are found to be within the $4 \mathrm{ml}$ limit and, again, more than 80 percent of the determinations are within $\pm 1 \mathrm{ml}$. The errors in determination of densities from retention volumes are therefore of the same order as determinations from DAMV values as given in table $18 \mathrm{C}$. 


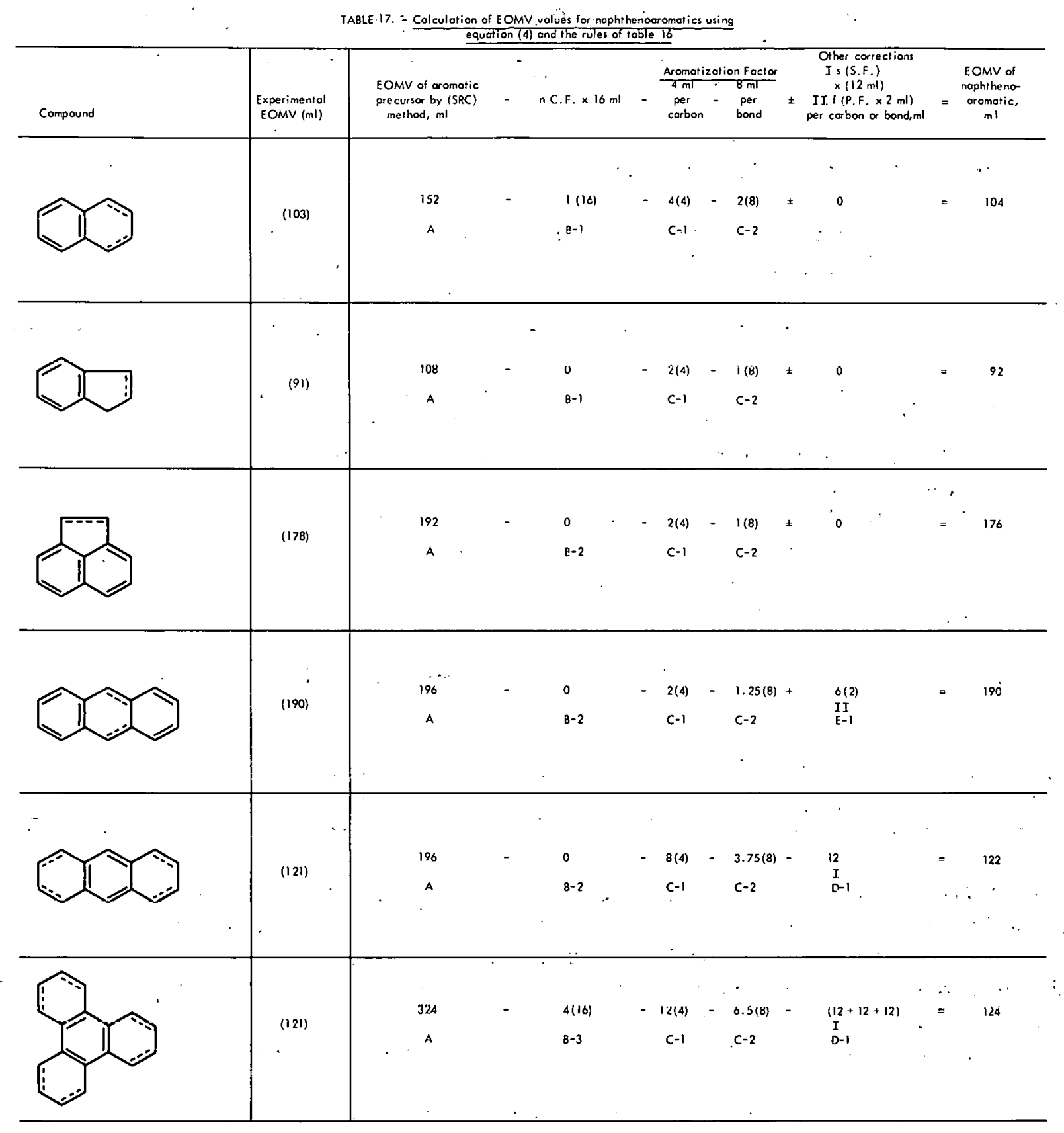




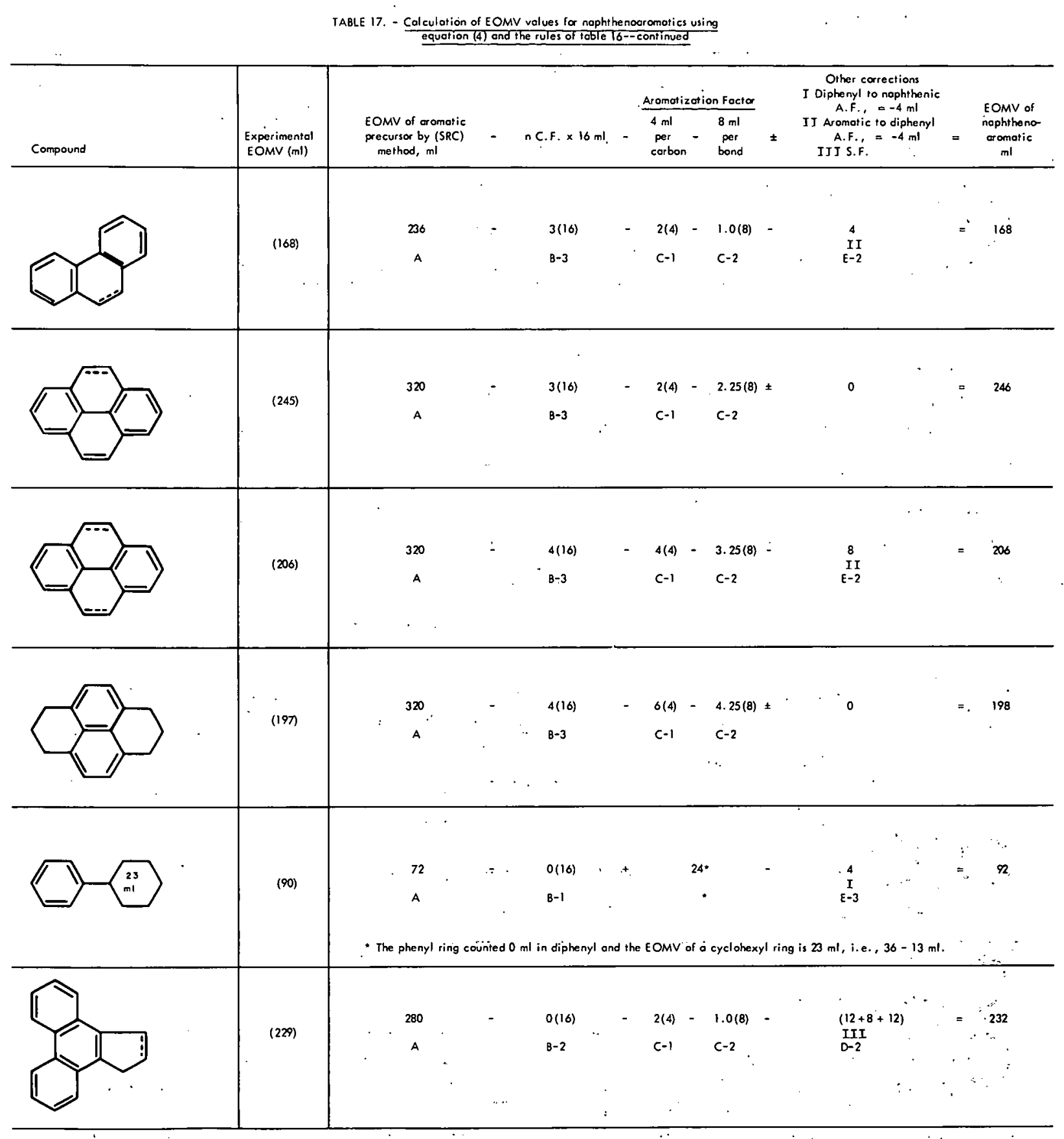


TABLE 18. - DAMV, EOMV, molecular volume, and density value errors

A. DAMV Errors

\begin{tabular}{|c|c|c|c|c|c|c|}
\hline Error, $\mathrm{ml}$ & $\underline{0}$ & 1 & 2 & 3 & $\geq 3$ & Determinations \\
\hline Aromatics, table 11 & 8 & 9 & 4 & - & - & 21 \\
\hline Aromatics, table A-2 & 4 & 9 & 3 & - & - & 16 \\
\hline Naphthenoaromatics, table 16 & 3 & 7 & 5 & 3 & - & $\underline{18}$ \\
\hline$\Sigma$ Determinations & 15 & 25 & 12 & 3 & 0 & 55 \\
\hline
\end{tabular}

\section{B. EOMV Errors}

Aromatics, table 15

Error, $\mathrm{ml} \rightarrow \frac{0}{5} \quad \frac{1}{6} \quad \frac{2}{2} \quad \frac{3}{2} \quad \frac{3}{-} \quad \frac{\text { Determinations }}{15}$

Aromatics, table A-4.

$\begin{array}{llllll}3 & 11 & 1 & 2 & - & 17\end{array}$

Naphthenoaromatics, table 17

$\frac{5}{13} \frac{4}{21} \quad \frac{1}{4} \quad \frac{2}{6} \frac{-}{0}=\frac{12}{44}$

$\mathbf{\Sigma}$ Determinations

\section{Molecular Volume and Density Errors}

\begin{tabular}{|c|c|c|c|c|c|c|c|}
\hline \multirow[b]{2}{*}{1} & \multirow{2}{*}{$\begin{array}{c}\begin{array}{c}\text { Molecular volume } \\
\text { range, } \mathrm{ml} / \mathrm{mole}\end{array} \\
89.5-163.5\end{array}$} & \multirow{2}{*}{$\frac{\begin{array}{c}\text { DAMV } \\
\text { error, } \mathrm{ml}\end{array}}{ \pm 3}$} & \multicolumn{4}{|c|}{$\begin{array}{c}\text { Maximum molecular volume error, } \\
\mathrm{ml} / \mathrm{mole} \text { and percent }\end{array}$} & \multirow{2}{*}{$\begin{array}{l}\text { Density error at given } \\
\frac{M . W . \text { of n-paraffin }}{1.3^{6}}\end{array}$} \\
\hline & & & $3 / 32 \underline{2}$ & .11 .93 & $=1.1 \underline{4}$ & $=1.25$ & \\
\hline II & $163.5-228.6$ & \pm 3 & $3 / 22$ & $\cdot 16.2$ & $=2.3$ & $=1.4$ & 1.4 \\
\hline III & $228.6-294.1$ & \pm 3 & $3 / 17$ & $\cdot 16.3$ & $=2.7$ & $=1.2$ & 1.2 \\
\hline IV & $294.1-359.8$ & \pm 3 & $3 / 14$ & $\cdot 16.4$ & $=3.3$ & $=1.1$ & 1.1 \\
\hline V & $359.8-425.6$ & \pm 3 & $3 / 11$ & $\cdot 16.4$ & $=4.1$ & $=1.1$ & 1.1 \\
\hline VI & $425.6-491.4$ & \pm 3 & $3 / 8$ & $\cdot 16.4$ & $=5.5$ & $=1.3$ & 1.3 \\
\hline VII & $491.4-557.2$ & \pm 3 & $3 / 6$ & $\cdot 16.5$ & $=8.3$ & $=1.7$ & 1.8 \\
\hline
\end{tabular}

1) Paraffins have the lowest molecular weight (M.W.) at a given molecular volume and hence the lowest density and, maximum density error. The $n$-paraffins are used here although some isoparaffins might give a slightly higher error.

2) The numerator of the fraction is the maximum error, the denominator is the retention volume increment $(\mathrm{ml})$ between adjacent carbon numbers of the $n$-paraffin homologous series.

3/ This value represents the molecular volume increment $(\mathrm{ml} / \mathrm{mole}$ ) between adjacent carbon numbers of the n-paraffin homologous series.

4/ Maximum molecular volume error in $\mathrm{ml} / \mathrm{mole}$.

5/ Maximum molecular volume error in percent.

6) Maximum error in percent. 


\section{DAMV PARAMETER-VARIATION AND USE IN MOLECULAR VOLUME DETERMINATIONS}

\section{DAMV Parameter Variation}

From the data in table $2 A$ and $2 B$, and table $3 A$ and $3 B$, although molecular-volume increments for a methylene group are essentially a constant, retention volume per methylene group varies across the 1,192 to $1,629 \mathrm{ml}$ retention-volume range. The result is that in the equation for DAMV of a given compound:

$$
\begin{aligned}
\text { DAMV }=1,561- & \text { Retention volume of a } n \text {-paraffin whose } \\
& \text { molecular volume is equal to that of the } \\
& \text { given compound. }
\end{aligned}
$$

One will find that DAMV values for additional $\mathrm{CH}_{2}$ groups will not all be constant, but rather, will vary as the retention-volume increment (variable) per molecular-volume increment (essentially constant) ratio varies. Since the DAMV values for the compounds used to derive the values used in the method all eluted in a retention-volume range where the benzene chain methylene plus a bond retention volume increment $(B C M+B)$ was essentially constant $(39.0 \mathrm{ml})$, DAMV values for several groups may always be expressed as a constant fraction of the $B C M+B$, regardless of what value the latter assumes. For example, a six-membered naphtheno group (DAMV = $104 \mathrm{ml}$ ). may be, like a methylene group, regarded as a constant molecular-volume increment and, after application of appropriate correction factors in table 11 , be subject to the same fractional decrease as the $B C M+B$. That is, if the $B C M+B$ is $19.5 \mathrm{ml}$, the six-membered naphthene ring DAMV value, if none of the corrections in table 11 are applicable, will be $104 \mathrm{ml} x$ $(19.5 \mathrm{ml} / 39.0 \mathrm{ml})=52 \mathrm{ml}$. The successful use of values of $104 \mathrm{ml}$ and $78 \mathrm{ml}$ for.all cyclohexane and cyclopentane rings, respectively, the SRC method, in appendix $C$, supports this conclusion.

\section{Molecular-Volume Determinations}

Empirical rules which estimate molecular volume values of $n$-paraffins and alkylated aromatics were developed from literature values on these types of compounds in order to check the molecular volume values determined from the DAMV. Table $19 \mathrm{~A}$ starts with a molecular volume of $131.6 \mathrm{ml} / \mathrm{mole}$ for $n$-hexane. Then $16.25 \mathrm{ml} / \mathrm{mole} /$ carbon number is added through $n$-hexadecane. For $n$-heptadecane and up, $16.45 \mathrm{ml} / \mathrm{mole} /$ carbon number is added. In table 19 B, 1-n-alkyl derivatives or the "equivalent" and 2-n-alkyl derivatives or the "equivalent" of aromatic compounds add the values shown to be parent homologs molecular volume for up to $C_{4}$ substitution, add $16.55 \mathrm{ml} / \mathrm{mole} / \mathrm{alkyl}$ carbon number to the $C_{4}$ substituted alkyl derivative between $C_{5}$ and $C_{10}$ substitution, and add 16.45 $\mathrm{ml} / \mathrm{mole} / \mathrm{alkyl}$ carbon number for $\mathrm{C}_{11}$ and higher homologs. Table $19 \mathrm{C}$ shows the effect of poly-substitution (discussed earlier) on molecular volume using alkyl benzenes. The mean molecular volume and maximum deviation from the mean value are given for all 
TABLE 19. - Values and rules for estimating molecular volumes for homologous series ond for different substifution isomers

A. Factors to estimate molecular volumes of $n$-paraffins from table 1
1. n-Paraffins
$C_{6}=131.6 \mathrm{ml} / \mathrm{mole}$
2. $n$-Paraffins
$\mathrm{C}_{7}-\mathrm{C}_{16}=+16.25 \mathrm{ml} / \mathrm{mole} /$ carbon number
3. n-Paraffins
$C_{16}-C_{n}=+16.45 \mathrm{ml} / \mathrm{mole} /$ carbon number $\ldots$

B. Empirical rules for estimating molecular volumes of n-alkylhydrocarbons from literature values

1. Parent homolog molecular volume (P) plus
o. Methyl$$
\underline{l-n-a|k y| ~ o r ~ " e q u i v a l e n t " ~} 1 /
$$
b. Ethyl
$\mathrm{P}+18.4 \mathrm{ml} / \mathrm{mole}$
$\frac{2-n \text { alkyl or "equivalent" - }}{P+21.0 \mathrm{ml} / \mathrm{mole}}$
c. Propyl
$\mathrm{P}+34.0 \mathrm{ml} / \mathrm{mole}$
$P+36.5 \mathrm{ml} / \mathrm{mole}$
d. Butyl
$\mathrm{P}+50.8 \mathrm{ml} / \mathrm{mole}$
P । $53.5 \mathrm{ml} / \mathrm{mole}$
e. $C_{5}-C_{10}$
$\mathrm{P}+67.3 \mathrm{ml} / \mathrm{mole}$
$\mathrm{P}+69.5 \mathrm{ml} / \mathrm{mole}$
f. $C_{11}-C_{n}$
$+16.55 \mathrm{ml} / \mathrm{mole} /$ carbon no.
$+16.55 \mathrm{ml} / \mathrm{mole} /$ carbon no.
$+16: 45 \mathrm{ml} / \mathrm{mole} /$ carbon no.
$+16.45 \mathrm{ml} / \mathrm{mole} /$ carbon no.

C. Data showing the effect of mono- to pentasubstitution on molecular volume

1. n-Alkylbenzene molecular volume for all isomers for which literature values are ovailable and for mono- to pentasubstituted types as groups
$C_{\text {No. }}$
a.
b. $C_{9}$
c. $c_{10}$
All
Normal, mono-
isomers,
substituted,
$\frac{\mathrm{ml} / \mathrm{mole}}{137.5 \pm 2.6}$ $\mathrm{ml} / \mathrm{mole}$
140.1
mono- substituted, $\frac{\mathrm{ml} / \mathrm{mole}}{140.1 \pm 0.5}$
$153.5 \pm 4.6$
156.8
$156.9 \pm 1.3$
173.52
$172.1 \pm 1.92 /$
AlI
disubstituted, . $\mathrm{ml} / \mathrm{mole}$
$138.6 \pm 1.6$
$155.3 \pm 2.1$
$171.1 \pm 3.82 /$
All
trisubstituted, $\mathrm{ml} / \mathrm{mole}$
$137.3 \pm 2.3$
$153.5 \pm 2.4$
$170.0 \pm 2.7^{2 /}$
All
tetro-
substituted, $\mathrm{ml} / \mathrm{mole}$
$150.4 \pm 1.5$
$166.9 \pm 1.82 /$
All pento- substituted,
$\mathrm{ml} / \mathrm{mole}$ $\mathrm{mi} / \mathrm{mole}$
162.4 I

D. Empirical rules for determining the molecular volume for different degrees of substitution from the normal, monosubstitution value

Normal, monosubstituted isomer $(N)$ value as determined in $B$, above
Degree of substitution

\begin{tabular}{|c|c|c|c|c|}
\hline Mono- & Di- & Tri- & Tetra- & Penta- \\
\hline $\begin{array}{l}N-\Delta=N- \\
1.4 \mathrm{ml} / \mathrm{mole}^{2}\end{array}$ & $\begin{array}{l}N-\Delta=N- \\
2.4 \mathrm{ml} / \mathrm{mole}^{2} /\end{array}$ & $\begin{array}{l}N-\Delta=N- \\
3.5 \mathrm{mi} / \mathrm{mole}^{2} /\end{array}$ & $\begin{array}{l}N-\Delta=N- \\
6.6 \mathrm{ml} / \mathrm{mole}^{2}\end{array}$ & $\begin{array}{l}N-\Delta=N- \\
11.1 \mathrm{ml} / \mathrm{mole}^{2} /\end{array}$ \\
\hline
\end{tabular}

1/ An example of "equivalent" here is the 3 position on benzothiophene corresponding to the 1 position in naphthalene, and the 2 position of benzothiophene to the 2 position on naphthalene.

2/ The difference between the mono normal isomer and mono-, di-, etc., substituted mean values at. carbon number 11 of part .C are used for the correlation in part $D$. 
isomers at $C_{9}, C_{10}$, and $C_{11}$ in the third column. In columns four to nine, the mean value and maximum deviation for all monosubstituted, all disubstituted, etc., isomers at carbon numbers 9,10 , and 11 are given. This breakdown by degree of substitution greatly reduces the deviation from the mean value and suggests a method for determining the value of compounds of all degrees of substitution from the average value for all monosubstitution isomers. The difference between the $n$-alkyl derivative value and the values for the various degrees of substitution are given in table 19D for this purpose. The maximum error, $3.8 \mathrm{ml} / \mathrm{mole}$ for the disubstituted alkyl derivatives (at carbon number $11 \mathrm{in}$ table $19 \mathrm{C}$ ) leads to a maximum density calculation error of 2.3 percent.

\section{EOMV Parameter and Retention Volume Determinations}

The effect of alkylation on EOMV values is illustrated by $n$-alkylbenzenes and $1-n$-alkylnaphthalenes in table $20 \mathrm{~A}$ and $20 \mathrm{~B}$. For the first substitution, EOMV values rise for a methyl group and then decrease as additional methylenes are added. Since n-paraffins, by definition, have no EOMV and the effect of alkylation on the EOMV of an aromatic is what is really desired, an ample method of estimating EOMV will be given (so that retention volume can be obtained using the DAMV alkyl substitution correlations given earlier). The EOMV values of one-ring and two-ring aromatics were given in table $20 \mathrm{~A}$ and $20 \mathrm{~B}$. For three-ring and four-ring monomethyl compounds, the EOMV will be about $20 \mathrm{ml}$ greater than the parent compound and will vary for the possible different substitution isomers. For dimethyl derivatives, the EOMV will be about $12 \mathrm{ml}$ greater than the parent compound and again will vary for the possible substitution isomers. The ethyl isomers will have an EOMV of about $60 \mathrm{ml}$ less than the methyl compound, again varying for the possible substitution isomers. So far, retention volumes have been estimated using the estimated EOMV and the DAMV alkyl correlations given above using: 1,561 ml - DAMV $+E O M V=$ retention volume. For $n$-propyl and higher alkylation, the process is reversed-that is, the EOMV is determined using the same equation and a retention volume estimated as follows: for $n$-propyl and higher alkyl substitution, one-ring to four-ring aromatics have essentially the same retention volume (that of the $1-n$-alkylbenzene) when they have the same substitution carbon number--that is, $C_{5}$. substituted isomers of one-ring to four-ring aromatics all elute with $n$-amylbenzene--1,446 $\mathrm{ml}$ in table $2 \mathrm{~B}$. This rule is subject to the corrections given in the section or effects of polysubstitution in appendix $C$.

To re-emphasize, if DAMV and EOMV values are calculated from structure correlations by. the methods given earlier; the GPC retention volume can be determined without experimentation using the relationship:

$$
1,561 \mathrm{ml}-\mathrm{DAMV}+\mathrm{EOMV}=\text { retention volume. }
$$

\section{SUMMARY}

From GPC-retention-volume data for a series of $n$-paraffin homologs and molecular volume data for these compounds and the system solvent (benzene) from the literature, the 
TABLE 20. - Effect of alkylation on EOMV values

Change due to alkylation using benzene $=68 \mathrm{ml}$ Compound EOMV, ml as reference

$\begin{array}{llr}\text { A. 1. Benzene } & 68 & -- \\ \text { 2. Toluene } & 76 & +8 \\ \text { 3. Ethylbenzene } & 71 & +3 \\ \text { 4. n-Propylbenzene } & 65 & -3 \\ \text { 5. n-Butylbenzene } & 58 & -10 \\ \text { 6. n-Hexylbenzene } & 57 & -11 \\ \text { 7. n-Decylbenzene } & 56 & -12 \\ \text { 8. n-Tridecylbenzene } & 46 & -22 \\ \text { 9. n-Pentadecylbenzene } & 41 & -27 \\ \text { 10. n-Nonadecylbenzene } & 28 & -40\end{array}$

Change due to alkylation using naphthalene $=154 \mathrm{ml}$ as reference

B. 1. Naphthalene 154

2. 1-Methylnaphthalene 184

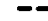

3. 1-Ethylnaphthalene

124

$+30$

4. 1-Butylnaphthalene

112

$+3$

$-42$

C. Three- and four-ring compounds

\section{Derivative}

1. Monomethyl

2. Dimethyl

3. Ethyl

4. $C_{3}$ and up

$$
\begin{aligned}
& \text { EOMV, } \mathrm{ml} \\
& \begin{array}{l}
P+20 \mathrm{ml} \\
P+12 \mathrm{ml}
\end{array} \\
& P+60 \mathrm{ml}
\end{aligned}
$$

a. All isomers at each carbon number are estimated by the retention volume of the n-alkylbenzene

b. The values are subject to the substitution corrections of table 7 .

1/ $P=E O M V$ of parent member of a homologous series. 
molecular volume and densities for many compounds can now be determined without experimentation. This is possible by three methods (two for completely aromatic and one for naphthenoaromatic compounds) which correlate a single GPC parameter (DAMV) with compound structure, and a few empirical rules which predict the effects of alkylation and substitution on retention volume and molecular volume.

In addition, retention volumes of many compounds can be accurately estimated by means of the above data. This is possible by three methods (two for completely aromatic and one for naphthenoaromatic compounds) which correlate a single GPC parameter (EOMV) with compound structure and a few empirical rules which predict the effects of alkylation and substitution on retention volume and molecular volume. If the retention volume of a compound of known structure is obtained, this parameter (EOMV) can also be used to determine the molecular volume and density of the compound. The following relationship between the DAMV and EOMV parameters was established: 1,561 ml - DAMV + EOMV = retention volume.

It can be shown that the methods could probably be extended (with very little additional data) to the determination of molecular volumes and densities for many heteroatom compounds ( $S, N$, and $O$ as heteroatoms). Further, it should be possible to transform the parameters, values, rules, and calculation methods so as to make them applicable to other: GPC systems (other gels, gel sizes, and solvents).

\section{ACKNOWLEDGMENTS}

The authors wish to thank John W. Goetzinger and F. O. Cotton for the radioassay analyses of several tritium and carbon- 14 labeled compounds and R. F. Kendall for gasliquid chromatographic analyses of several unlabeled compounds and for preparation of pellets for density determinations.

\section{REFERENCES}

1. Coleman, H. J., J. E. Dooley, D. E. Hirsch, and C. J. Thompson. Compositional Studies of a High-Boiling $370^{\circ}-535^{\circ} \mathrm{C}$ Distillate from Prudhoe Bay, Alaska, Crude Oil. Anal. Chem., v. 45, No. 9, 1973, pp. 1724-1737.

2. Coleman, H. J., D. E. Hirsch, and J. E. Dooley. Separation of Crude Oil Fractions by Gel Permeation Chromatography. Anal. Chem., v. 41, No. 6, 1969, pp. 800-804.

3. Dooley, J. E., D. E. Hirsch, H. J. Coleman, and C. J. Thompson. CompoundType Separation and Charnoterization Studies for a $370^{\circ}$ to $535^{\circ} \mathrm{C}$ Distillate of Swan Hills (South Field), Alberta, Canada, Crude Oil. BuMines RI 7821, 1973, $30 \mathrm{pp}$. 
4. Dooley, J. E., R. L. Hopkins, D. E. Hirsch, H. J. Coleman, and C. J. Thompson. Compound-Type Separation and Characterization Studies for a $370^{\circ}$ to $535^{\circ}$ C Distillate of Gach Saran, Iran, Crude Oil. BuMines RI 7770, 1973, 25 pp.

5. Dooley;, J. E., G. P. Sturm, Jr., P. W. Woodward, J. W. Vogh, and C. J. Thompson. Analyzing Syncrude from Utah Coal. BERC/RI-75/7, 1975, $24 \mathrm{pp}$.

6. Hirsch, D. E., J. E. Dooley, and H. J. Coleman. Correlations of Basic Gel Permeation Chromatography Data and Their Applications to High-Boiling Petroleum Fractions. BuMines RI 7875, 1974, 77 pp.

7. Hirsch, D.E., J.E. Dooley, H.J. Coleman, and C. J. Thompson. CompoundType Separation and Characterization Studies for a $370^{\circ}$ to $535^{\circ} \mathrm{C}$ Distillate of Wilmington, Calif., Crude Oil. BuMines RI 7893, 1974, 28 pp.

8. Hirsch, D. E., J. E. Dooley, H. J. Coleman, and C. J. Thompson. Qualitative Characterization of $370^{\circ}$ to $535^{\circ} \mathrm{C}$ Aromatic Concentrates of Crude Oils From GPC Analyses. BuMines RI 7974, 1974, 25 pp.

9. Sturm, G. P., Jr., P. W. Woodward, J. W. Vogh, S. A. Holmes, and J. E. Dooley. Analyzing Syncrude From Western Kentucky Coal . BERC/RI-75/12, 1975,27 pp.

10. Thompson, C. J., J. E. Dooley, J.W. Vogh, and D. E. Hirsch. Analyzing Heavy Ends of Crude (Recluse). Hydrocarbon Processing, v. 53, No. 8, August 1974, pp. 93-98.

11. Woodward, P. W., G. P. Sturm, Jr., J. W. Vogh, S. A. Holmes, and J. E. Dooley. Compositional Analysis of Synthoil from West Virginia Coal. BERC/RI-76/2, 1976, 22 pp. 


\section{APPENDIX A. - ADDITIONAL METHODS FOR DETERMINING THE DAMV AND EOMV OF WHOLLY AROMATIC COMPOUNDS}

\section{An SRC Method for Determining DAMV Values}

The second method for calculating the DAMV of aromatics is called the saturate ring count (SRC) method. This method starts by assuming that the precursor to the aromatics is the saturate ring compound with the same skeletal structure as the aromatic compound being calculated. The rules for determining the SRC and the other elements of the method; the number of condensation factors $(n)$, total aromatic carbons minus one $(m-1)$, and the L.F. count values for four-ring molecules-are given in table $A-1$. The general equation for determining aromatic DAMV values by this method is as follows:

$$
\begin{gathered}
\text { SRC, } \mathrm{ml}-\mathrm{n}(C . F .), \mathrm{ml}-(\mathrm{m}-1) \times(8 \mathrm{ml})-\mathrm{L} . \mathrm{F} . \underset{\mathrm{ml}}{\mathrm{ml}} \mathrm{me},= \\
\text { DAMV } \\
\begin{array}{c}
\text { value, (of a given aromatic)... } \\
\mathrm{ml}
\end{array}
\end{gathered}
$$

The calculations for several aromatic compounds and the rules and values of table A-1 employed are given in table A-2. The fact that the number of condensation factors is not the same as in the first method is not troublesome. When starting with the saturate ring compound of the same skeletal structure, some. condensation (that of the naphthene rings) has already been accomplished, although the total DAMV value of each naphthene ring is used--that is, instead of a reduced SRC which includes a factor for naphthene ring condensation. In addition, total carbons minus one are used and no factor for bonds employed. Finally, the L.F. has a different value for the L.F. count in table A-ID compared to the carbon and bond count method in the text.

\section{A Total Ring Count Method for Determining. EOMV Values}

The second method of determining the EOMV for aromatics, the total ring count method, is derived from the first, utilizing the fact that the six-membered aromatic rings may have one of four values $(34 \mathrm{ml}, 51 \mathrm{ml}, 68 \mathrm{ml}$, or $85 \mathrm{ml})$ depending upon whether they are substituted on a one-bond, two-bond, or three-bond ring, whether they are substituted on a double or single bond, and the fact that the ring EOMV values are linearly additive. Five-membered or ace rings have a value of $40 \mathrm{ml}$. Thieno rings use their previously determined 53.5 or $70 \mathrm{ml}$ values and act as analogs of benzene, The rules for determining the ring value to be used, and the values for L. F. counts are given in table A-3. Calculations using the method are shown in table A-4. 
TABLE A-1 - Rules for determining values for the coefficients and constants in equation A-1 for calculating DAMV values of wholly aromatic compounds by the (SRC) method

A. The saturate ring count (SRC) is determined for all but one benzene ring (since the DAMV of benzene is zero) as follows:

1. Six-membered hydrocarbon rings count $104 \mathrm{ml}$ each.

2. Five-membered hydrocarbon rings count $78 \mathrm{ml}$ each.

3. Thiacyclopentane rings count $88 \mathrm{ml}$ each.

4. Cyclohexyl rings count $169 \mathrm{ml}$ each.

B. Condensation factors (C.F.) to be multiplied by $16 \mathrm{ml}$ and subtracted are counted $(n)$ as follows:

1. One-fourth C.F. for all diaromatics.

2. One-fourth C.F. plus the C.F. count of the remaining aromatic portion of phenyl derivatives of aromatics.

3. One C.F. per six-membered ring above naphthalene or indene in nonlinear molecules.

4. Two C.F. per six-membered ring above naphthalene in linear molecules.

5. Zero C.F. per five-membered ring with only one side common to other rings.

6. Extra C.F.'s are added to triaromatics and polyaromatics as follows:

a. One C.F. per adjacent side if a six-membered ring has adjacent sides common to other aromatic rings-that is, peri-condensation.

b. Fur Five-membered rings;

(1) Zero C.F. if all carbons of a five-membered ring are common to other rings.

(2) One C.F. if all but one carbon of a fivemembered ring are common to other rings.

(3) Two C:F.'s if all but two carbons of a fivemembered ring are common to other rings.

7. Thieno groups are considered analogous to a benzo group in the same environment, yield nonlinear molecules when internal, and yield linear or nonlinear molecules when external depending upon their position. 
TABLE A-1 - Rules for determining values for the coefficients and constants in equation A-1 for calculating DAMV values of wholly aromatic compounds by the (SRC) method--Continued

C. The total aromatic carbons factor (TACF) to be multiplied by $8 \mathrm{ml}$ and subtracted is obtained as follows:

1. Total aromatic carbons above benzene minus one or $\lceil\dot{m}-1(8 \mathrm{ml})]$.

a. Naphthenic carbons in ace rings are not counted.

b. A sulfur atom counts as two aromatic carbons.

2. Diphenyl itself is shown as an exception, $m+3(8 \mathrm{ml})$ is employed.

D. For four-ring molecules the linearity factor (L.F.) count, obtained as in table 7 , subtracts the following values:

1. If the L.F. count is one, $4 \mathrm{ml}$ is subtracted.

2. If the L.F. count is two, $8 \mathrm{ml}$ is subtracted.

3. If the L.F. count is three, $12 \mathrm{ml}$ is subtracted. 


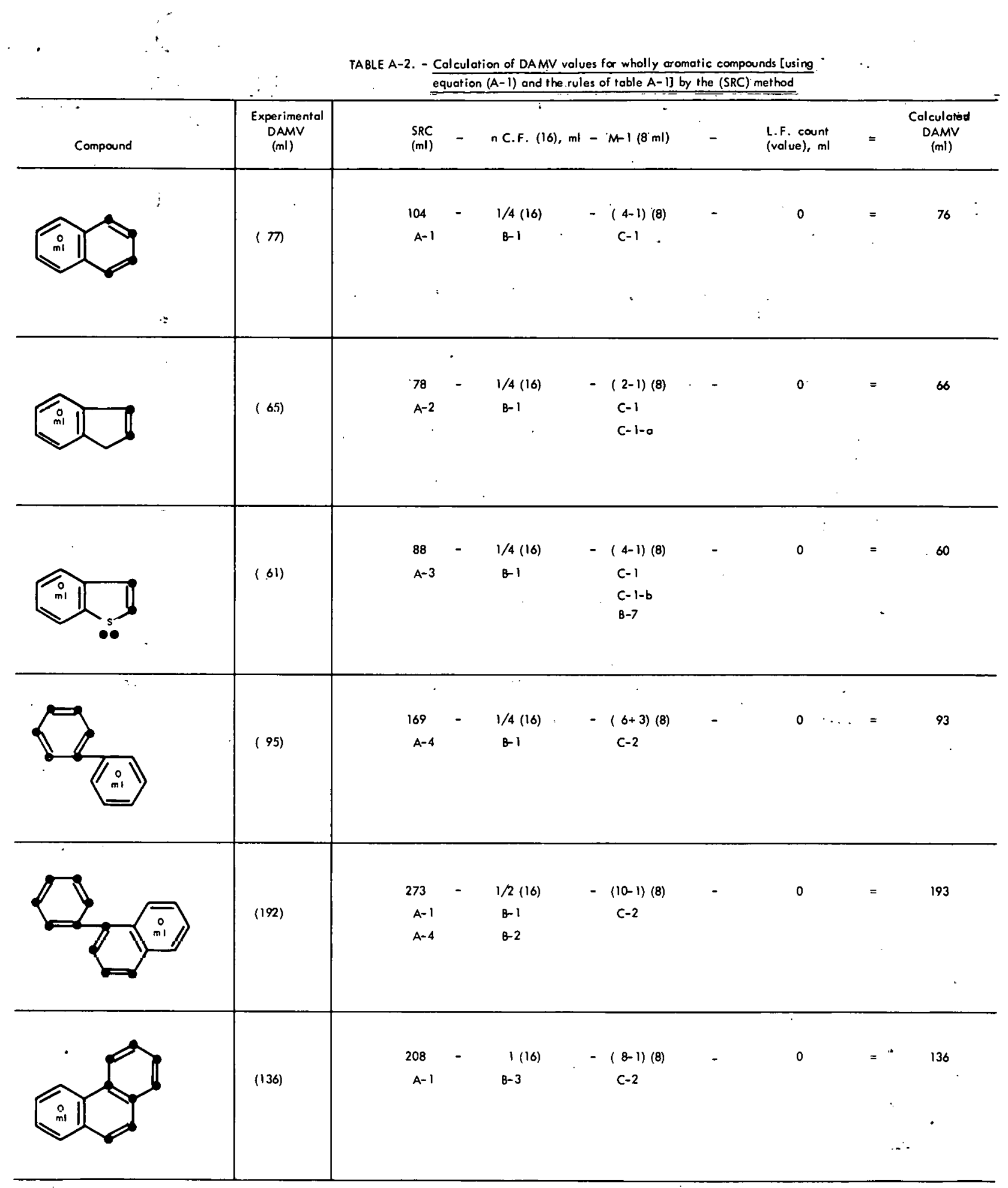




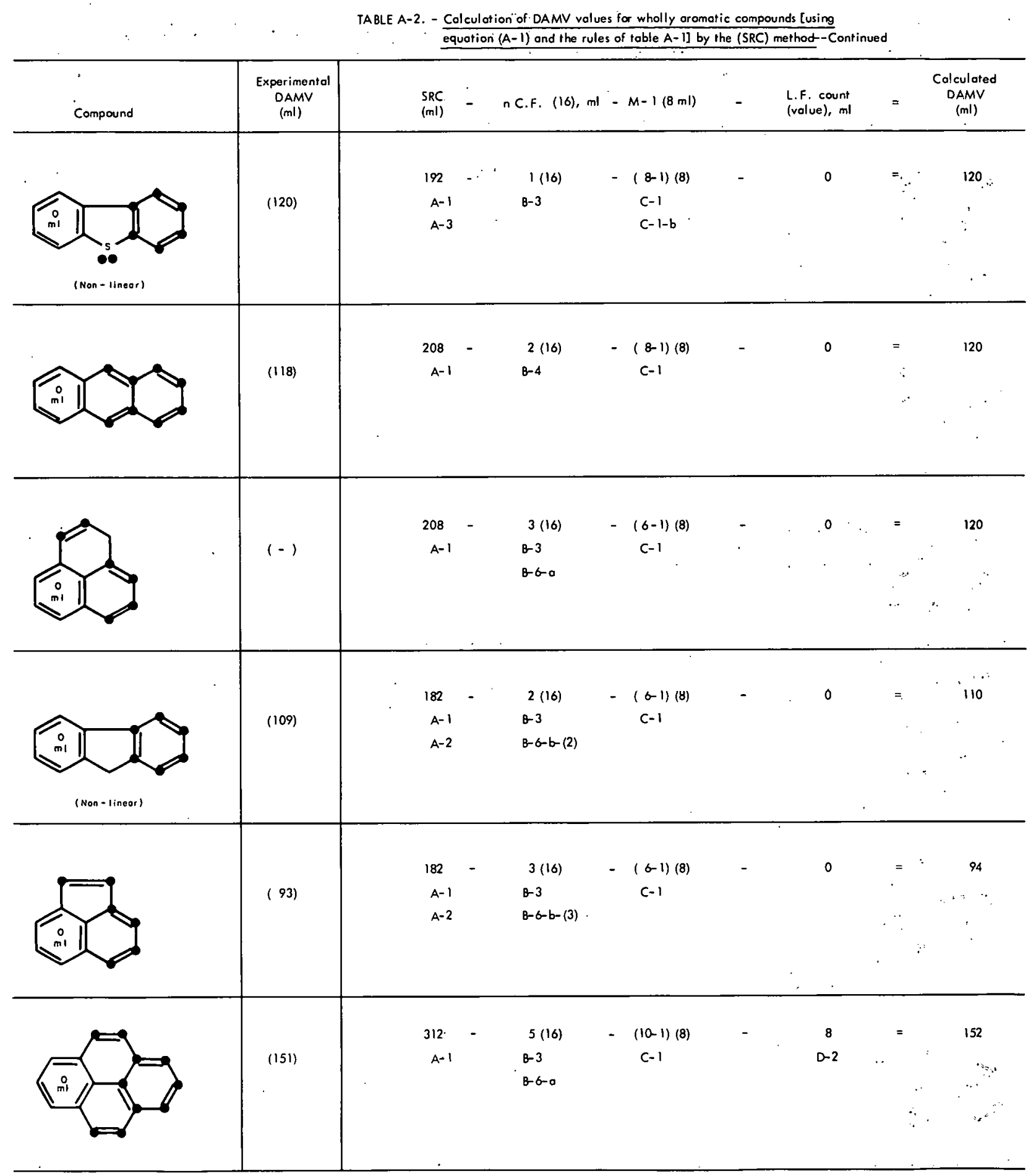




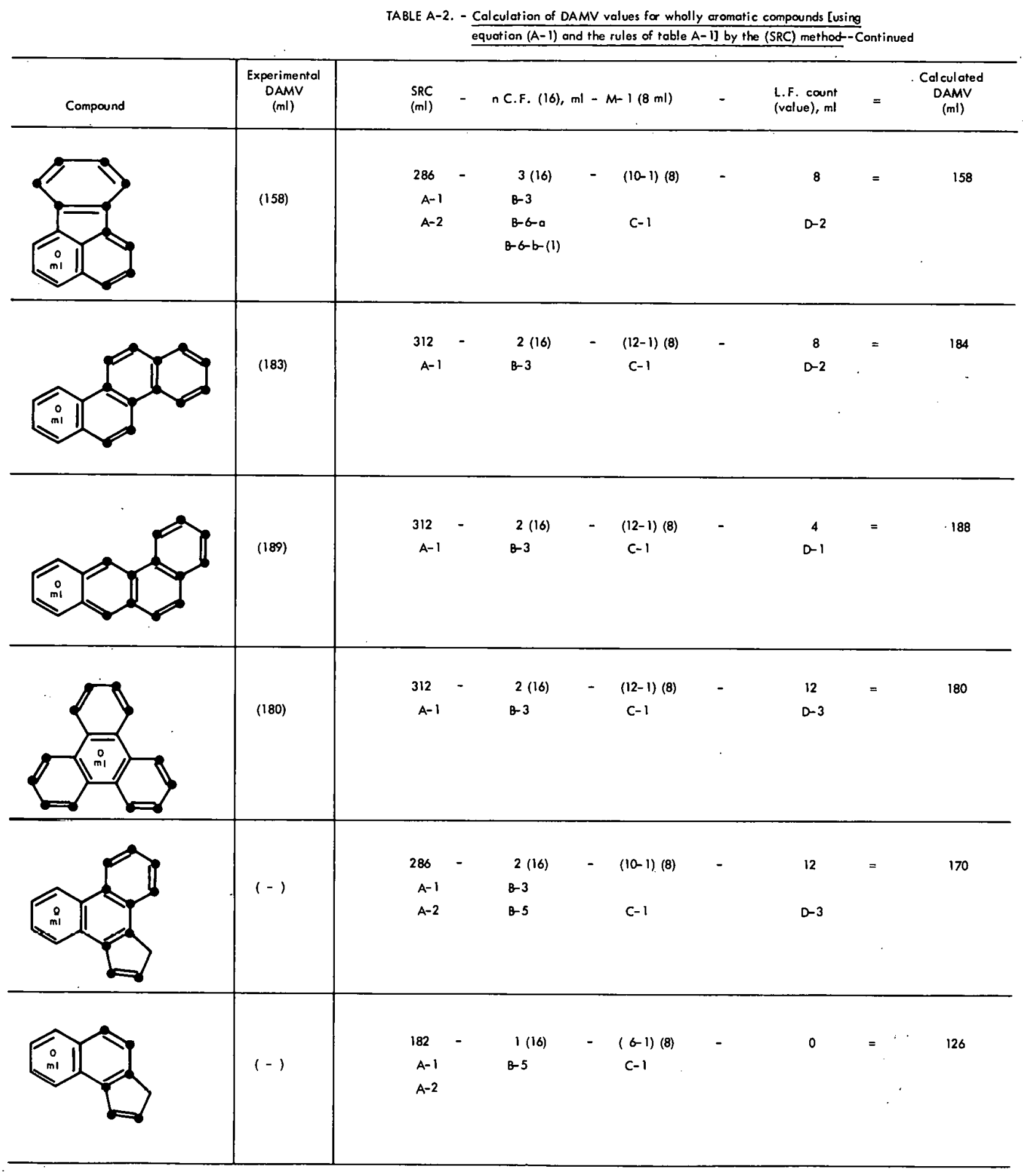


TABLE A-3 - Rules for determining values for the rings used in calculating EOMV values for wholly aromatic compounds by the total ring count method

A. Six-membered aromatic hydrocarbon ring EOMV values are all multiples of $17 \mathrm{ml}^{1}$ or $17 \mathrm{ml}$ less $1 \mathrm{ml}$ each for additional common sides above one.

B. The EOMV count of a ring depends upon the number of double bonds in it and whether it is substituted on a double or single bond of another ring, starting with a value of $68 \mathrm{ml}$ for one three-bond, six-membered ring (benzene).

1. Benzo has the following values depending upon the environment given:

a. $85 \mathrm{ml}$ if added to the double bond of a three-double bond, six-membered ring or to the double bond of a five-membered hydrocarbon ring which has two other sides common to aromatic rings.?

b. $68 \mathrm{ml}$ if added to the double bond of a two-double bond, six-membered ring.

c. $51 \mathrm{ml}$ if added to the single bond of a three-double bond, six-membered ring.

d. $51 \mathrm{ml}$ if added to the double bond of a one-double bond, five-membered ring.

e. $34 \mathrm{ml}$ if added to the single bond of a two-double bond, six-membered ring.

f. $17 \mathrm{ml}$ per additional common side are added when more than one side of an added ring are common to other six-membered aromatic rings.

g. $0 \mathrm{ml}$ for a phenyl ring and $4 \mathrm{ml}$ for a diphenyl bond are added for diphenyl and phenyl derivatives.

2. Five-membered hydrocarbon rings have a value of $40 \mathrm{ml}$.

3. Thieno rings are considered analogous to benzo group in the same environment and have values of $70.5 \mathrm{ml}, 53.5 \mathrm{ml}$, etc., corresponding to benzo counts of $85 \mathrm{ml}, 68 \mathrm{ml}$, etc., respectively. 
TABLE: A-3"- Rules for determining values for the rings used in calculating EOMV values for wholly aromatic compounds by the total ring count method--Continued

4. If the rules in B-1, above, lead to different counts for the same molecule calculated two or more ways, the high and low value average will yield the correct EOMV value.

C. For four-ring molecules, a linearity factor (L.F.) count, obtained as in table 7 , is added or subtracted as follows:

1. If the L.F. count is one, $2 \mathrm{ml}$ is added.

2. If the L.F. count is two, $2 \mathrm{ml}$ is subtracted.

3. If the L.F. count is three, $2 \mathrm{ml}$ is added.

1 Note in table A-4, which follows, that some molecules are calculated using more than one set of the above rules to further show the internal consistency of these rules.

2 Indene's five-membered ring has one-double bond, but acenaphthalene with two sides opposite the double bond common to other aromatic rings has "effectively" two-double bonds which corresponds to a three-double bond, six-membered ring. 
TABLE A-4. - Colculation of EOMV volues for wholly aromatic compounds using the total ring count method and the rules of toble A-3

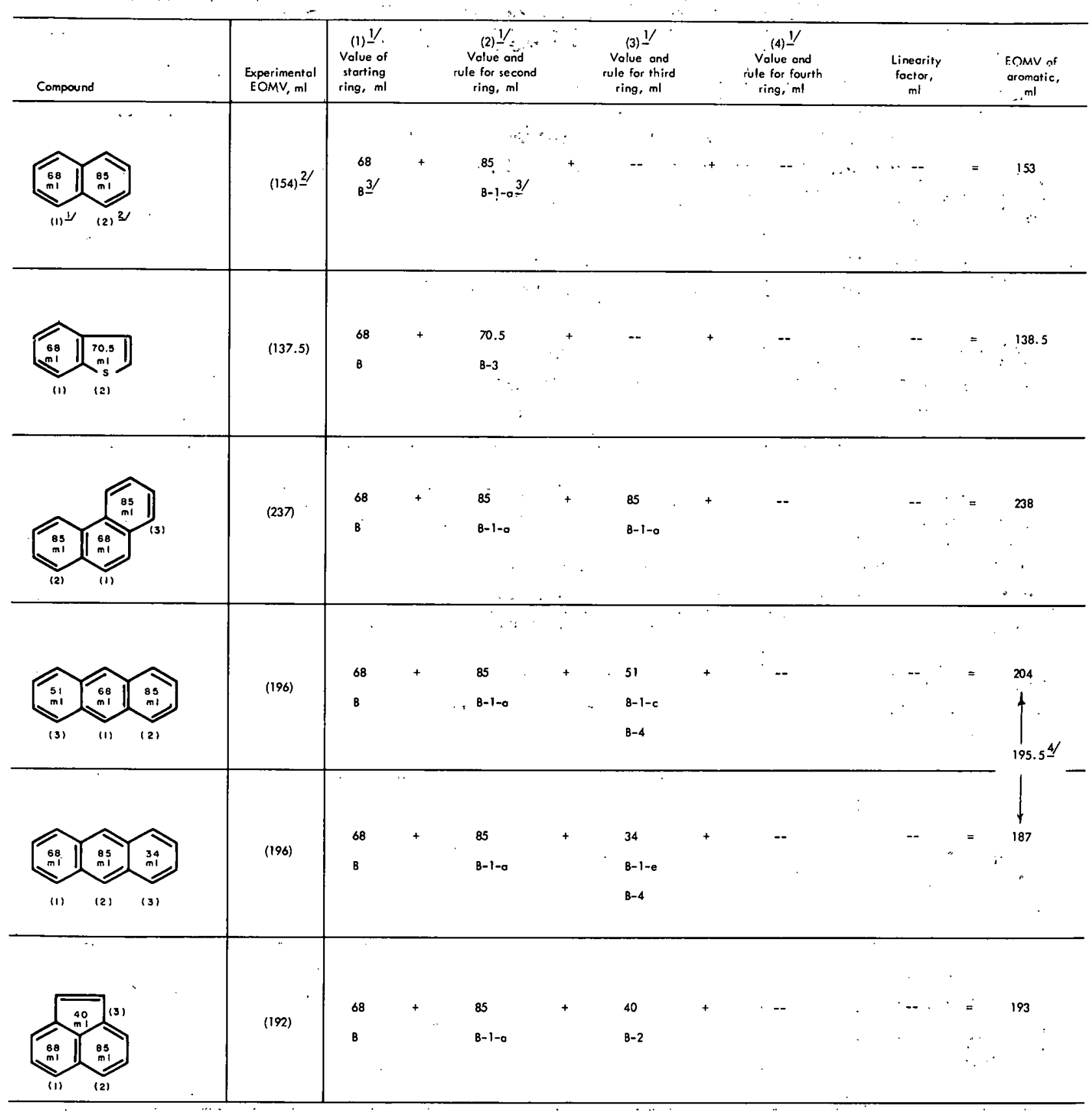




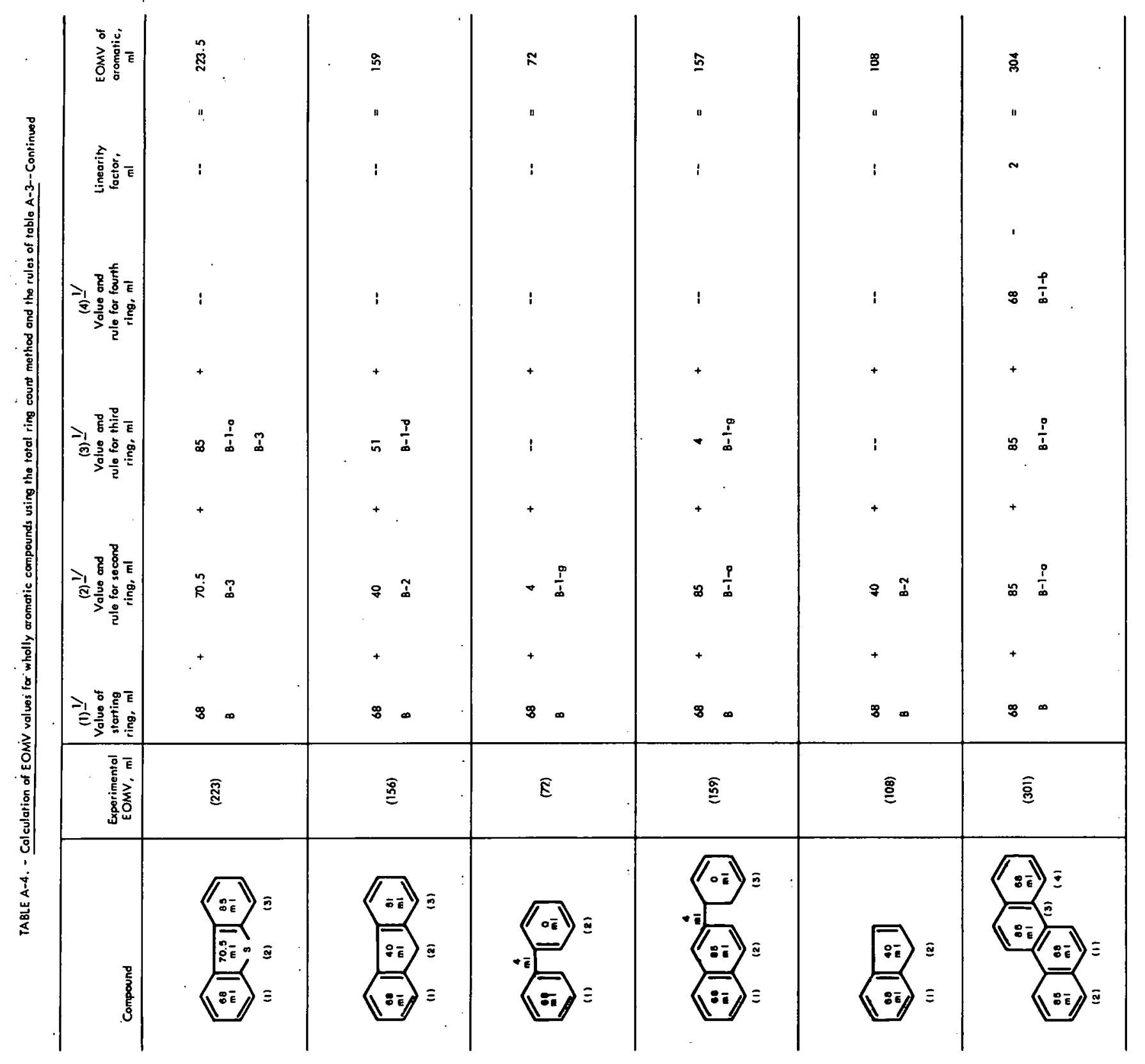


TABLE A-4. - Cal eulation of EOMV volues for wholly aromatic compounds using the total ring count method and the rules of toble A-3--Continued

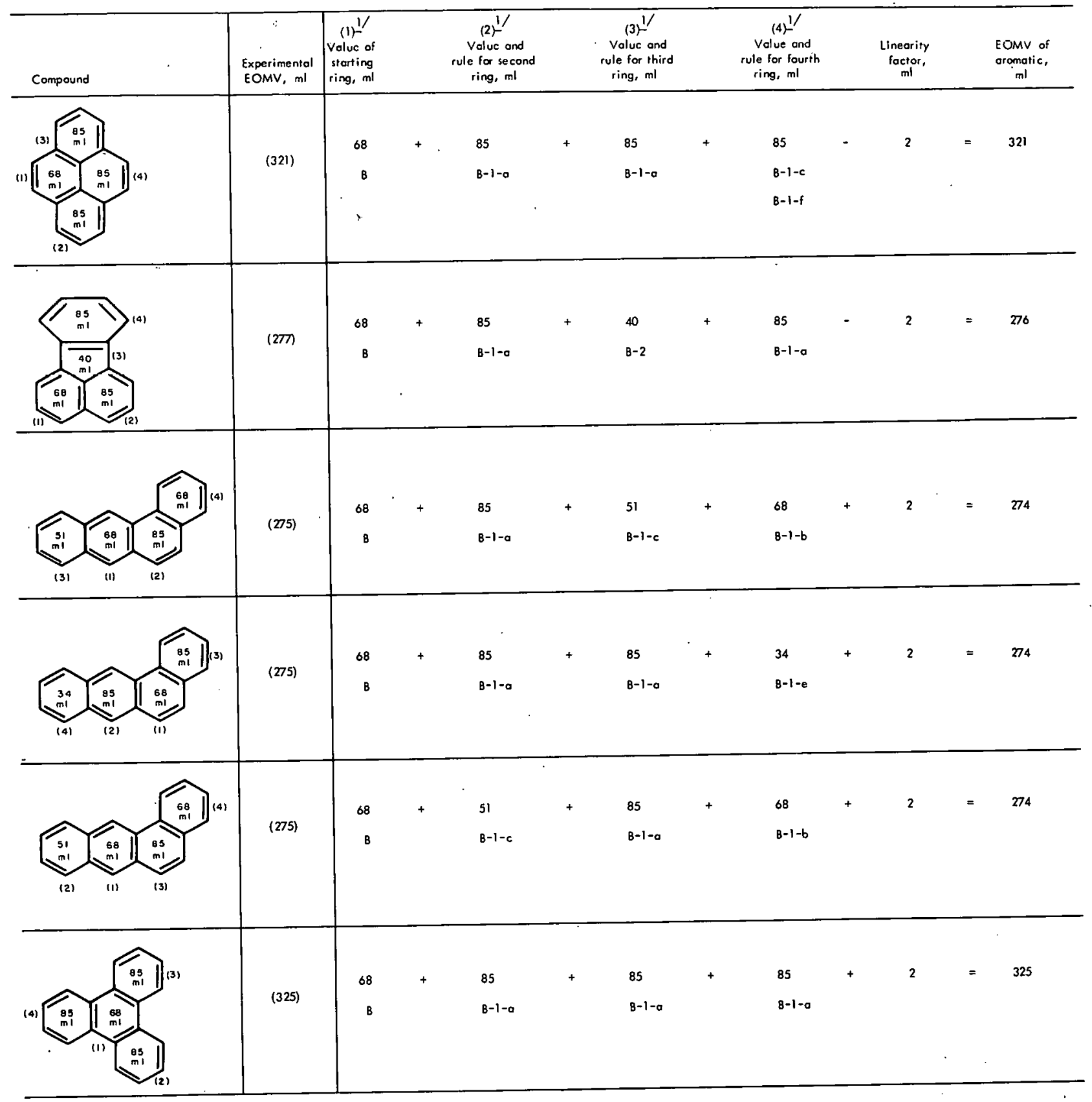




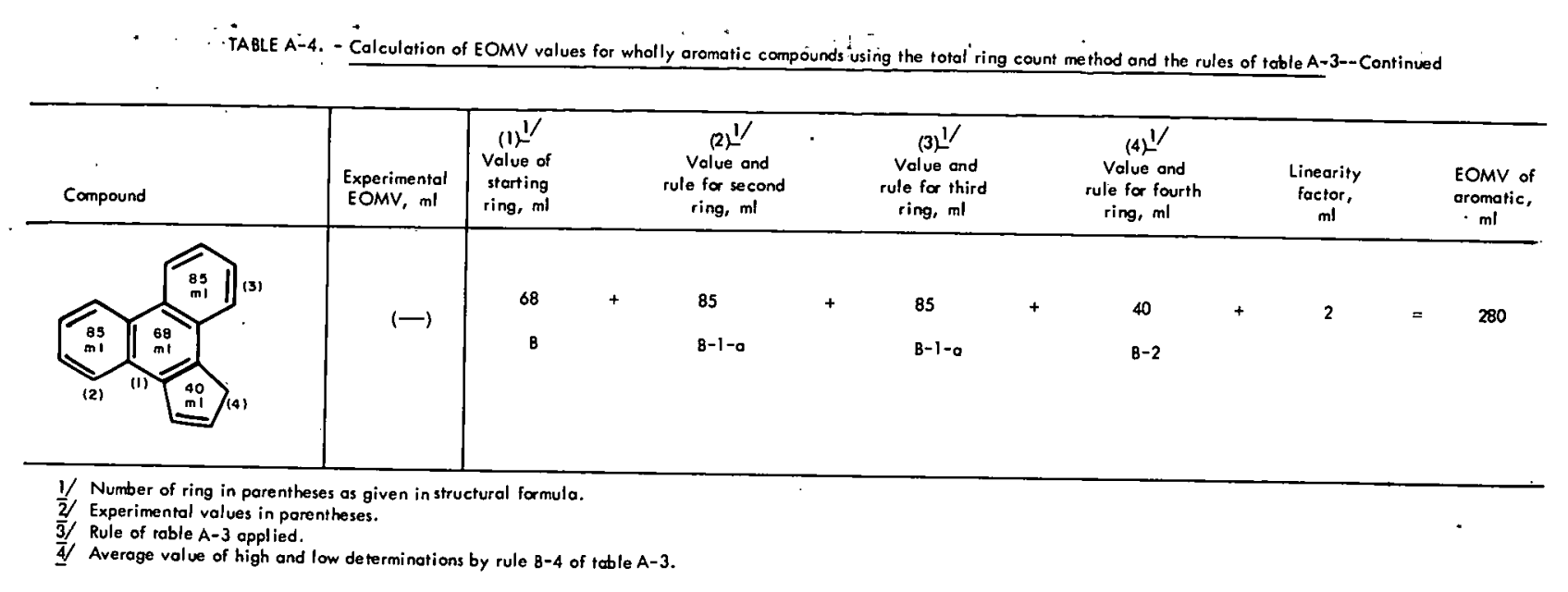




\section{APPENDIX B. - DETERMINATION OF DAMV AND EOMV INCREMENTAL VALUES}

\section{Determination of DAMV Values for Carbons and Bonds}

The derivation of the fundamental DAMV and EOMV values for carbons and bonds, condensation factors, and aromatization factors used in the six computation methods of the text and appendix $A$ are given below.

An overview of the data showed that, in addition to different incremental retentionvolume values for aromatic, naphthene, and paraffin carbons and bonds, aromatic molecules had an additional. difference from the naphthene molecules--an additional factor due to condensation of the aromatic molecule (or it might be thought of as a difference due to aromaticity).

To establish the fundamental incremental value attributable to each structural element (carbons and bonds) for aromatics, naphthenes, and paraffins (that is, the incremental value for each of their carbons and bonds), two assumptions were made. First, it was assumed that in addition to one count for each carbon and bond in the group, the following amounts would be added: 1 . One count is added to a naphtheno group if a naphtheno group is added to an aromatic double bond (this means that benzene can be regarded as having six carbons and eight total carbon-carbon bonds instead of nine). The aromatic double vs single bonds refer to the bonds as represented in correct structure drawings. 2. One-half count is added if a benzo, thieno, or five-membered one double bond ring is added to an aromatic double bond. 3. One-quarter count is added if benzo, thieno, a five-membered one double bond ring, or naphtheno groups are added to an aromatic single bond. 4. One-quarter count is added if a five- or six-membered one double bond ring (e.g., an ace group--bridged aromatic carbons) were added to two aromatic single bonds. The second assumption is that a condensation factor (C.F.) does exist and must be employed when considering an aromatic ring to be formed by aromatization of naphthene ring and vice versa. Also, when two aromatic rings are condensed, e.g., when benzo is added to benzene to form naphthalene, a condensation factor must be employed.

From these assumptions, values of $4 \mathrm{ml}$ per carbon, $4 \mathrm{ml}$ per bond, and $8 \mathrm{ml}$ per ring (C.F.) were established for the difference between naphthenic and aromatic rings. In addition, paraffin carbons and bonds were found to be double those of naphthenes. The validity of these assumptions stand rigorously supported by data on model compounds whose values are computed from six computation methods already offered. The validity of these assumptions are also verified using the compounds from which they were derived. The conclusions are drawn from the following systems:

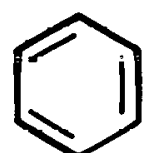

DAMV $=0 \mathrm{ml}$ and

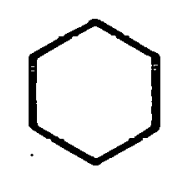

$\mathrm{DAMV}=48 \mathrm{ml}$ 
System (1), above, shows the DAMV difference between benzene and cyclohexane to be $48 \mathrm{ml}$. However, benzene, when assigned to a value of zero, had an 8- $\mathrm{ml}$ condensation factor difference from cyclohexane already built into it according to the second assumption above. This is in addition to different DAMV values for the carbons and bonds. The total difference is then $48+8=56 \mathrm{ml}$. Based upon the eight carbon-carbon bond, six carbon benzene of part (1) of the first assumption, above, thus these are 14 carbons and bonds, total which yield $56 \mathrm{ml}$ total DAMV difference. Placing the total difference on a per carbon and per bond basis gives: $56 \mathrm{ml} / 14$ carbons and bonds $=4 \mathrm{ml}$ per carbon and bond difference between aromatic and naphthene carbons and bonds.

$$
\begin{aligned}
& \mathrm{C}-\mathrm{C}-\mathrm{C}-\mathrm{C}-\mathrm{C}-\mathrm{C}-\quad \text { and } \\
& \text { DAMV }=96 \mathrm{ml}
\end{aligned}
$$

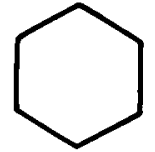

DAMV $=48 \mathrm{ml}$

System (2), above, shows clearly that paraffin carbons and bonds have double the DAMV value of naphthene carbons and bonds.

With the relationships of aromatic and paraffin carbons and bonds to naphthene carbons and bonds established in systems (1) and (2), above, if the DAMV increment per carbon and bond can be determined for naphthenes, the increments for aromatic and paraffin carbons and bonds can be calculated.

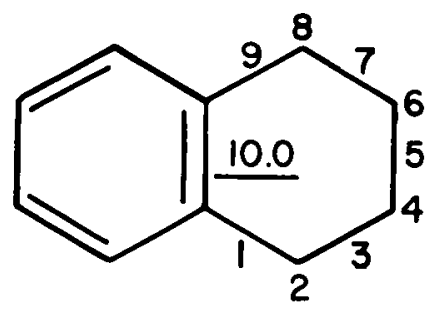

$$
\begin{aligned}
& \text { Experimental DAMV }=103 \mathrm{ml} \\
& \text { Corrected DAMV }=119 \mathrm{ml} \\
& \mathrm{N}=\text { naphthenic carbon and bond } \\
& \text { count }=10.0
\end{aligned}
$$

Part 1 of the first assumption made in the introduction of the section presents the situation in System (3), above. Tetralin with a DAMV value of $103 \mathrm{ml}$ must be corrected for the two-carbon and two-bond aromatic side at the $4 \mathrm{ml}$ per carbon and bond value difference between aromatics and naphthenes. The first assumption also establishes its total carbon and bond count as 10.0 . The $103 \mathrm{ml}$ DAMV value plus $16 \mathrm{ml}$ correction on four carbons and bonds yields $119 \mathrm{ml}$ and $119 \mathrm{ml} / 10$ carbons and bonds equals approximately $12 \mathrm{ml}$ as a DAMV increment value for naphthenic carbons and bonds. Similar treatment of indane; System (4), below, yields $79 \mathrm{ml}$ DAMV plus $16 \mathrm{ml}$ correction $=95 \mathrm{ml}$. The carbon and bond count is 8.0 , so $95 \mathrm{ml} / 8.0$ carbons and bonds equal approximately $12 \mathrm{ml}$.

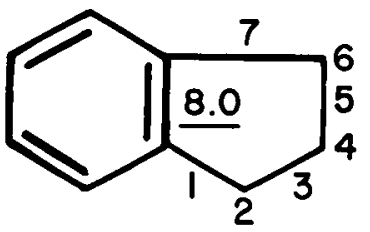

$$
\begin{aligned}
& \text { Experimental DAMV }=79 \mathrm{ml} \\
& \text { Corrected DAMV }=95 \mathrm{ml} \\
& N=\text { naphthenic carbon and bond count }=8.0
\end{aligned}
$$


Since the DAMV increment value per naphthenic carbon and bond is $12 \mathrm{ml}$, that for aromatics, from System (1), above, is $12 \mathrm{ml}-4 \mathrm{ml}=8 \mathrm{ml}$. For paraffinic carbons and bonds (from System (2) above), the DAMV increment value is $2 \times 12 \mathrm{ml}=24 \mathrm{ml}$.

Next, to confirm the "derived" DAMV increment value for a diphenyl bond as given in table 9, naphthalene is assumed to open up and form diphenyl as in System (5) below:

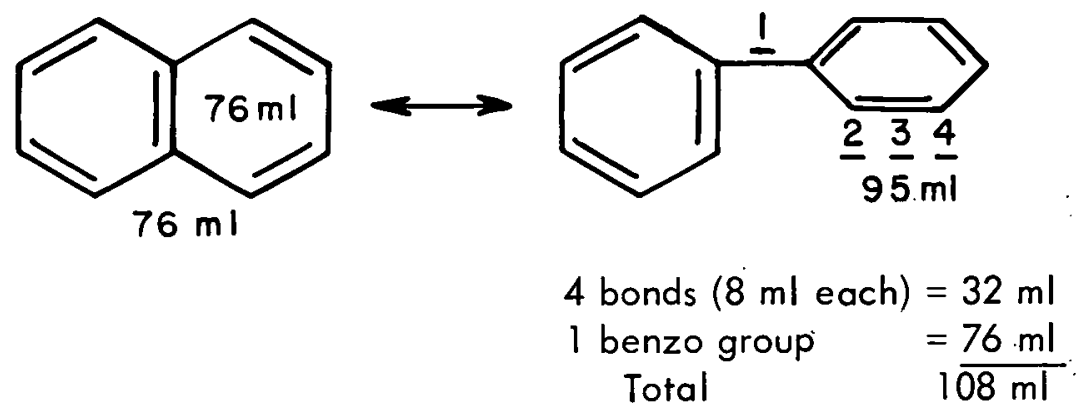

$108 \mathrm{ml}-16 \mathrm{ml}($ C.F.) $=92 \mathrm{ml}$ vs $95 \mathrm{ml}$ given which means the bond 1 in the system must equal $3 \mathrm{ml}$ more than the $8 \mathrm{ml}$ used in the calculation, or $11 \mathrm{ml}$. This is within experimental error of a value of $12 \mathrm{ml}$ for this bond; $12 \mathrm{ml}$ gives uniformly more consistent results. The bond is taken then as equivalent to a naphthenic bond.

Finally, the value of $88 \mathrm{ml}$ used for the thiacyclopentane ring in table A-2 was.calculated from literature values for its molecular volume and the $1,561 \mathrm{ml}$ column constant (see figure 1 and related discussion).

The overall success of these "derived" values in the calculation methods given earlier is offered as further confirmation of the ir validity.

\section{Derivation of the DAMV Aromatization Factor}

At first glance, there may appear to be a contradiction between the $4 \mathrm{ml}$ per carbon and bond difference between aromatics and naphthenes derived in System (1). of the previous section and the $2 \mathrm{ml}$ per carbon and $4 \mathrm{ml}$ per bond values given in table 5 and checked in the computation method of tables 12 and 13 , but there is no contradiction. In tables 12 and 13 , the second assumption of the previous section does not apply because the condensation factors are left in the remaining aromatic ring or rings of the molecule. In addition, part 1 of the first assumption of the previous section does not apply because the "difference" in number of bonds (Table 8 ) in the precursor and the end molecule is used in the calculations. In this case, therefore, one works with only the $48 \mathrm{ml}$ difference between benzene and cyclohexane shown in System (1) of the previous section. Thus, the $48 \mathrm{ml}$ DAMV difference is between a nine carbon-carbon bond benzene and cyclohexane which works out $9 \times 4 \mathrm{ml}$ per bond $+6 \times 2 \mathrm{ml}$ per carbon $=36 \mathrm{ml}+12 \mathrm{ml}=48 \mathrm{ml}$. 
The success of the three DAMV computation methods, given in the text and appendix A, is considered confirmation of the derived values.

\section{Derivation of the DAMV Condensation Factor}

System (1) below was used to establish a $16-\mathrm{ml}$ condensation factor for two aromatic rings mutually condensed. The DAMV C.F. is negative (because the molecule is smaller than the sum of the elements used to form it). The derivation of the value using the ring count method and $8 \mathrm{ml}$ per aromatic carbon and bond "derived" DAMV increment value obtained earlier follows:

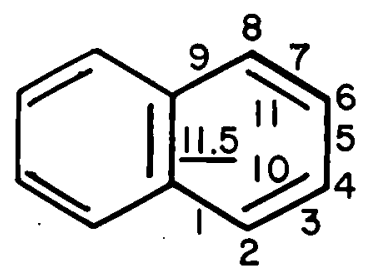

Experimental DAMV $=77 \mathrm{ml}$

$N=$ total aromatic carbon and bond count

The carbon and bond count using part 2 of the first assumption given at the beginning of the appendix is $N=11.5$ (i.e., one-half count extra for a benzo group added to an aromatic double bond). (11.5 $88 \mathrm{ml}$ per aromatic carbon and bond $)=92 \mathrm{ml}$ DAMV. $(92 \mathrm{ml}$ - $77 \mathrm{ml})=15 \mathrm{ml}$, which is within experimental error of a $16-\mathrm{ml}$ value for the C.F. that gives a uniformly better data fit when all aromatics tested are considered. This is also equal to two times the fundamental aromatic structural element values of $8 \mathrm{ml}$ each. Finally, for two rings, it is twice the $8-\mathrm{ml} \mathrm{C.F.} \mathrm{value} \mathrm{for} \mathrm{one} \mathrm{ring} \mathrm{found} \mathrm{in} \mathrm{assumption} 2$ at the beginning of this appendix.

\section{Determination of EOMV Values for Carbons and Bonds}

To establish the fundamental EOMV increment value attributable to each structural element for aromatics and naphthenoaromatics (that is, for each of their carbons and bonds), one assumption was made. It was assumed that since paraffins, by definition, have no EOMV, two carbons of a ring structure and their included bond acted as a chain and made no contribution to the EOMV of the ring. This assumption will be shown to be uniformly consistent. System (1), below, shows the calculation for the EOMV increment value for naphthenic carbons and bonds and a cyclohexano ring. System (2) shows how a value is obtained for cyclopentano rings.

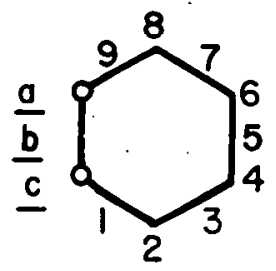

Experimental $E O M V=36 \mathrm{ml}$

$N=$ naphthenic carbon and bond count $=9$

$\underline{a}, \underline{b}$, and $\underline{c}$ act as a chain and have no 
Two carbons and a bond (hollow points and their included bond) act as a chain and make no contribution to the EOMV value. The other nine naphthenic carbons and bonds contribute to the difference in retention volume between cyclohexane and a hypothetical $n$-paraffin of equivalent molecular volume $(E O M V=36 \mathrm{ml}) .36 \mathrm{ml} /(\mathrm{N}=9)=4 \mathrm{ml}$ per naphthenic carbon and bond.

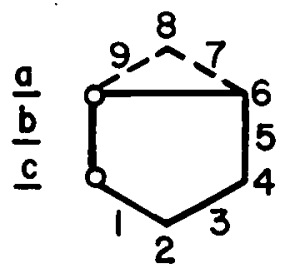

Experimental EOMV $=24 \mathrm{ml}$

$N=$ naphthenic carbon and bond count $=6$

$\underline{a}, \underline{b}$, and $\underline{c}$ act as a chain and have no count

Cyclopentane is considered as cyclohexane less the dashed portion $(7,8$, and 9 ) or $36 \mathrm{ml}$ - $(3 \times 4 \mathrm{ml})=36 \mathrm{ml}-12 \mathrm{ml}=24 \mathrm{ml}$. Note this is $4 \mathrm{ml}$ per carbon and $4 \mathrm{ml}$ per bond difference.

Next, we determine the EOMV increment for aromatic carbons and bonds. Again, an overview of the data suggests an 8- $\mathrm{ml}$ condensation factor for a benzene ring--this will be verified later. System (3) below gives the derivation based upon this assumption.

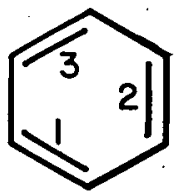

$$
\text { Experimental } \mathrm{EOMV}=68 \mathrm{ml}
$$

Benzene $(68 \mathrm{ml})$ minus cyclohexane $(36 \mathrm{ml})=32 \mathrm{ml}$. This is counted as $8 \mathrm{ml}$ for each of the three double bonds and $8-\mathrm{ml}$ condensation factor (C.F.) for the single ring. The C.F. arises from a shrinking of the ring on creation of aromaticity in it. This means the aromatic carbons and bonds may be considered to count $4 \mathrm{ml}$ each, that is, $(6 \times 4)+(9 \times 4)$ $+8 \mathrm{ml}$ (C.F.) $=68 \mathrm{ml}$. Note that this makes the aromatic double bonds count $4 \mathrm{ml}+4 \mathrm{ml}$ $=8 \mathrm{ml}$.

Next, we derive the EOMV increment value for thiacyclopentane using thiophene (4) and the $8 \mathrm{ml}$ condensation factor assumption which will be verified at the end of this section.

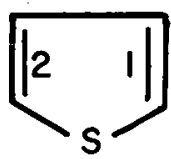

$$
\text { Experimental } E O M V=53.5 \mathrm{ml}
$$

Analogous to benzene, (3) above, there is an 8-ml C.F. for one ring: Two double bonds count $8 \mathrm{ml}$ each. Thus, the EOMV for thiacyclopentane will be $53.5 \mathrm{ml}-(3 \times 8=24 \mathrm{ml})$ $=29.5 \mathrm{ml}$. See SRC method, table 15. Counting the sulfur as one aromatic corbon, the aromatic carbons as $4 \mathrm{ml}$ each, the carbon-carbon bonds as $4 \mathrm{ml}$ each, and the carbonsulfur bonds as $3 \mathrm{ml}$ each, we have $[(4+1) \times 4 \mathrm{ml}]+(5 \times 4 \mathrm{ml})+(2 \times 3 \mathrm{ml})+8 \mathrm{ml}(C . F$. $=54 \mathrm{ml}$, which is within experimental error. 
Finally, with diphenyl, (5) below, we determine the value of the EOMV increment of a diphenyl bond and verify it further using 1 -phenylnaphthalene (6).

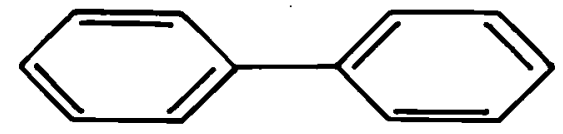

Experimental $E O M V=72 \mathrm{ml}$

The benzene plus a phenyl and a bond must count $72 \mathrm{ml}-68=4 \mathrm{ml}$.

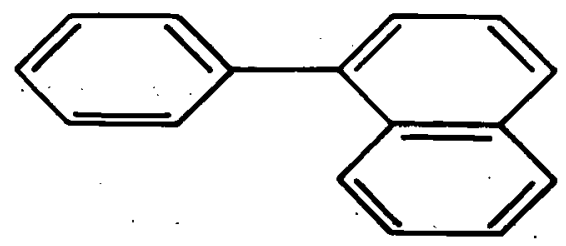

Experimental EOMV = $159 \mathrm{ml}$

Naphthalene experimental EOMV $=154 \mathrm{ml}$

The benzene plus a phenyl and a bond above naphthalene must count $159 \mathrm{ml}-154 \mathrm{ml}$ $=5 \mathrm{ml}$, which is within experimental error of the $4 \mathrm{ml}$ value obtained in (6) above. $4 \mathrm{ml}$ will be the value used for this group.

\section{Derivation of the E.OMV Aromatization Factor}

(1)

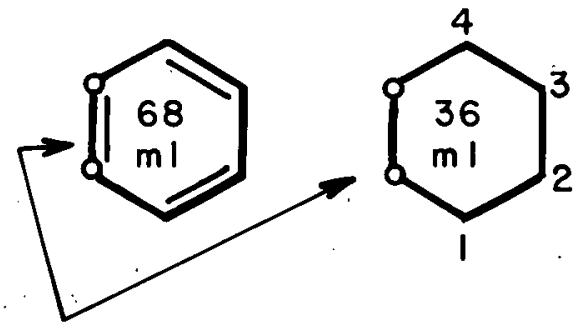

This side has $\mathrm{EOMV}=0$
$68 \mathrm{ml}-36 \mathrm{ml}=32 \mathrm{ml}$

Two double bonds $=\frac{16 \mathrm{ml}}{16 \mathrm{ml}}, 8 \mathrm{ml}$ each, Table9
Remainder

Four carbons $\quad 16 \mathrm{ml}=4 \mathrm{ml}$ each

System (1) above uses the $8 \mathrm{ml}$ per double bond derived in three of the previous sections to establish a 4-ml per carbon value. Again, as with the DAMV, there is no contradiction. In '(3) of the previous section total carbons and bonds were considered as the basis and, in this case, only elements which contribute to the aromaticity (aromatic carbons and double bonds) are significant. This was confirmed by the calculation methods.

Next, the aromatic double bond has a value of $8 \mathrm{ml}$ and a value of $4 \mathrm{ml}$ for a diphenyl bond, (5) and (6) of the previous section, establishes the $4 \mathrm{ml}$ difference in table 9.

Finally, the non-ring bond of cyclohexyl, (2) below, acts as a continuation of those carbons considered to be in a chain in the ring and has no EOMV. Hence, the $4 \mathrm{ml}$ established for a diphenyl bond, (5) and (6) of the previous section, leaves the $4 \mathrm{ml}$ difference between these bonds in table 9 . 
(2)

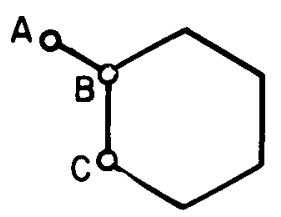

Hollow-point chain $A C$ includes the cyclohexyl bond $A-B$. Chain has an EOMV of zero, therefore, so does the bond $A-B$.

The derived values in the calculation methods are again offered as further confirmation of the validity of the values.

\section{Derivation of the EOMV Condensation Factor}

Benzothiophene, (1) below and naphthalene (2) below, are used to derive a value of +16 $\mathrm{ml}$ for the EOMV condensation factor. Again, the success of the value in the calculation methods verifies the validity of the choice.<smiles>c1ccc2sccc2c1</smiles>

\section{Experimental EOMV $=138 \mathrm{ml}$}

[Benzothiophene $(138 \mathrm{ml})$ - benzene $(68)]=70 \mathrm{ml}$, that is within experimental error of $16 \mathrm{ml}$ more than $53.5 \mathrm{ml}$ found in (4) at the beginning of this section. This $16-\mathrm{ml}$ C.F. for two rings is twice the 8- $\mathrm{ml}$ value for one ring found in (3) at the beginning of this section.

[Benzothiophene $(138 \mathrm{ml})$ - thiophene $(53.5 \mathrm{ml})]=84.5 \mathrm{ml}$, that is within experimental error of $16 \mathrm{ml}$ more than the $68 \mathrm{ml}$ found for benzene. This $16-\mathrm{ml} \mathrm{C}$.F. for two rings is twice the $8-\mathrm{ml}$ value found for one ring in (3) at the beginning of this section.

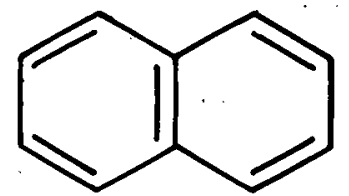

$$
\text { Experimental } \mathrm{EOMV}=154 \mathrm{ml}
$$

[Naphthalene $(154 \mathrm{ml})$ - benzene $(68 \mathrm{ml})]=86 \mathrm{ml}$, that is within experimental error of $16 \mathrm{ml}$ more than $68 \mathrm{ml}$ in (1) above. The $16-\mathrm{ml} \mathrm{C.F.} \mathrm{value} \mathrm{for} \mathrm{two} \mathrm{rings} \mathrm{is} \mathrm{twice} \mathrm{the}$ $8-\mathrm{ml}$ value found for one ring in (1) above. The $16-\mathrm{ml}$ value gives a uniformly better fit of data for the several aromatic compounds that have been presented in tables 15, 17, and A-4. 


\section{APPENDIX C. . DETERMINATION OF DAMV AND EOMV SUBSTITUTION FACTOR VALUES}

Some information was given in the discussion of table 7. Substitutions of several types are evaluated using the systems of table $\mathrm{C}-1$. Note that the same weighted fractions, obtained by comparing the retention volumes of the various polysubstituted benzenes and naphthenoaromatics to that of the n-alkylsubstituted benzenes, are used in determining both DAMV and EOMV values. In addition, in appendix $B$ a paraffinic carbon equaled two naphthenic carbons.

For the DAMV, the weighted fraction is used to determine the fraction of a full weight, 104-mI DAMV, ring one is working with.

For EOMV values, the data for various substitutions can be calculated from the weighted fractions using an equation of the following type:

$$
\begin{aligned}
\text { Total EOMV }=[36 \mathrm{ml}- & n(13 \mathrm{ml})]-\left(1-C_{\mathrm{fr}}\right)[36 \mathrm{ml}-\mathrm{n}(13 \mathrm{ml})] \text { where: } \\
\mathrm{n}= & 1 \text { for fourth substitution and } C_{\mathrm{fr}}=3 / 4 \text { for } 1,2,4,5 \text {-tetra- } \\
& \text { substitution, } \\
\mathrm{n}= & 2 \text { for fifth substitution and } C_{\mathrm{fr}}=1 / 2 \text { for } 1,2,3,4 \text {-tetra- } \\
& \text { substitution, } \\
\mathrm{n}= & 3 \text { for sixth substitution and } C_{\mathrm{fr}}=3 / 8 \text { for penta- and hexa- } \\
& \text { substitution. }
\end{aligned}
$$

Reasoning the weighting of the "effective" substitution as for the DAMV above, the fivemembered rings will; therefore, have an EOMV of $[(2 / 3-12 \mathrm{ml})+(1-12 \mathrm{ml})] / 2=(5 / 6$ $-12 \mathrm{ml}$ ) of a six-membered ring similarly substituted. (Note, the equation, C-1, developed for "total" EOMV values has a 13-ml increment. The calculation methods of the text use the 12-ml "derived" EOMV increment of table 5 and appendix $B$ and $C$ in its place since the $13-\mathrm{ml}$ value is used to determine the weighted fraction lost due to subslitution, and this is then converted th the number of "derived" $12-\mathrm{ml}$ increments lost. For example, if $5 / 8$ of the full weight is lost, five of eight total 12-ml "derived" EOMV increments are lost, etc.

In panel $A$ of table 8, we use n-propylbenzene, n-butylbenzene, 1,2,4,5-tetramethylbenzene (durene), and $1,2,3,4,5,6,7,8$-octahydroanthracent to compute the DAMV and EOMV values for "effective" 1,2,4,5-tetrasubstitution. Compared to n-propyl-and n-butylbenzene, durene has a retention-volume commensurate with $33 / 4$ carbons in a straight chain. Thus, for octahydroanthracene, ring $A$ has a full DAMV count of $104 \mathrm{ml}$, ring $B$ by definition has no DAMV, and ring $C$ has a "fractional "full DAMV value count equal to $(3$ and $3 / 4) / 4=15 / 16$, (see counts inside the $C$ ring). As in the discussion of table 7 , count the first three carbons as one "effective" substitution and the remaining carbon as a second "effective" substitution equal to $3 / 4$ of the first "effective" 
A. 1,2,4,5-retrasubstitution.<smiles>CC(C)(C)c1ccccc1</smiles>

Effective chain carbons substitution by retention volume vs. n-alkyl benzene.<smiles>Cc1cc(Br)c(C)cc1N</smiles>

$\underline{33 / 4}$<smiles>Cc1ccc(C)c(C)c1C</smiles>

Effective chain carbons substitution by retention volume vs. n-alkylbenzene.<smiles>CC1(C)CC2CCCC1c1cc3c(cc12)C1C=CC3CC1</smiles>

$\underline{33 / 4}$

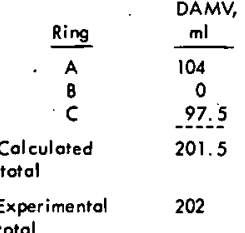

lotol
EOMV $\frac{\mathrm{ml}}{36}$ 68
-17
---121<smiles>CC1(C)C2C=CC1c1c2ccc2c1C1C=CCC2C1</smiles>
totol Experimental tatal

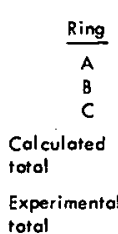

$\underline{31 / 2}$

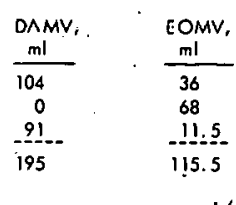

197
C. $1,2,3,4,5,6$ - hexasubstitution.<smiles>O=C(O)c1ccccc1</smiles><smiles>N#Cc1c(O)c(Br)c(Br)c(Br)c1C#N</smiles>

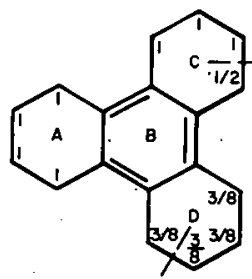

$41 / 4$

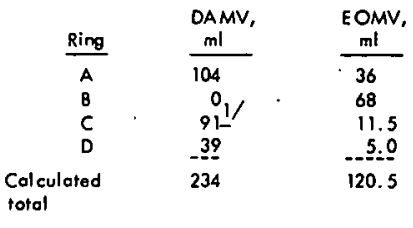

Experimental 235 . by retention volume vs. n-olkylbenzene.

$\underline{41 / 4}$

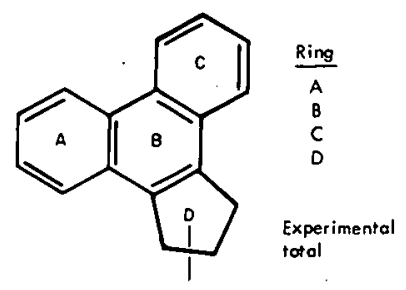

$\frac{(2 / 3+1)}{2}=5 / 6$ of overoge six-membered

ring $=5 / 6(78 \mathrm{ml}) \stackrel{2 /}{\prime}=65 \mathrm{ml}$
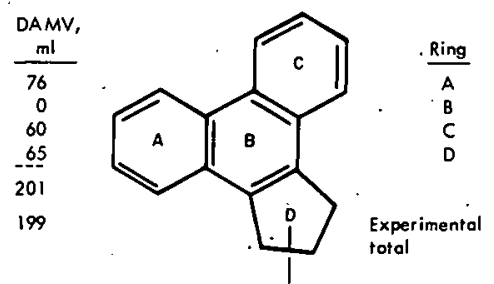

\begin{tabular}{c} 
EOMV \\
ml \\
\hline 85 \\
-68 \\
85 \\
-8 \\
-230 \\
229
\end{tabular}

. An example of "effective" substitution with a 5 -membered naphthene ring.

$\frac{(2 / 3-12 \mathrm{ml})+(1-12 \mathrm{ml})}{2}=5 / 6-12 \mathrm{ml}$ $5 / 6(5 \mathrm{ml}) 3 /-12 \mathrm{ml}=-8 \mathrm{ml}$

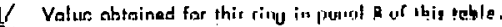

2/ Value obtoined for an overage six-membered ring in panel $C$ of this table.

3i Volve obtained for fifth and sixth substitutions for a six-membered ring in panel $C$ of this table. 
substitution. The DAMV value of ring $C$ is then $15 / 16(104 \mathrm{ml})=97.5 \mathrm{ml}$ giving a 201.5 DAMV value to the compound which is within experimental error of the 202-ml experimental value. $98 \mathrm{ml}$ is the one-half "derived" DAMV increment (or $6 \mathrm{ml}$ difference) which was found in table 7 of the text.

For the EOMV in panel $A$ of table 8 , ring $A$ has a full EOMV value of $36 \mathrm{ml}$ obtained for tetralin, ring $B$ is benzene whose EOMV value was given earlier as $68 \mathrm{ml}$, and ring $C$ is computed by substitution in equation $(\mathrm{C}-\mathrm{l})$ above to be:

$(36 \mathrm{ml}-13 \mathrm{ml})-(1-3 / 4)(36 \mathrm{ml}-13 \mathrm{ml})=17 \mathrm{ml}$ (note, again, that the $3 / 4$ fraction is the same as obtained in the DAMV computation). The total calculated EOMV value is then $121 \mathrm{ml}$--in exact agreement with the experimental value.

In panel B of table 8, similar compound comparisons are used to calculate DAMV and EOMV values for "effective" 1,2,3,4-tetrasubstitution. Here, 1,2,3,4-tetramethylbenzene elutes equivalent to $(3$ and $1 / 2$ ) carbons in a chain. Hence, for the DAMV value of the second naphthene ring, the fractional value is $(3$ and $1 / 2) / 4=7 / 8$, and $7 / 8$ of $104 \mathrm{ml}$ is $91 \mathrm{ml}$ to give a total DAMV value for the compound (octahydrophenanthrene) of $195 \mathrm{ml}$ that is within experimental error of the $197-\mathrm{ml}$ value obtained.

For the EOMV, equation (C-1) becomes: $(36 \mathrm{ml}-13 \mathrm{ml})-(1-1 / 2)(36 \mathrm{ml}-13 \mathrm{ml})=11.5$ $\mathrm{ml}$ to give a $115.5-\mathrm{ml}$ total EOMV value (as shown in the table) for octahydrophenanthrene. Note, again the fraction $1 / 2$ is the same as used in the DAMV calculation.

In panel $C$ of table 8 , hexamethylbenzene is shown to elute commensurate with (4 and $1 / 4$ ) carbons in a straight chain. Since pentamethylbenzene was not available, the fifth and sixth substitutions are combined and since 1,2,3,4-tetrasubstitution (in panel B) gave ( 3 and $1 / 2$ ) carbons in a chain, the difference, ( 4 and $1 / 4)-(3$ and $1 / 2)=3 / 4$ carbon is divided by 2 to give a value of $3 / 8$ carbon to each the fifth and sixth substitutions. For the DAMV the fractional value for "effective" hexasubstitution (dodecahydrotriphenylene) is (as shown inside the $D$ ring ) $(12 / 8) / 4=3 / 8$ full count ring or $3 / 8$ (104 $\mathrm{ml}$ ) $=39 \mathrm{ml}$ to give a total DAMV value for dodecahydrotriphenylene of $234 \mathrm{ml}$ that is within experimental error of the $235-\mathrm{ml}$ value obtained. The average value for the three naphthene rings, needed later, - is $(104 \mathrm{ml}+91 \mathrm{ml}+39 \mathrm{ml}) / 3=78 \mathrm{ml}$.

For the EOMV value, equation $(\mathrm{C}-1)$ for combined fifth and sixth substitutions becomes: $(36 \mathrm{ml}-26 \mathrm{ml})-(1-3 / 8)(36 \mathrm{ml}-26 \mathrm{ml})-[(36 \mathrm{ml}-39 \mathrm{ml})-(1-3 / 8)(36 \mathrm{ml}-39 \mathrm{ml})]$ $=5.0 \mathrm{ml}$. The total EOMV value for dodecahydrotriphenylene is then $120.5 \mathrm{ml}$ that is within experimental error of the $123 \mathrm{ml}$ value obtained.

In panel D of table 8, we have a case of two aromatic rings and one naphthene ring substituted on the benzene ring. This randomizes the "effective" substitutions the naphthene ring represents (that is: first and second, third and fourth, or fifth and sixth). For DAMV, the value is, therefore, the average of the values the ring could have. If the naphthene 
ring were six-membered, the value would be $78 \mathrm{ml}$ as obtaincd in the discussion of panel $C$, above. It was pointed out just prior to this discussion of table 8 , that a five-membered ring would have a value of $(2 / 3+1) / 2=5 / 6$ of a six-membered ring. Thus, the value for the cyclopentano ring in cyclopentanophenanthrene is $5 / 6(78 \mathrm{ml}$ ) equals $65 \mathrm{ml}$. This gives a total DAMV value of $201 \mathrm{ml}$ that is within experimental error of the 199-ml value obtained.

For the EOMV, it was pointed out in discussion of table 7 , that a five-membered ring would have a value of $[(2 / 3-12 \mathrm{ml}) / 2+(1-12 \mathrm{ml})] / 2=(5 / 6-12 \mathrm{ml})$ of a six-membered ring. Here, however, examination of the data also showed that, unlike the DAMV situation, the aromatic rings count as the lowest orders of substitution while the naphthene ring counts as the highest order of substitution (that is, the fifth and sixth substitutions). The value of a fifth and sixth "effective" substitutions six-membered naphthene ring in panel $C$ of this table was found to be $5.0 \mathrm{ml}$. The EOMV value of the cyclopentano ring in cyclopentanophenanthrene is therefore $5 / 6(5 \mathrm{ml})-12 \mathrm{ml}$ or approximately $-8 \mathrm{ml}$. This gives a value of $230 \mathrm{ml}$ for the compound that is within experimental error of the $229-\mathrm{ml}$ value obtained. 